Prepared for the U.S. Department of Energy

under Contract DE-AC05-76RL01830

\title{
Nationwide Snapshot
}

\section{TS Mapes}

MM Iverson

LL Fassbender

ML Britt

September 2011

\section{Pacific Northwest}

NATIONAL LABORATORY

Proudly Operated by Battelle Since 1965 


\title{
DISCI.ATMFR
}

This report was prepared as an account of work sponsored by an agency of the United States Government. Neither the United States Government nor any agency thereof, nor Battelle Memorial Institute, nor any of their employees, makes any warranty, express or implied, or assumes any legal liability or responsibility for the accuracy, completeness, or usefulness of any information, apparatus, product, or process disclosed, or represents that its use would not infringe privately owned rights. Reference herein to any specific commercial product, process, or service by trade name, trademark, manufacturer, or otherwise does not necessarily constitute or imply its endorsement, recommendation, or favoring by the United States Government or any agency thereof, or Battelle Memorial Institute. The views and opinions of authors expressed herein do not necessarily state or reflect those of the United States Government or any agency thereof.

\author{
PACIFIC NORTHWEST NATIONAL LABORATORY \\ operated by \\ BAT'TELLE \\ for the \\ UNITED STATES DEPARTMENT OF ENFRGY \\ under Contract DE-ACO5-76RL01830 \\ Printed in the United States of America \\ Available to DOE and DOE contractors from the \\ Office of Scientific and Technical Information, \\ P.O. Box 62, Oak Ridge, 'TN 37831-0062; \\ ph: (865) 576-8401 \\ fax: $(865) 576-5728$ \\ email: reports@adonis.osti.gov \\ Available to the public from the National Technical Information Service, \\ U.S. Department of Commerce, 5285 Port Royal Rd., Springfield, VA 22161 \\ ph: (800) 553-6847 \\ fax: $(703) 605-6900$ \\ email: orders@ntis.fedworld.gov \\ online ordering: http://www.ntis.gov/ordering.htm
}

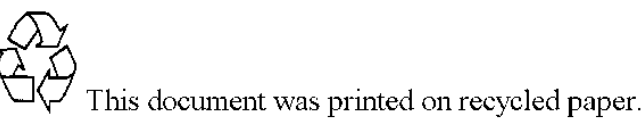

(9/2003) 


\section{Nationwide Snapshot}

TS Mapes

MM Iverson

LL Fassbender

ML Britt

September 2011

Prepared for

the U.S. Department of Energy

under Contract DE-AC05-76RL01830

Pacific Northwest National Laboratory

Richland, Washington 99352 



\section{Summary}

The purpose of this effort was to create a nationwide snapshot of the current residential building practices in the United States, and to identify trends in building practices as they relate to building energy efficiency. Information on typical insulation levels, heating, ventilation, and air conditioning (HVAC) efficiencies, window profiles, and other residential building components and assemblies provided a foundation for 1) identifying trends in residential building practices over time, 2) assessing energyefficiency improvements in single-family homes over time and correlating them with the applicable building energy codes if possible, and 3) identifying building energy code adoption and compliance needs. This report seeks to identify trends in the residential building practice from 1996 to 2009 .

In the beginning of the project, the staff intended to survey building departments, and gather residential construction data across the International Energy Conservation Code (IECC) climate zones in areas of substantial growth throughout that past ten years. Limitations on conducting surveys on behalf of the U.S. Department of Energy led the team to purchase the National Association of Home Builders (NAHB) Builder Practices Reports. NAHB data was obtained for 1996, 1999, 2004, and 2009 that reflected changes in building practices over the course of four published energy codes. The NAHB mails an Annual Builder Practices Survey to a random sample of home builders nationwide every year. The NAHB tabulates survey responses to provide estimates of building materials and equipment used in residential construction throughout the country. Data are compiled for the nine geographical census divisions.

The data showed changes in building practices with regard to windows, ducts and insulation that could be potentially attributed to building energy codes. However, as collected and tabulated, the data did not significantly indicate trends that could be directed attributed to building energy codes in general, nor the evolution of building energy codes from the 1992 MEC through the 2009 IECC. There appear to be two reasons for this: The questionnaires were not designed to correlate with aspects of construction that directly corresponded to the building energy codes, and secondly the geographical census divisions do not correlate well to climate zones.

In the future, use of the data from the web-based REScheck tool and the BECP Score and Store ${ }^{\mathrm{TM}}$ online tool which is available to states for storing building evaluation data collected in the field should provide more useful data on building trends specifically related to building energy codes. There may also be value in evaluating NAHB data in tandem with BECP stored data. 



\section{Acronyms and Abbreviations}

$\begin{array}{ll}\text { HVAC } & \text { heating, ventilation, and air conditioning } \\ \text { IECC } & \text { International Energy Conservation Code } \\ \text { low-E } & \text { low-emittance } \\ \text { MEC } & \text { Model Energy Code } \\ \text { NAHB } & \text { National Association of Home Builders } \\ \text { SEER } & \text { seasonal energy efficiency ratio }\end{array}$





\section{Contents}

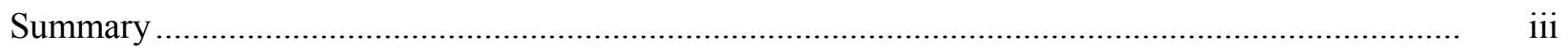

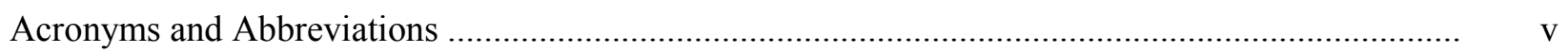

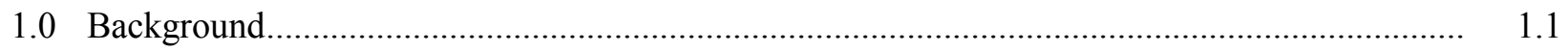

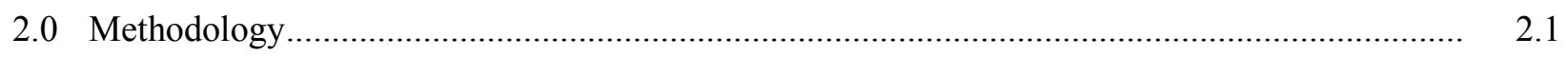

2.1 Annual Builder Practices Survey ............................................................................ 2.1

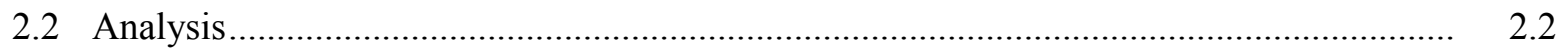

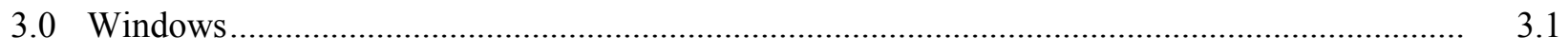

3.1 NAHB Survey Data Analysis - Frame Material ...................................................... 3.1

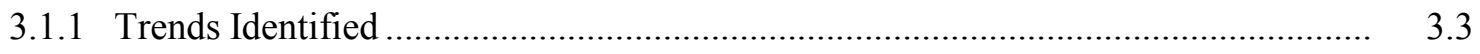

3.1.2 Possible Code Influences ............................................................................ 3.3

3.2 NAHB Survey Data Analysis - Glass Type .............................................................. 3.3

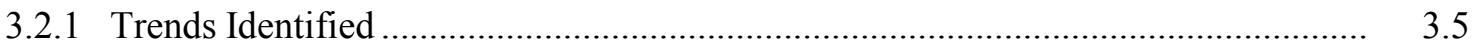

3.2.2 Possible Code Influences ........................................................................... 3.5

3.3 NAHB Survey Data Analysis - Glazing .................................................................. 3.5

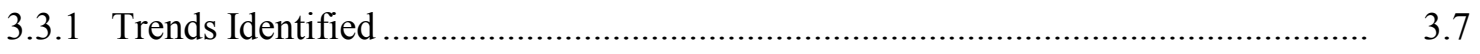

3.3.2 Possible Code Influences ...................................................................... 3.7

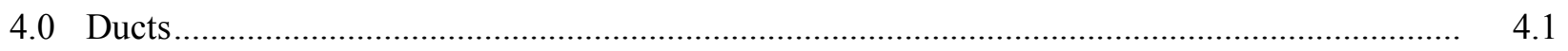

4.1 NAHB Survey Data Analysis - Ducted Versus Non-Ducted …..................................... 4.1

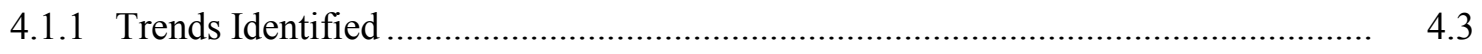

4.1.2 Possible Code Influences ................................................................................ 4.3

4.2 NAHB Survey Data Analysis - Metal Duct Insulation Method ....................................... 4.3

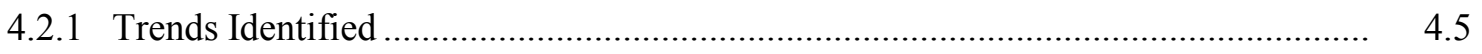

4.2.2 Possible Code Influences .......................................................................... 4.5

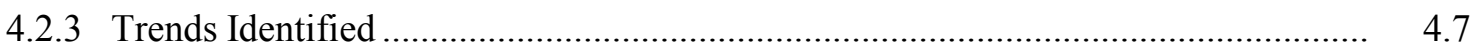

4.2.4 Possible Code Influences ....................................................................... 4.7

4.3 NAHB Survey Data Analysis - Location of Main Ducts and Run-Outs .......................... 4.7

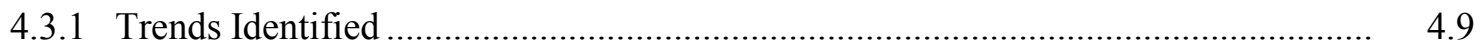

4.3.2 Possible Code Influences ........................................................................... 4.9

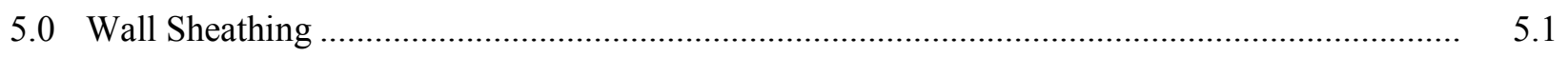

5.1 NAHB Survey Data Analysis - Single-Layer Wall Sheathing Types ............................. 5.1

5.1 .1 Possible Code Influences ................................................................................ 5.3

5.2 NAHB Survey Data Analysis - Single-Layer Wall Sheathing Extruded Foam

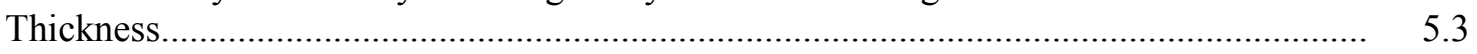

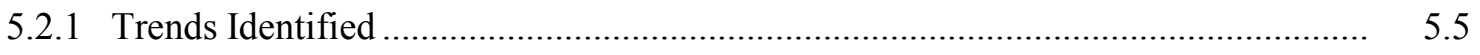

5.2.2 Possible Code Influences .............................................................................. 5.5

5.3 NAHB Survey Data Analysis - Single-Layer Wall Sheathing Polyisocyanurate Foam Thickness. 


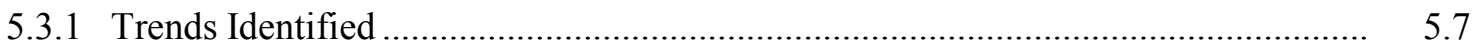

5.3.2 Possible Code Influences ........................................................................... 5.7

5.4 NAHB Survey Data Analysis - Homes with Two Layers of Wall Sheathing ................... 5.7

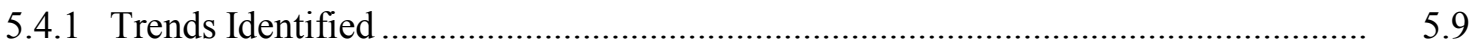

5.4.2 Possible Code Influences ....................................................................... 5.9

5.5 NAHB Survey Data Analysis - Double-Layer Wall Sheathing Extruded Foam

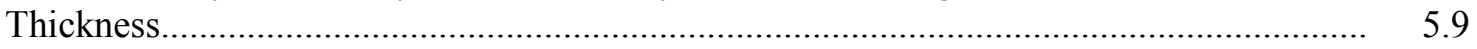

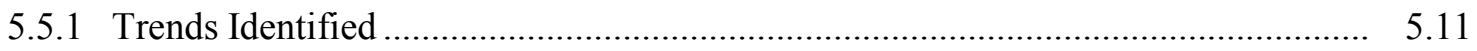

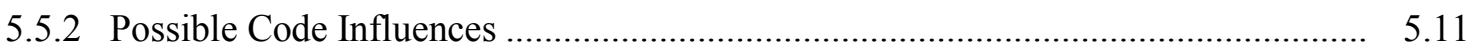

5.6 NAHB Survey Data Analysis - Double-Layer Wall Sheathing Expanded Foam

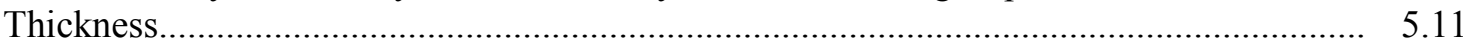

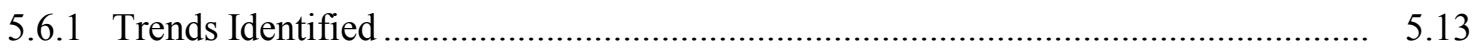

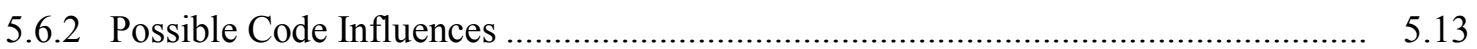

5.7 NAHB Survey Data Analysis - Double-Layer Wall Sheathing Polyisocyanurate Foam

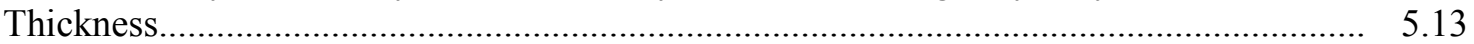

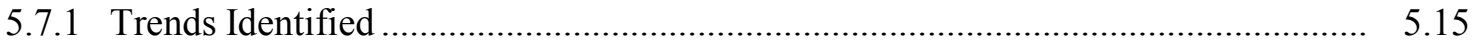

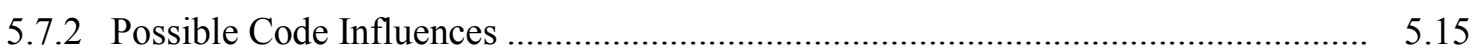

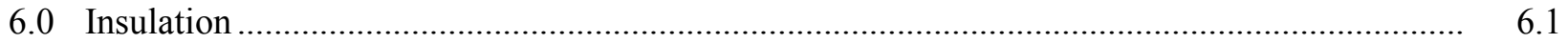

6.1 NAHB Survey Data Analysis - Slab-on-Grade Homes Without Insulation....................... 6.1

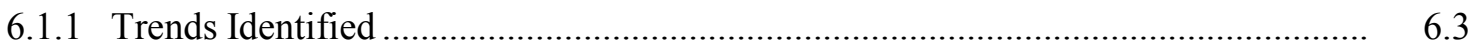

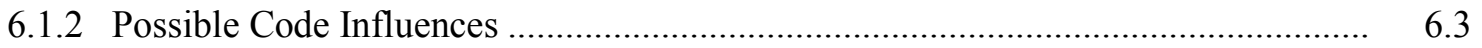

6.2 NAHB Survey Data Analysis - Slab Floor Insulation R-Value........................................ 6.3

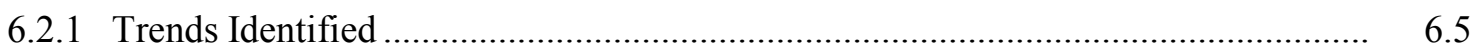

6.2.2 Possible Code Influences ................................................................................ 6.5

6.3 NAHB Survey Data Analysis - Slab Perimeter Insulation R-Value.................................. 6.5

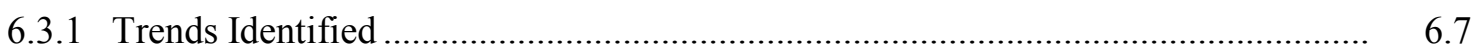

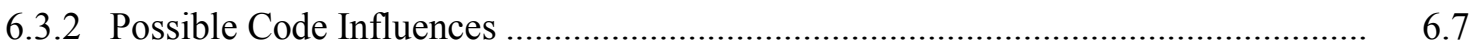

6.4 NAHB Survey Data Analysis - Crawl Space Insulation R-Value ................................... 6.7

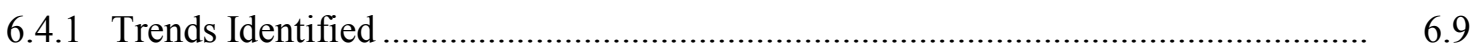

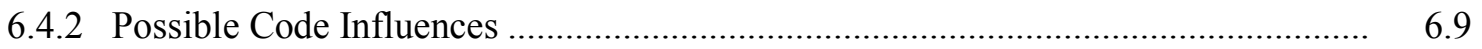

6.5 NAHB Survey Data Analysis - Crawl Space Insulation Type ........................................ 6.9

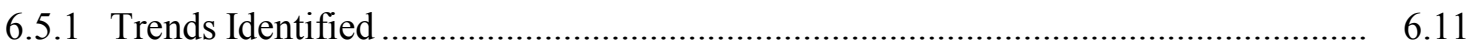

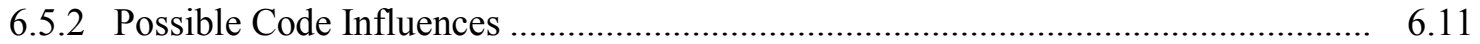

6.6 NAHB Survey Data Analysis - Crawl Space Wall Insulation R-Value ........................... 6.11

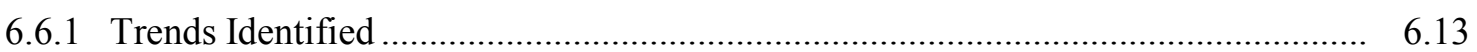

6.6.2 Possible Code Influences ............................................................................... 6.13

6.7 NAHB Survey Data Analysis - Crawl Space Wall Insulation Type.................................. 6.13

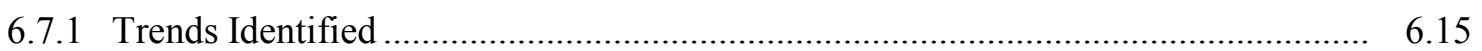

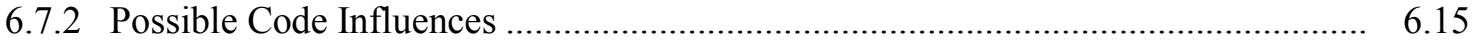


6.8 NAHB Survey Data Analysis - Basement Floor Insulation Type ................................... 6.15

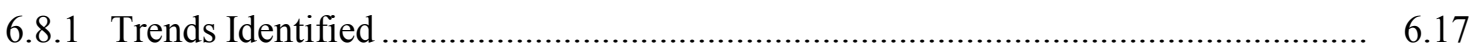

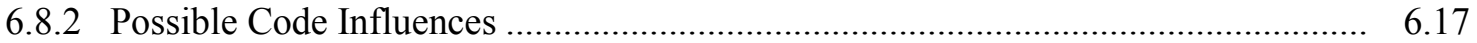

6.9 NAHB Survey Data Analysis - Basement Floor Insulation R-Value ............................... 6.17

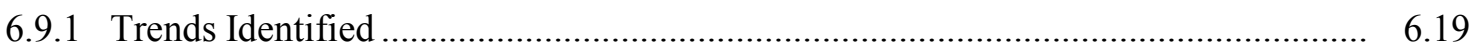

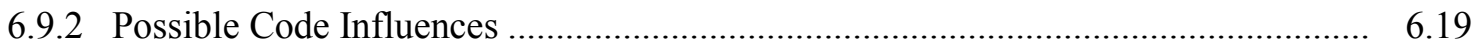

6.10 NAHB Survey Data Analysis - Basement Wall Insulation R-Value............................... 6.19

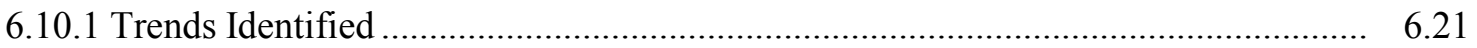

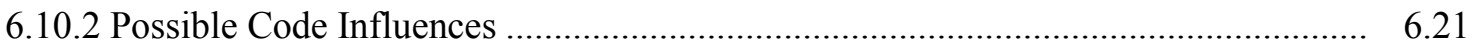

6.11 NAHB Survey Data Analysis - Basement Wall Insulation Type .................................... 6.21

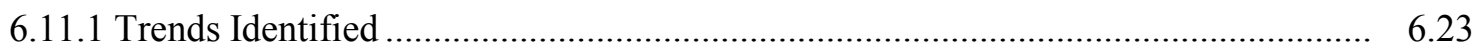

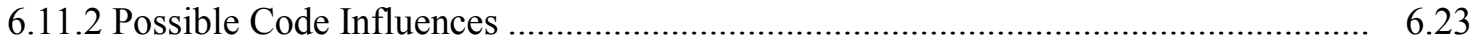

6.12 NAHB Survey Data Analysis - Exterior Wall Insulation Type....................................... 6.23

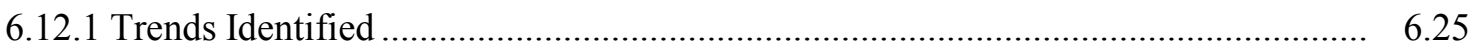

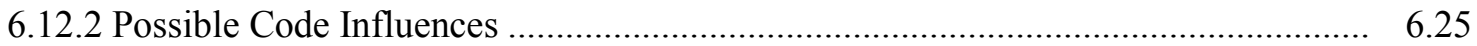

6.13 NAHB Survey Data Analysis - Exterior Wall Cavity R-value....................................... 6.25

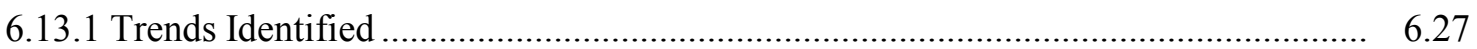

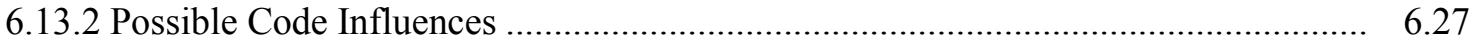

6.14 NAHB Survey Data Analysis - Flat Ceiling Insulation Type........................................ 6.27

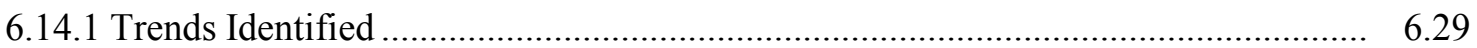

6.14.2 Possible Code Influences ...................................................................................... 6.29

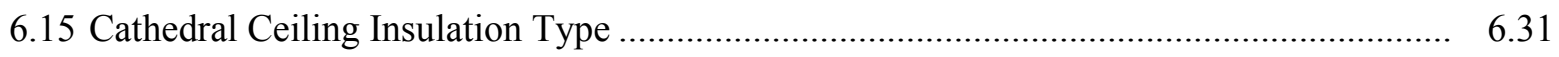

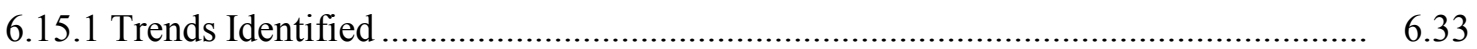

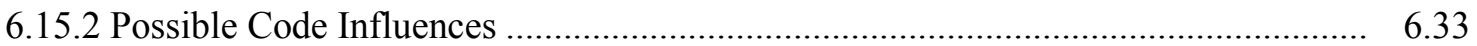

6.16 NAHB Survey Data Analysis - Ceiling Insulation R-Value ........................................... 6.33

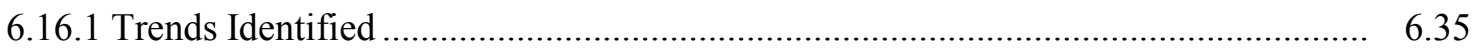

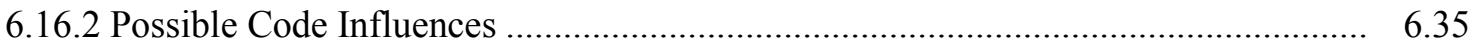

7.0 Heating, Ventilation, and Air Conditioning ....................................................................

7.1 NAHB Survey Data Analysis - Type of Heating Equipment Units ................................ 7.1

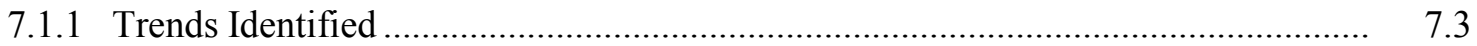

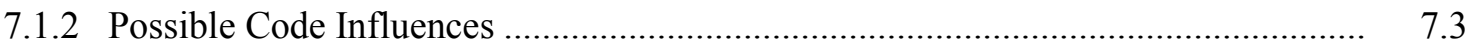

7.2 NAHB Survey Data Analysis - Type of Heating and Cooling Systems ............................ 7.3

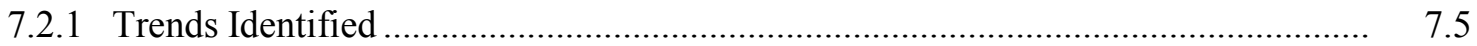

7.2.2 Possible Code Influences ............................................................................... 7.5

7.3 NAHB Survey Data Analysis - Special Types of HVAC Units ...................................... 7.5

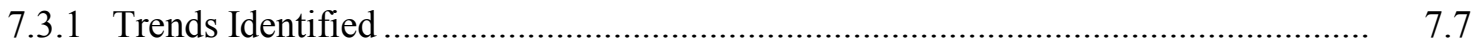

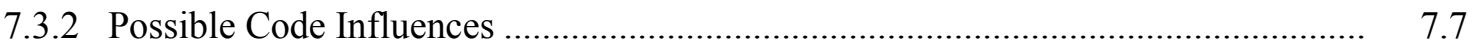

7.4 NAHB Survey Data Analysis - Efficiency Rating of Gas and Oil Furnace Units.............. 7.7

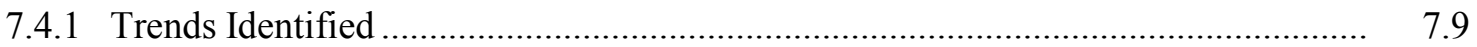




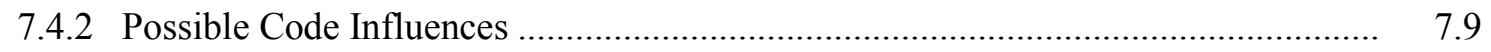

7.5 NAHB Survey Data Analysis - Air Conditioner Efficiency Rating …............................. 7.9

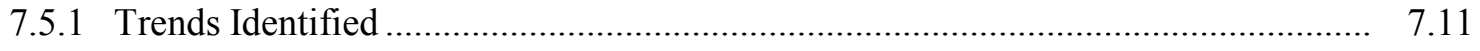

7.5.2 Possible Code Influences ............................................................................ 7.11 


\section{Figures}

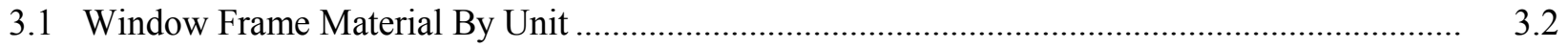

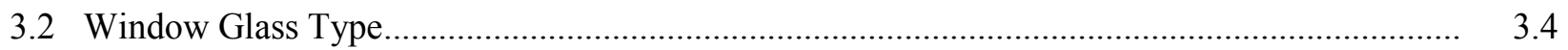

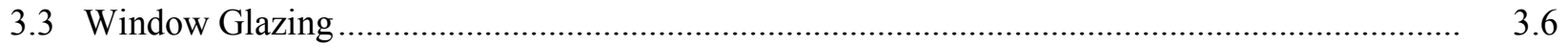

4.1 Ducted Versus Non-Ducted Homes ..................................................................................... 4.2

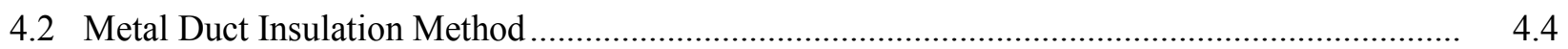

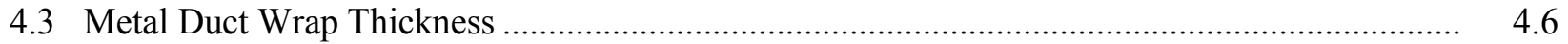

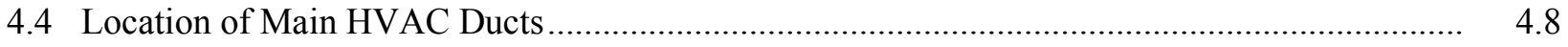

5.1 Single-Layer Wall Sheathing Types .............................................................................. 5.2

5.2 Single-Layer Wall Sheathing Extruded Foam Thickness ...................................................... 5.4

5.3 Single-Layer Wall Sheathing Polyisocyanurate Foam Thickness ........................................... 5.6

5.4 Homes with Two Layers of Wall Sheathing .................................................................... 5.8

5.5 Double-Layer Wall Sheathing Extruded Foam Thickness …................................................ 5.10

5.6 Double-Layer Wall Sheathing Expanded Foam Thickness ................................................... 5.12

5.7 Double-Layer Wall Sheathing Polyisocyanurate Foam Thickness.......................................... 5.14

6.1 Slab-on-Grade Homes Without Insulation............................................................................. 6.2

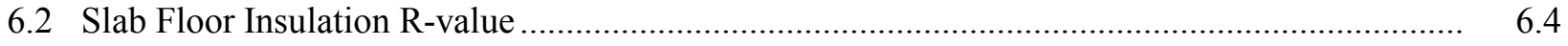

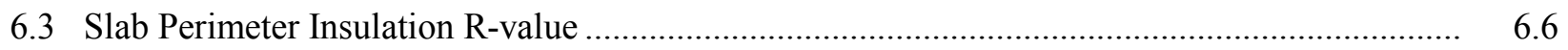

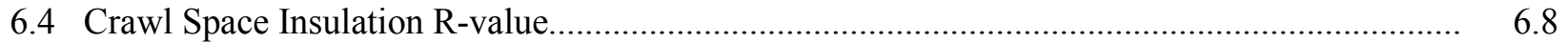

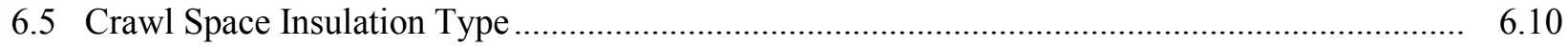

6.6 Crawl Space Wall Insulation R-value .......................................................................... 6.12

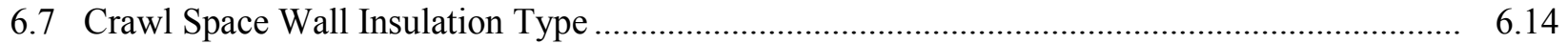

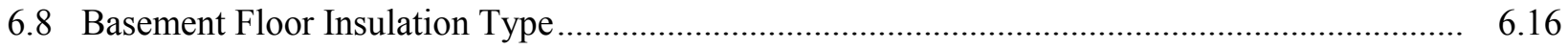

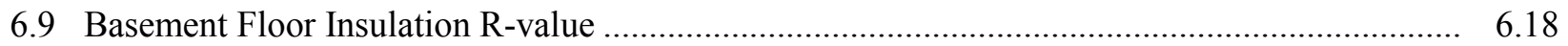

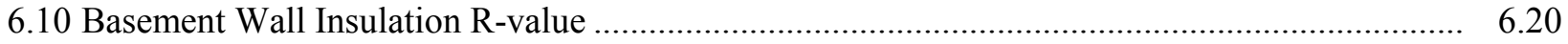

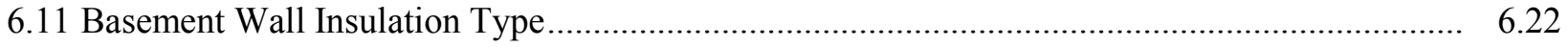

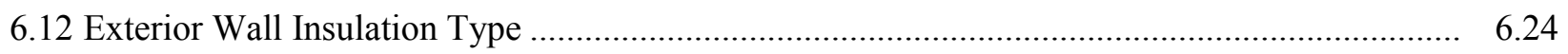

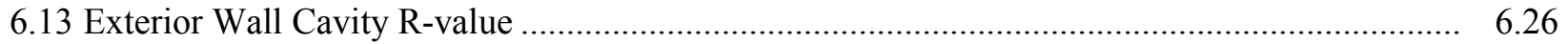

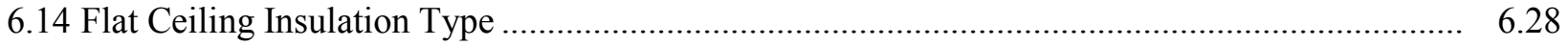

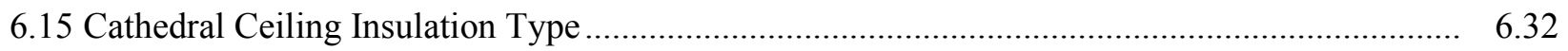

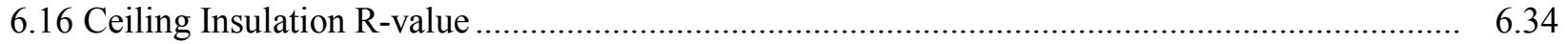

7.1 Type of Heating Equipment Units ….............................................................................

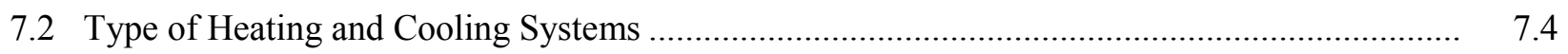

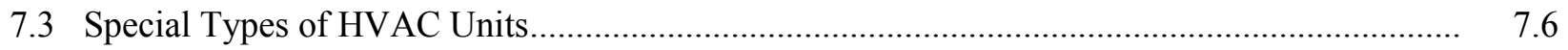

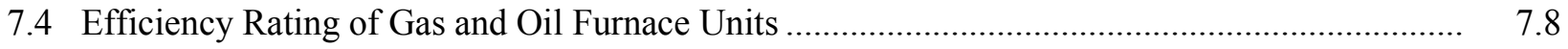

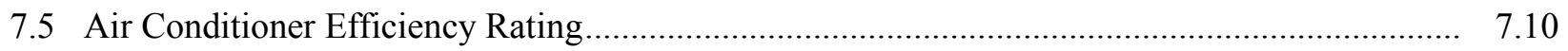




\section{Tables}

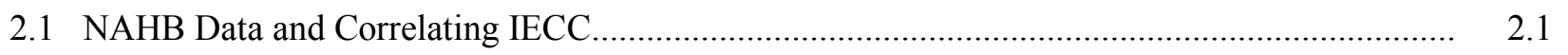

2.2 Census Division State and Climate Zone Breakdown ....................................................... 2.1 


\subsection{Background}

The purpose of this effort was to create a nationwide snapshot of the current residential building practices in the United States, and to identify trends in building practices as they relate to building energy efficiency. Information on typical insulation levels, heating, ventilation, and air conditioning (HVAC) efficiencies, window profiles, and other residential building components and assemblies provided a foundation for 1) identifying trends in residential building practices over time, 2) assessing energyefficiency improvements in single-family homes over time and correlating them with the applicable building energy codes if possible, and 3) identifying building energy code adoption and compliance needs.

This report seeks to identify trends in the residential building practice from 1996 to 2009. 



\subsection{Methodology}

In the beginning of the project, the staff intended to survey building departments, and gather residential construction data across the International Energy Conservation Code (IECC) climate zones in areas of substantial growth throughout that past ten years. Limitations on conducting surveys on behalf of the U.S. Department of Energy led the team to purchase the National Association of Home Builders (NAHB) Builder Practices Reports. NAHB data was obtained for 1996, 1999, 2004, and 2009 that reflected changes in building practices over the course of four published energy codes. The available building energy codes for these years are shown in Table 2.1States adopt newly published codes on varying timetables, and some states such as California, Washington, Oregon and Florida have had state developed codes. However on a national basis, due to an unquantified spillover effect of codes across jurisdictional boundaries, the report takes into consideration the dates of published model codes :

Table 2.1. NAHB Data and Correlating IECC

\begin{tabular}{cl}
\hline NAHB Data & \multicolumn{1}{c}{ Applicable Building Energy Code } \\
\hline 1996 & 1995 Model Energy Code (MEC) \\
1999 & 1998 IECC \\
2004 & 2003 IECC \\
2009 & 2006 IECC \\
\hline
\end{tabular}

\subsection{Annual Builder Practices Survey}

The NAHB mails an Annual Builder Practices Survey to a random sample of home builders nationwide every year. The NAHB tabulates survey responses to provide estimates of building materials and equipment used in residential construction throughout the country. Data are compiled for the nine geographical census divisions with the corresponding IECC Climate Zones, as shown in Table 2.2.

Table 2.2. Census Division State and Climate Zone Breakdown

\begin{tabular}{lll}
\hline \multicolumn{1}{c}{ Census Division } & \multicolumn{1}{c}{ States } & \multicolumn{1}{c}{ IECC Climate Zone } \\
\hline New England & Connecticut & 5 \\
& Massachusetts & 5 \\
& Rhode Island & 5 \\
& Maine & 6 , except Aroostook Co (7) \\
& New Hampshire & $5-6$ \\
& Vermont & 6 \\
Middle Atlantic & New Jersey & $5-6$ \\
& New York & $5-6$ \\
& Pennsylvania & 4,5, and 6
\end{tabular}




$\begin{array}{lll}\text { South Atlantic } & \text { Delaware } & 4 \\ & \text { Maryland } & 4 \text {, except Garrett Co (5) } \\ \text { District of Columbia } & 4 \\ \text { Georgia } & 2,3 \text {, and } 4 \\ \text { Florida } & 1-2 \\ \text { North Carolina } & 3,4 \text {, and } 5 \\ \text { South Carolina } & 3 \\ \text { Virginia } & 4 \\ \text { West Virginia } & 4-5\end{array}$

Table 2.2. (contd)

\begin{tabular}{|c|c|c|}
\hline Census Division & States & IECC Climate Zone \\
\hline \multirow[t]{5}{*}{ East North Central } & Illinois & $4-5$ \\
\hline & Indiana & $4-5$ \\
\hline & Michigan & 5,6 , and 7 \\
\hline & Ohio & $4-5$ \\
\hline & Wisconsin & $6-7$ \\
\hline \multirow{4}{*}{ East South Central } & Alabama & $2-3$ \\
\hline & Mississippi & $2-3$ \\
\hline & Kentucky & 4 \\
\hline & Tennessee & $3-4$ \\
\hline \multirow[t]{7}{*}{ West North Central } & Iowa & $5-6$ \\
\hline & Nebraska & 5 \\
\hline & Kansas & $4-5$ \\
\hline & Missouri & $4-5$ \\
\hline & Minnesota & $6-7$ \\
\hline & North Dakota & $6-7$ \\
\hline & South Dakota & $5-6$ \\
\hline \multirow[t]{4}{*}{ West South Central } & Arkansas & $3-4$ \\
\hline & Oklahoma & 2,3 , and 4 \\
\hline & Louisiana & $2-3$ \\
\hline & Texas & 2,3 , and 4 \\
\hline \multirow[t]{8}{*}{ Mountain } & Arizona & $2,3,4$, and 5 \\
\hline & Nevada & 3 and 5 \\
\hline & New Mexico & 3,4, and 5 \\
\hline & Colorado & $4,5,6$, and 7 \\
\hline & Utah & 3,5, and 6 \\
\hline & Idaho & $5-6$ \\
\hline & Montana & 6 \\
\hline & Wyoming & 5,6 , and 7 \\
\hline \multirow[t]{5}{*}{ Pacific } & California & $2-7$ \\
\hline & Hawaii & 1 \\
\hline & Oregon & $4-5$ \\
\hline & Alaska & $7-8$ \\
\hline & Washington & 4,5 , and 6 \\
\hline
\end{tabular}

\subsection{Analysis}

Pacific Northwest National Laboratory developed graphs of key energy efficiency elements from the survey: windows, ducts, wall sheathing, insulation, and HVAC. Each graph was analyzed to identify trends that occurred in the various categories of residential building materials and equipment over the past 
13 years. These residential trends were correlated with building energy code requirements, where possible based on analyzed climate zones, code changes and building elements. The lack of a strong relationship between climate zones and census regions limited the correlation. 



\subsection{Windows}

Windows offer significant opportunities for building energy efficiency, reducing heating and cooling bills by up to $25 \%{ }^{1}$. High performance innovations, such as vinyl and fiberglass frames, multiple glazing, inert gas fills, and low-emittance (low-E) coatings have dramatically increased the insulative quality of windows used in heating dominated (Northern) climates. Additionally, coatings were developed to specifically decrease the solar heat gain of windows used in cooling dominated (Southern) climates. Beginning in 2006, the IECC included comprehensive prescriptive requirements for overall U-value and solar heat gain coefficient.

The windows data set includes:

- frame material

- glass type

- glazing (number of panes).

\subsection{NAHB Survey Data Analysis - Frame Material}

The NAHB survey results for window frame material are presented in Figure 3.1. Builders were asked, of all of the window units they installed, what percentage were constructed from each of the following frame materials:

- wood (no cladding)

- wood, aluminum-clad

- wood, vinyl-clad

- aluminum

- vinyl

- composite (fiberglass)

- other (please specify).

\footnotetext{
${ }^{1}$ Department of Energy Savers http://www.energysavers.gov/tips/windows.cfm
} 


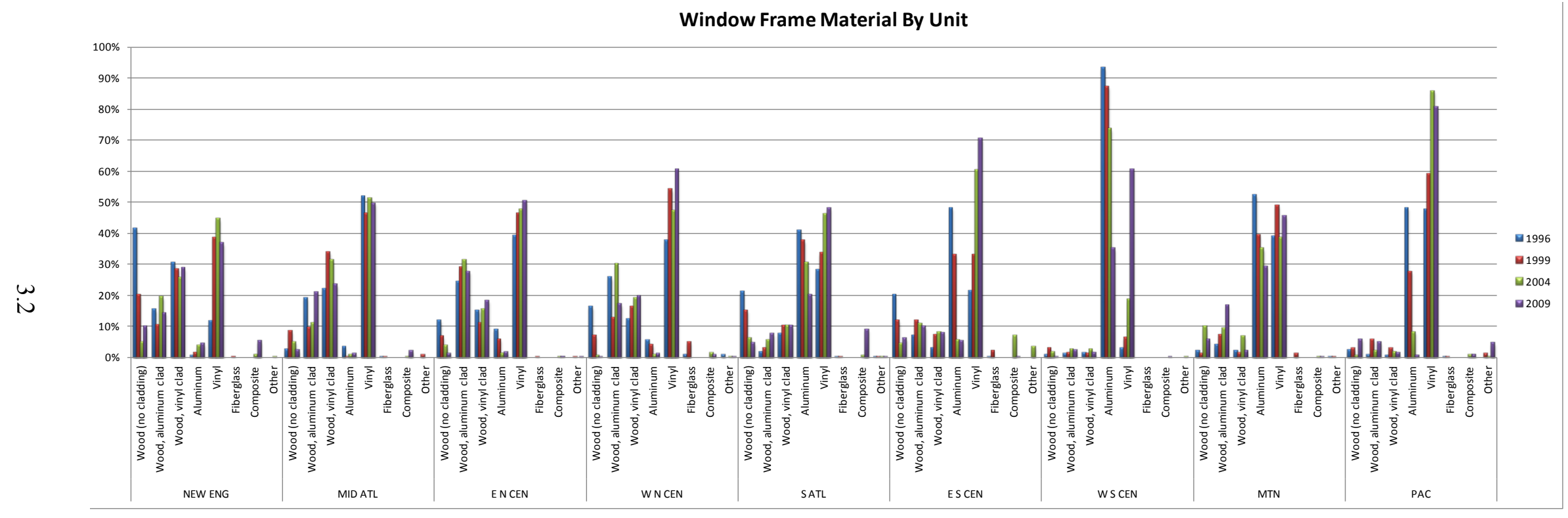

Figure 3.1. Window Frame Material By Unit 


\subsubsection{Trends Identified}

Nationwide, between 1996 and 2009, wood frame use declined by more than 70\%, and aluminum frame use declined by almost $60 \%$. However, vinyl window frames used in single-family homes increased by $75 \%$. In addition, the use of wood and aluminum frames was lower in several regions from 1996 to 2004, but the use of vinyl frames was higher in several regions from 1996 to 2009.

In $1996,38 \%$ of the installed windows had aluminum frames, almost $32 \%$ had vinyl frames, about $12 \%$ had wood frames, about $9 \%$ had aluminum-clad wood frames, and about $9 \%$ had vinyl-clad wood frames. In contrast, by 2009 , over $56 \%$ of the installed windows had vinyl frames, about $16 \%$ had aluminum frames, about $11 \%$ had aluminum-clad wood frames, almost $10 \%$ had vinyl-clad wood frames, about $3.5 \%$ had wood frames, and almost $3 \%$ had composite frames.

Census divisions where aluminum windows were predominantly used in 1996 showed a market transition to vinyl frames by 2009. This was shown most clearly in the West South Central and Pacific Census Divisions, using from $93 \%$ and $48 \%$ aluminum, respectively, to $61 \%$ and $81 \%$ vinyl, respectively. This same trend appears in the Mountain, East South Central, and South Atlantic Census Divisions, although it is not as dramatic because there were still some wood, aluminum-clad wood, and vinyl-clad wood window frames used.

In general, the census divisions using a variety of frame types in 1996 and 1999 retained that diversity into 2009, with a lesser trend to vinyl frames. In the Middle Atlantic Census Division, the percentage of vinyl window frames has hovered right around $50 \%$ since 1996 . The other $50 \%$ is a mixture of wood with no cladding, aluminum-clad wood, and vinyl-clad wood frames.

\subsubsection{Possible Code Influences}

Wood and aluminum-framed windows have dropped because of the increased availability of vinyl windows in several markets. Aluminum window reduction may have been caused by fenestration Ufactor requirement that dropped to $0.65 \mathrm{U}$-factor in hot climates in 2000; this requirement was difficult to meet with an aluminum window without a thermally broken frame.

\subsection{NAHB Survey Data Analysis - Glass Type}

The NAHB survey results for glass type are presented in Figure 3.2. Builders were asked what type of glass they installed most commonly, and they were given the following choices:

- clear (no low-E coating)

- low-E

- argon-filled

- tinted

- impact resistant. 


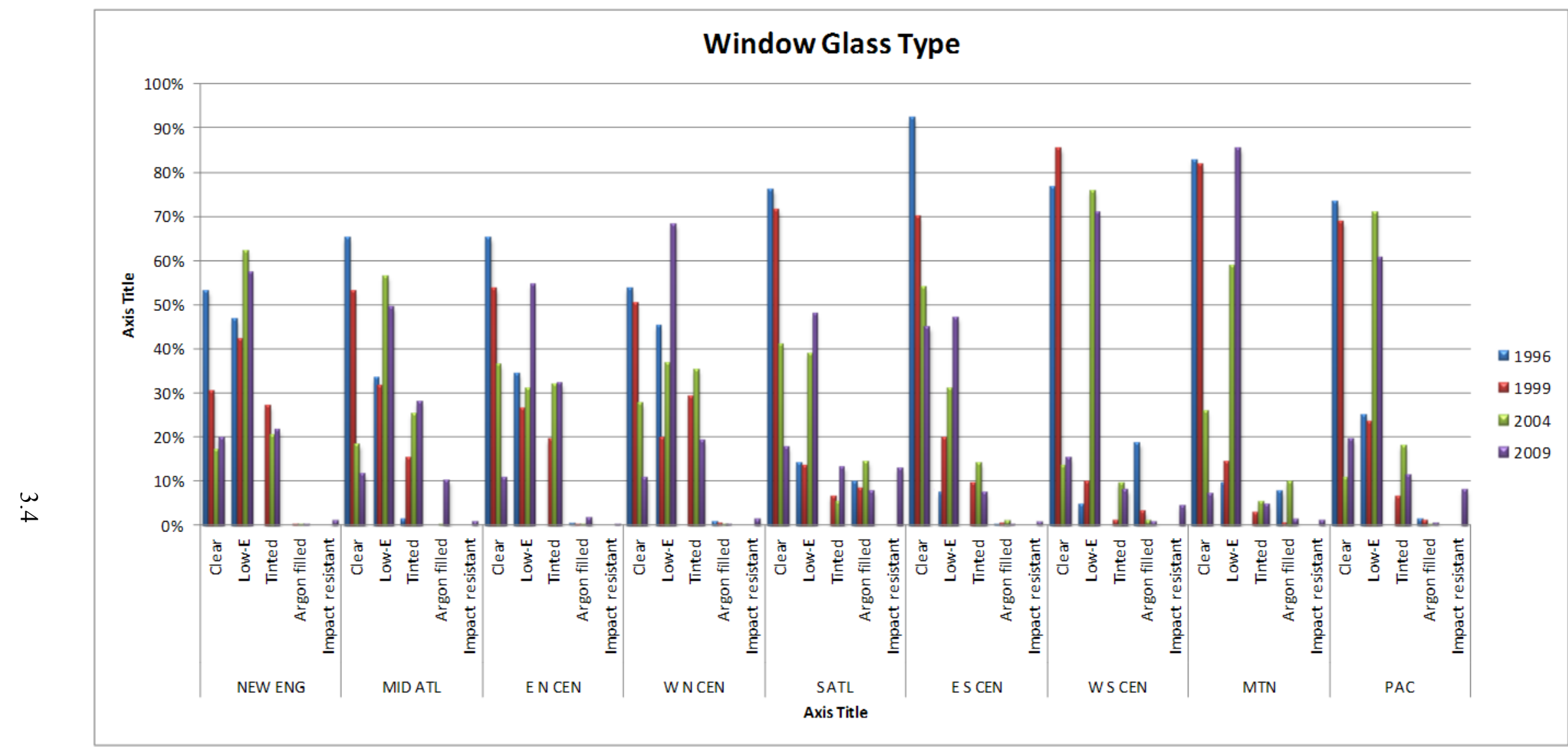

Figure 3.2. Window Glass Type 


\subsubsection{Trends Identified}

In 1996 nationwide, almost $73 \%$ of the window glass installed in single-family homes was clear, $21 \%$ was low-E, and $6 \%$ was tinted. By 2009 , these percentages had changed to $75 \%$ low-E glass, $13 \%$ argonfilled glass, $9 \%$ clear glass, $2 \%$ impact-resistant glass, and less than $1 \%$ tinted glass.

In all census divisions, clear glass windows predominated in 1996, including over $90 \%$ of the inventory in the East South Central Census Division in that survey year. Over the decade between 1999 and 2009, the use of clear glass windows was reduced as the use of low-E glass increased in all census divisions. For example, in the cooling dominant East South Central Census Division, the use of clear glass declined from $70 \%$ in 1999 to $45 \%$ in 2009 , while the use of low-E glass increased from $20 \%$ to $47 \%$ over the same period. In addition, argon-filled glass use remained low, appearing in only about $10 \%$ of the single-family homes in the Middle Atlantic and South Atlantic Census Divisions in the 2009 survey data. Impact-resistant glass was installed in approximately $10 \%$ of the single-family homes in the South Atlantic and Pacific Census Divisions in the 2009 survey data. Further, the survey illustrated a regional trend of tinted glass use in the New England, Middle Atlantic, East North Central, and West North Central Census Divisions, ranging from $20 \%$ to $30 \%$ of the survey population. Tinted glass represented $5-10 \%$ of the survey populations in all other regions except the Pacific, where is it rarely used.

\subsubsection{Possible Code Influences}

Low-E glass may have increased because of the requirements for low U-factors in climate zones 5 and above, and the requirement for a 0.40 solar heat gain coefficient in climate zone 3 and below that came into the 2000 IECC.

\subsection{NAHB Survey Data Analysis - Glazing}

The NAHB survey results for window glazing are presented in Figure 3.3. Builders were asked what percent of all the window units they installed were of each of the following types:

- single-glazed

- double-glazed

- triple-glazed

- Heat-Mirror ${ }^{\circledR}$. 


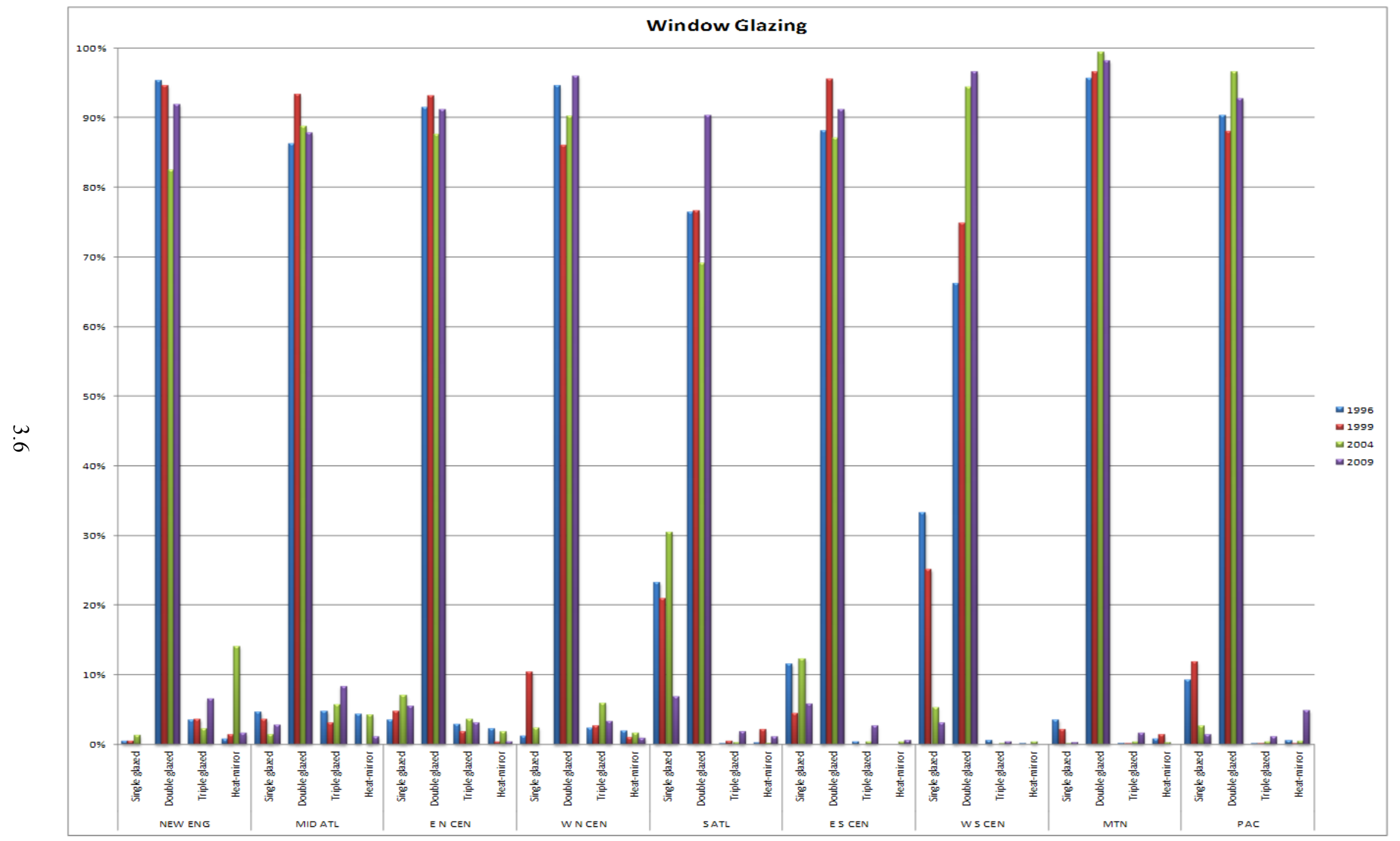

Figure 3.3. Window Glazing 


\subsubsection{Trends Identified}

Double-glazed windows dominate all categories in every survey year. In 2009, they comprise 90$100 \%$ of the survey population of single-family homes in the survey. Populations of triple-glazed and heat-mirror windows are low in every census region, although heat-mirror glass reached a high of $14 \%$ of the survey population in New England in 2004. The use of single-glazed windows appears to have decreased to less than $10 \%$ of the population as of 2009 .

\subsubsection{Possible Code Influences}

Beginning in 1998, the IECC required double-glazed windows in most construction. 



\subsection{Ducts}

In a typical house, about $20 \%$ of the air that moves through the duct system is lost due to leaks, holes, and poorly connected ducts. In addition to improved comfort and indoor air quality, proper ductwork can lead to significant energy savings. The average homeowner spends more than $\$ 600$ on space heating and cooling each year, and can reduce annual utility bills by $\$ 120$ or more with tightly sealed and well insulated ducts ${ }^{1}$.

The duct data set illustrates changes in duct construction based on:

- the percentages of single-family homes that are ducted

- metal duct insulation method

- metal duct wrap thickness

- location of main ducts and run-outs.

\subsection{NAHB Survey Data Analysis - Ducted Versus Non-Ducted}

The NAHB survey results for the percentage of single-family homes that are ducted are presented in Figure 4.1. Builders were asked what percent of all the single-family homes they built were ducted.

\footnotetext{
${ }^{1}$ http://www.energystar.gov/ia/new_homes/features/DuctSystems_062906.pdf
} 


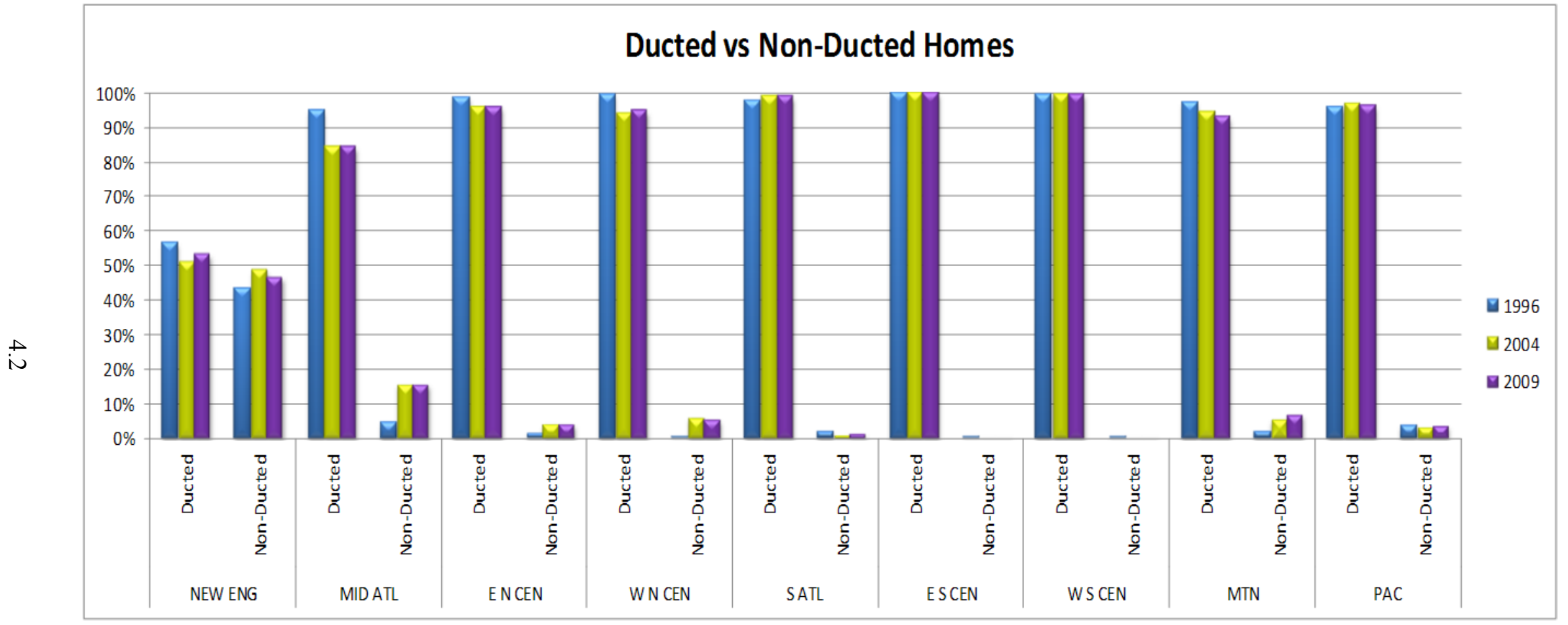

Figure 4.1. Ducted Versus Non-Ducted Homes 


\subsubsection{Trends Identified}

Nationwide, at least 93\% single-family homes built between 1996 and 2009 were ducted. However, the New England Census Division data on ducting of single-family homes was an anomaly. In 1996, only about $57 \%$ of single-family homes built in New England were ducted. The percentage dropped to $51 \%$ in 2004 , and then increased to $53 \%$ in 2009 . This may be due to $48 \%$ of single-family homes in New England that did not have air-conditioning systems in 1996, 44\% that did not have air-conditioning systems in 2004, and $16 \%$ that did not have air-conditioning systems in 2009 . About $53 \%$ of these same homes were heated by hydronic systems (forced hot water or boiler) in 1996, 46\% had hydronic heating systems in 2004, and 41\% had hydronic heating systems in 2009. In addition, in the Middle Atlantic Census Division, $95 \%$ of single-family homes built in 1996 were ducted, but only $84 \%$ were ducted in 2004 and 2009.

\subsubsection{Possible Code Influences}

Trends were likely based on the widespread change from electric baseboards to heat pumps and furnaces due to the increased air conditioning demand. However, in hot climates, it was expected that with the use of mini-split air conditioning systems, there may be a reversal in the trend of moving to ducted systems.

\subsection{NAHB Survey Data Analysis - Metal Duct Insulation Method}

The NAHB survey results for the metal duct insulation method are presented in Figure 4.2. Builders were asked if they used any metal duct, what percentage of all the metal ducting they installed was insulated by the following methods:

- lined with insulation (insulation inside the duct)

- wrapped with insulation

- not insulated

- other. 


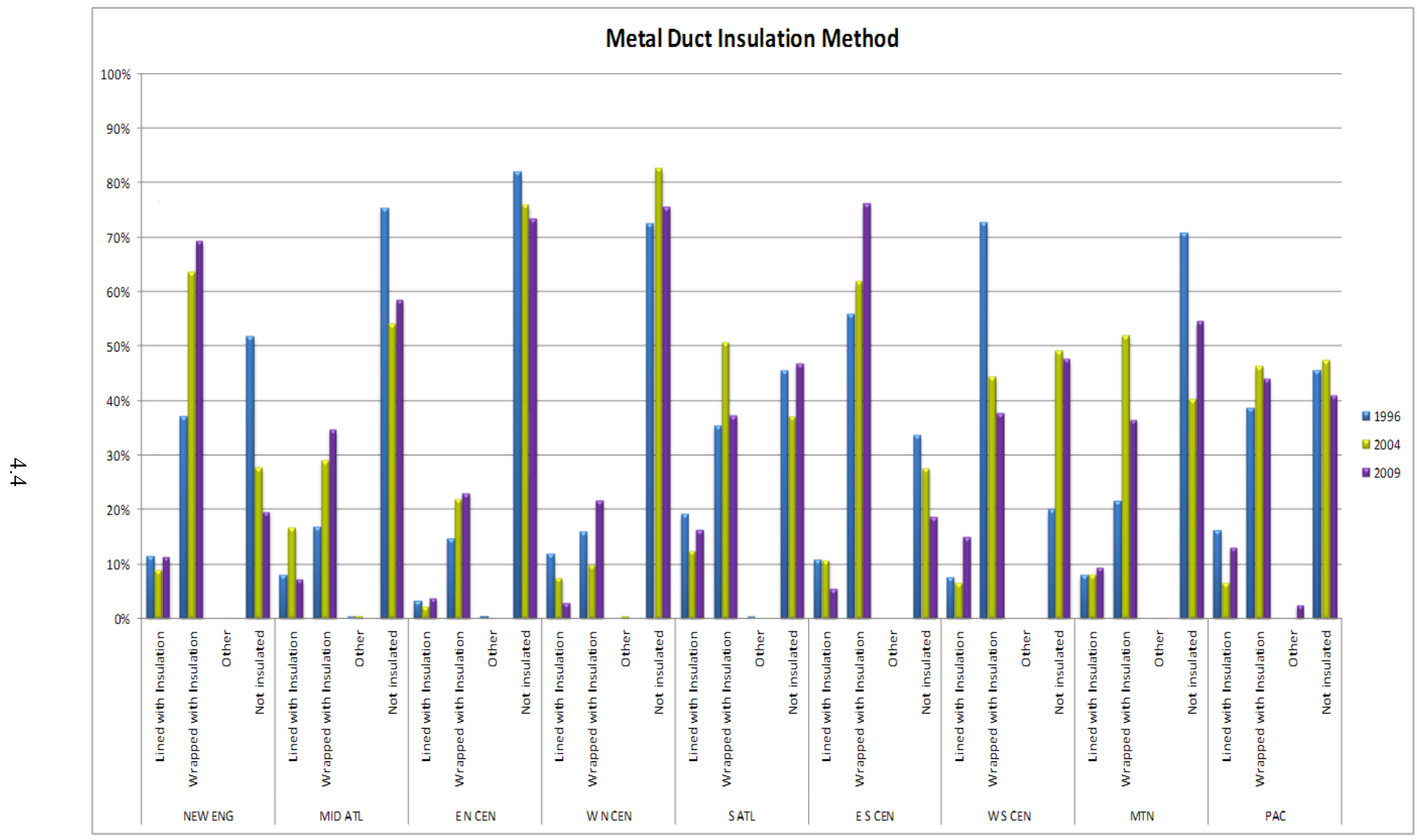

Figure 4.2. Metal Duct Insulation Method 


\subsubsection{Trends Identified}

Nationally, a large percentage of metal ducting was uninsulated in 2009 in all areas of the country (from $40 \%$ in the Pacific Census Division to $75 \%$ in the East South Central Census Division).

One explanation for this was that metal duct work was typically located in conditioned spaces, such as basements and stud cavities, and therefore, insulation is not required. The New England Census Division was an exception to the nationwide trend the ducting; in almost $70 \%$ of single-family homes in this region, the metal ducting was wrapped with insulation in 2009. In the South Atlantic, West South Central, and Pacific Census Divisions, there appeared to be comparable numbers of single-family homes with ducting that was wrapped with insulation and single-family homes with ducting that was not insulated at all.

\subsubsection{Possible Code Influences}

The 1992MEC and later codes required ducts in unconditioned spaces to be insulated. NAHB Survey Data Analysis - Metal Duct Wrap Thickness

The NAHB survey results for metal duct wrap thickness are presented in Figure 4.3. Builders were asked if they used any metal duct insulation wrap, what the typical thickness of the wrap was. They were given the following choices:

- $11 / 2$ in. or less

- 2 in.

- more than 2 in. 


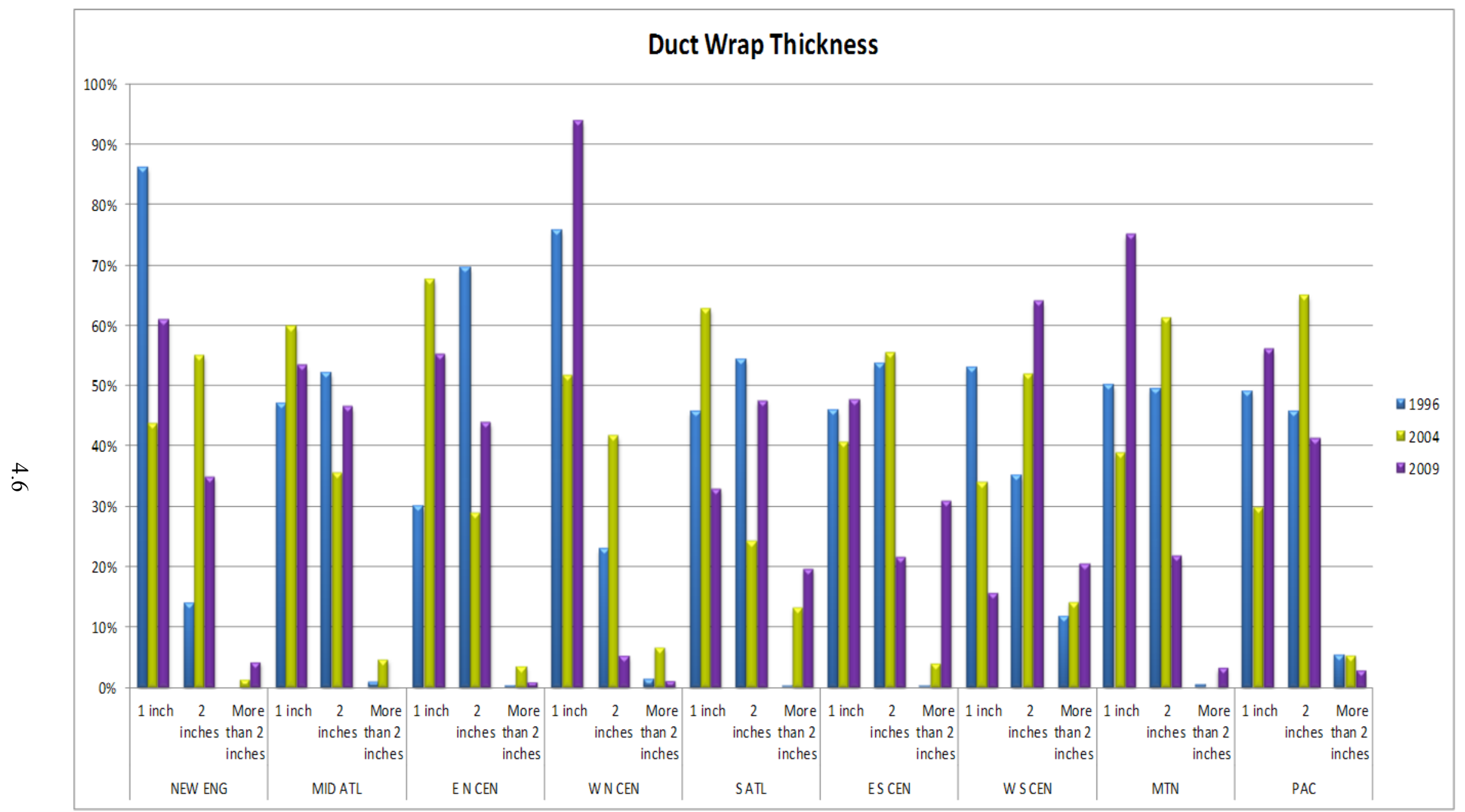

Figure 4.3. Metal Duct Wrap Thickness 


\subsubsection{Trends Identified}

Nationally, in 1996 in most areas of the country, there was a fairly even split between single-family homes with 2-in. thick wrapped insulation of ducts and those with $11 / 2$ in. or less. The biggest exception was the New England Census Division, where $86 \%$ of the homes had ducting with $11 / 2$ in. or less of insulation. In the West North Central Census Division, $75 \%$ of the homes had $11 / 2$ in. or less, and in the East North Central Census Division, $70 \%$ had 2 in. of insulation.

In 2004, duct insulation thickness improved in some areas of the country (New England, West North Central, East South Central, West South Central, Mountain, and Pacific Census Divisions), and declined in other areas (Middle Atlantic, East North Central, and South Atlantic Census Divisions).

In 2009, there was a fairly even split between 2 in. of insulation and $11 / 2 \mathrm{in}$. or less in the New England, Middle Atlantic, East North Central, South Atlantic, and Pacific Census Divisions. In the West North Central Census Division, more than $90 \%$ of the houses had $11 / 2$ in. or less and $75 \%$ of houses in the Mountain Census Division had 1 1/2 in. or less. About 20\% of houses in the South Atlantic and West South Central Census Divisions had more than 2 in. and 30\% in the East South Central Census Division had more than 2 in.

\subsubsection{Possible Code Influences}

The 1995 MEC required duct insulation which may have accounted for the increase in duct thickness during the subsequent years. The 2000, IECC required duct insulation of R-5 (1 in.). Duct insulation board used in duct systems may be responsible for increases in thickness to two inches.

\subsection{NAHB Survey Data Analysis - Location of Main Ducts and Run- Outs}

The NAHB survey results for the location of main ducts and run-outs are shown in Figure 4.4. Builders were asked what percentage of their houses, with ducted HVAC systems, located the main duct and run-outs in the following spaces:

- basement, crawl space, or in framed floors only

- attic only

- both attic and basement or crawl space

- in or under concrete floor slab

- both in attic and concrete floor slab. 


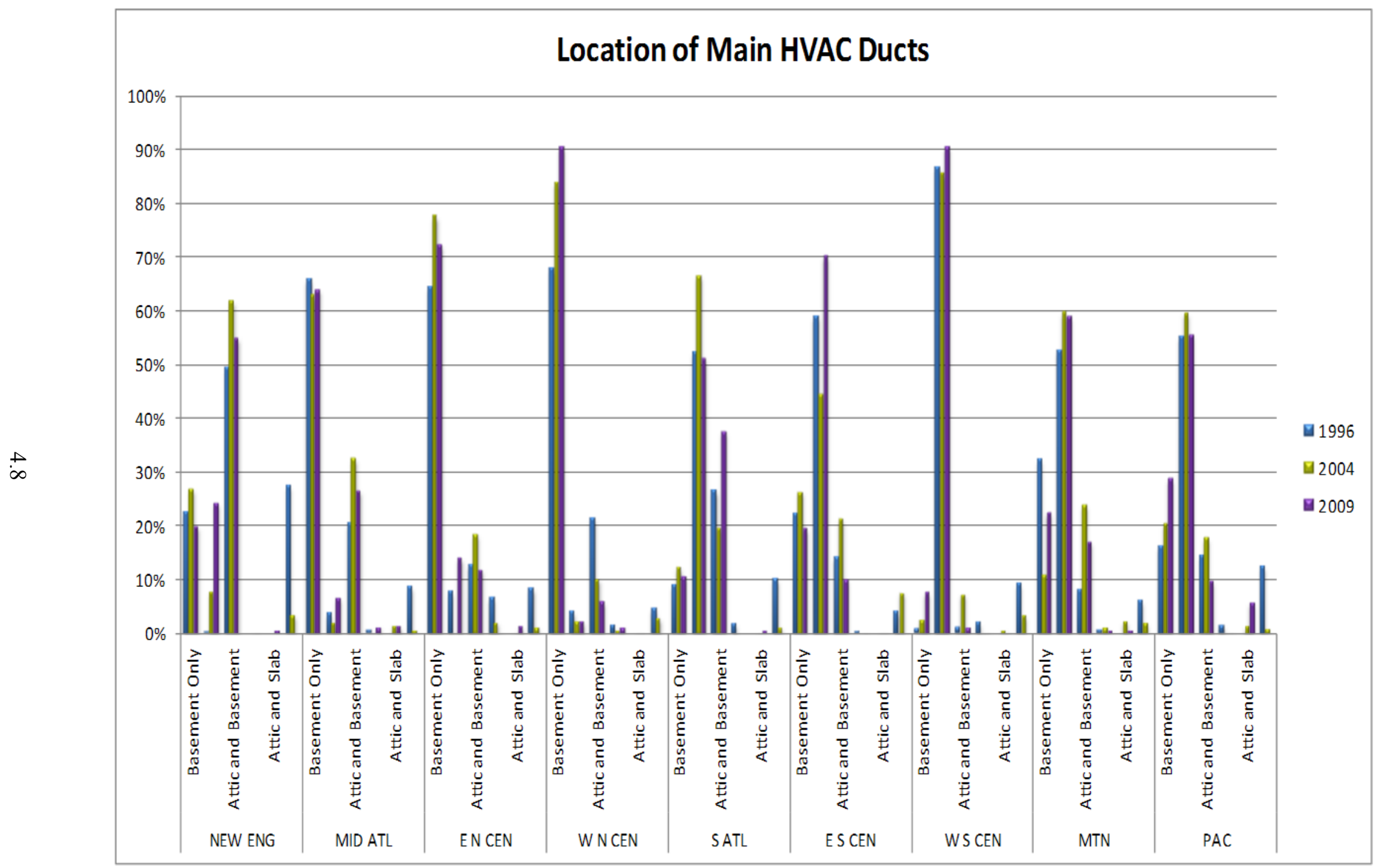

Figure 4.4. Location of Main HVAC Ducts 


\subsubsection{Trends Identified}

In the only identifiable national trend in each of the census divisions, building practices for main HVAC duct location seem to have remained fairly constant over the period from 1996 to 2009. In the South Atlantic, East South Central, West South Central Mountain, and Pacific Census Divisions, the majority of the main HVAC ducts were located in the attic only. In 2009, the attic-only ducting ranged from $50 \%$ in the South Atlantic Census Division to $90 \%$ in the West South Central Census Division. In the Middle Atlantic, East North Central, and West North Central Census Divisions, the majority of the main HVAC ducts were located in the basement only. In 2009, the basement-only ducting ranged from $60 \%$ in the Middle Atlantic Census Division to $90 \%$ in the West North Central Census Division. In the New England Census Division, over $50 \%$ of the main HVAC ducts were located in both the attic and the basement in 2009.

\subsubsection{Possible Code Influences}

The difference in duct locations is likely due to regional building practices and foundation types. 



\subsection{Wall Sheathing}

Wall sheathing was evaluated to identify pertinent trends in continuous wall insulation. The data set included information on:

- single-layer sheathing wall types

- single-layer extruded foam

- single polyisocyanurate foam

- two-layer wall sheathing home total

- two-layer extruded foam

- two-layer expanded foam

- two-layer polyisocyanurate foam.

\subsection{NAHB Survey Data Analysis - Single-Layer Wall Sheathing Types}

The NAHB survey results for single-layer wall sheathing types are presented in Figure 5.1. Builders were instructed to consider "sheathing" as the panel product that is fastened directly to the wall studs, and asked what percentage of their total exterior wall area was sheathed with:

- fiberboard

- cement board

- fiber cement

- gypsum

- 1/8-in. foil-faced three-ply kraft paper (e.g., Thermoply, EnergyBrace)

- lumber boards

- trends identified (no distinct nationwide trends were identified). 


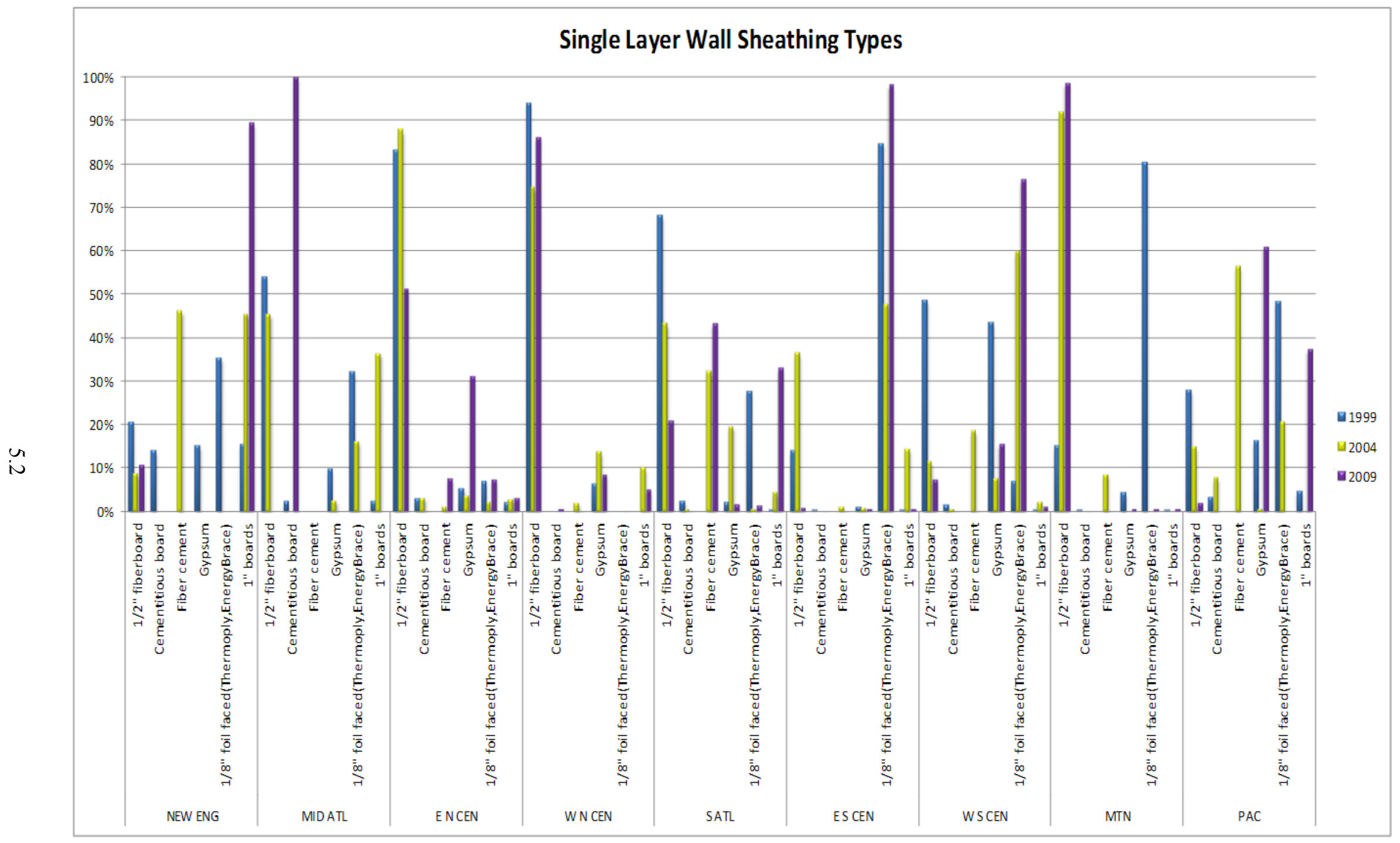

Figure 5.1. Single-Layer Wall Sheathing Types 
In 1999, Middle Atlantic, East North Central, West North Central, South Atlantic, and West South Central all primarily built their homes with $1 / 2$ in. fiberboard. In the following years, East North Central and West North Central kept similar home building practices with $1 / 2$ in. fiberboard. The South Atlantic equalized home building over $1 / 2$ in. fiberboard, fiber cement, and $1 \mathrm{in}$. boards. West South Central made a distinct change to $78 \%$ 1/8 in. foil-faced three-ply kraft paper. In 2009, the Middle Atlantic Division used $100 \%$ cement boards for their wall sheathing in new residential homes. The Pacific, Mountain, and East South Central all primarily built homes with 1/8 in. foil faced (Thermoply, EnergyBrace) and through 2009 only East South Central Division kept the dominance of 98\% in 1/8 in. foil-faced three-ply kraft paper. The Pacific Division moved towards fiber cement in 2004, but then redirected to gypsum and 1 in. boards in 2009. The Mountain Division moved $91 \%$ in 2004, and then $98 \%$ in 2009 to $1 / 2$ in. fiberboard sheathing. Data on wall sheathing types for 1996 was not reported.

\subsubsection{Possible Code Influences}

Single layer wall sheathing selection was not likely related to energy codes, but rather regional siding trends.

\subsection{NAHB Survey Data Analysis - Single-Layer Wall Sheathing Extruded Foam Thickness}

The NAHB survey results for single-layer wall sheathing extruded foam thickness are presented in Figure 5.2. Builders were asked about the typical thickness of the extruded foam they used, and given the following choices:

- $1 / 2$ in.

- $5 / 8$ in. or $3 / 4$ in.

- 1 in.

- $11 / 2$ in.

- 2 in. or greater. 


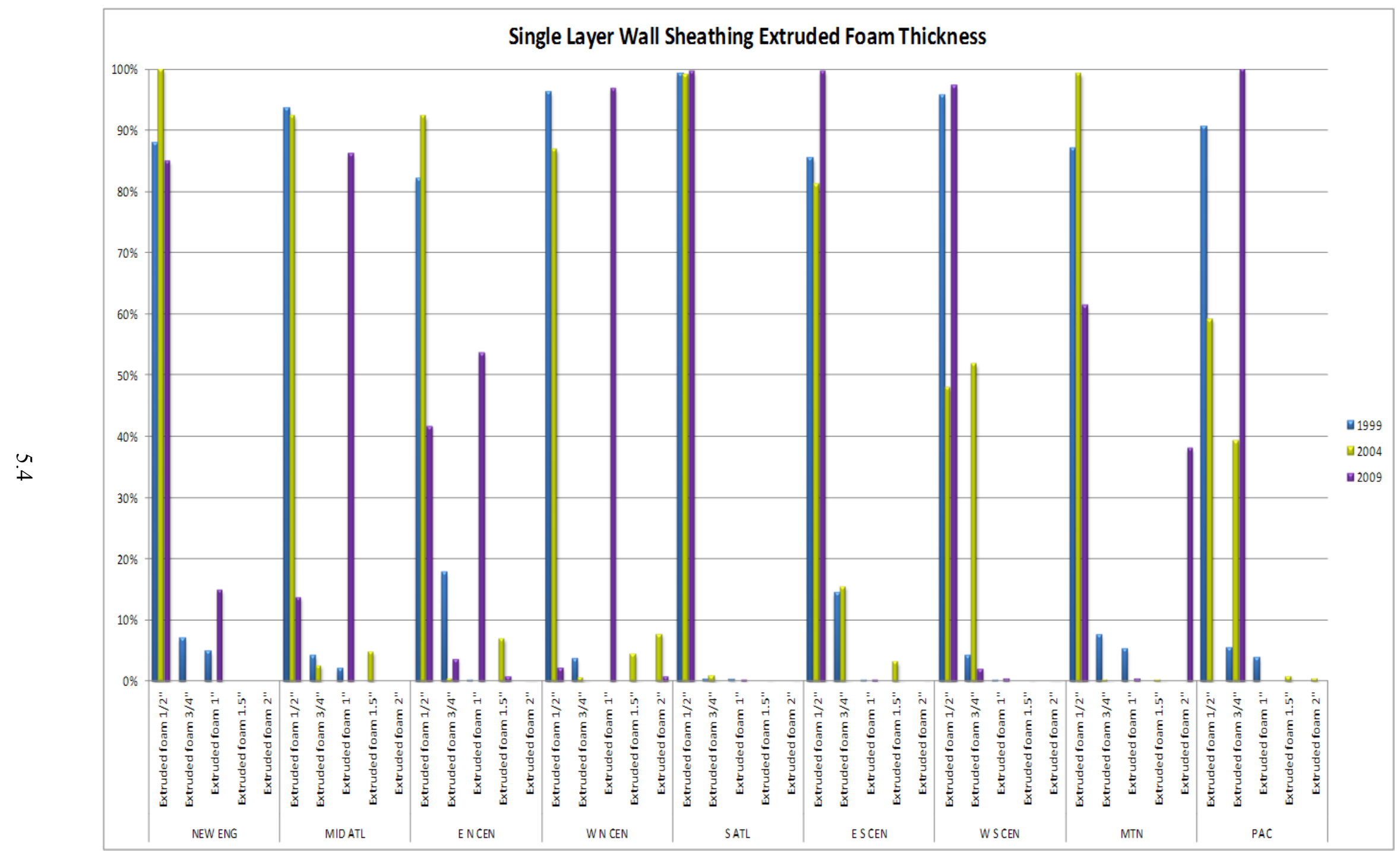

Figure 5.2. Single-Layer Wall Sheathing Extruded Foam Thickness 


\subsubsection{Trends Identified}

There was not a single nationwide trend; however, several regions showed an increased use of thicker foams. . West South Central also primarily used 1/2 in. extruded foam in 1999, as did the majority of the divisions, but in 2004, 3/4 in. extruded foam was used more than $50 \%$ of the time. In 2009 , the West South Central Division went back to primarily using $1 / 2$ in. extruded foam ( $97 \%$ of the time). The Pacific Division primarily used $1 / 2$ in. extruded foam in 1999 , then balancing between $1 / 2$ in. and $1 / 4$ in. extruded foam in 2004. There was a dramatic shift in 2009 when the Pacific Division used 100\% 3/4 in. extruded foam. Data was not reported in 1996.

\subsubsection{Possible Code Influences}

There does not appear to be a code-related change.

\subsection{NAHB Survey Data Analysis - Single-Layer Wall Sheathing Polyisocyanurate Foam Thickness}

The NAHB survey results for single-layer wall sheathing polyisocyanurate foam thickness are presented in Figure 5.3. Builders were asked about the typical thickness of the polyisocyanurate foam they used, and given the following choices:

- $1 / 2$ in.

- $5 / 8$ in. or $3 / 4$ in.

- 1 in.

- $11 / 2$ in.

- 2 in. or greater. 


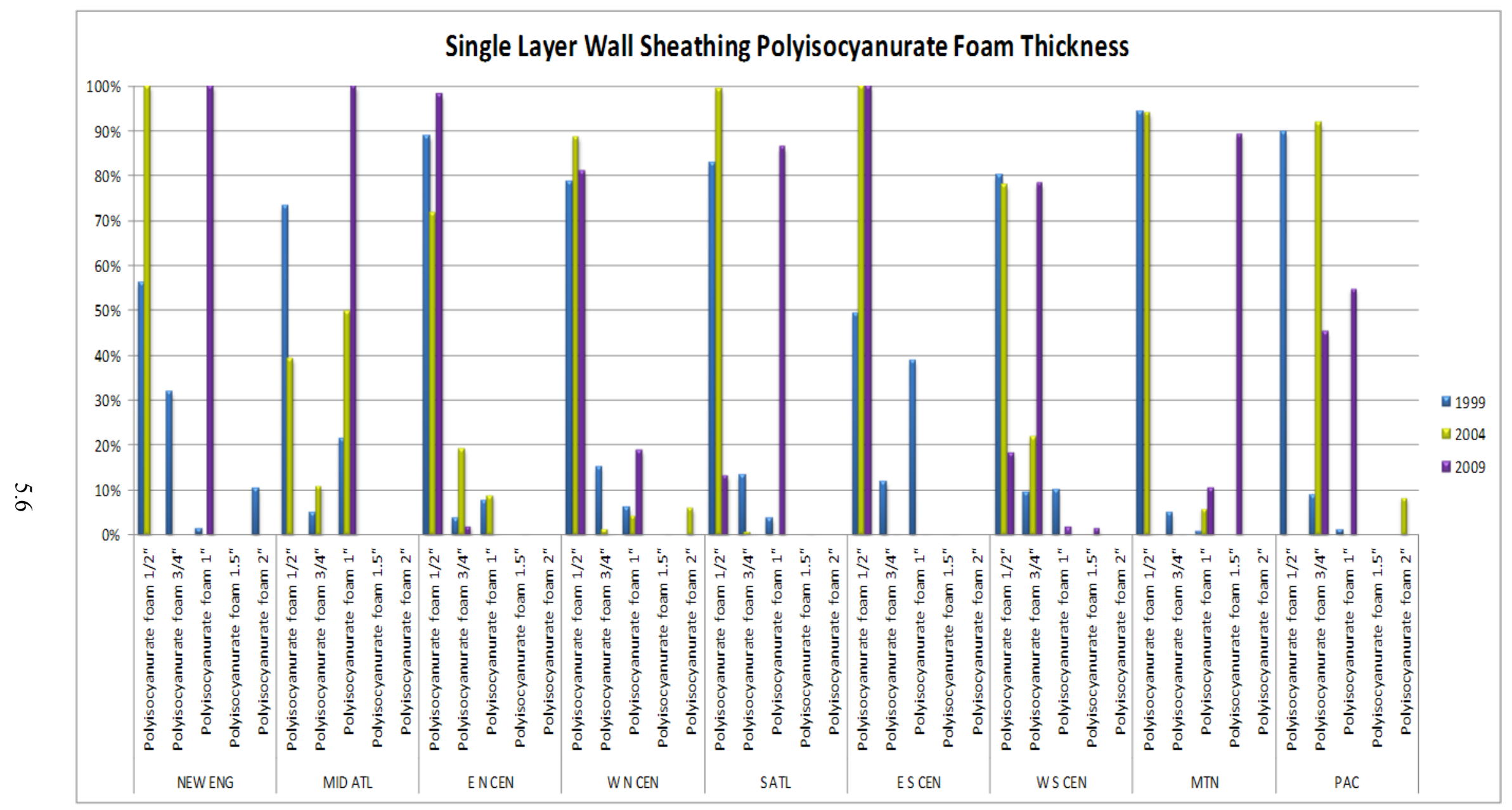

Figure 5.3. Single-Layer Wall Sheathing Polyisocyanurate Foam Thickness 


\subsubsection{Trends Identified}

Nationally, with the exception of the New England and East South Central Divisions, the 1/2 in. single polyisocyanurate foam was used the most. In New England and the East South Central Divisions, the data in 1999 showed a balance between 1/2 in. and 3/4 in. polyisocyanurate foams, with a higher favor for the 1/2 in. foam. From 2004 to 2009, the New England builders surveyed by NAHB indicated an overall change from $1 / 2$ in. foam to 1 in. foam $100 \%$ of the time, although no new codes were found to be in effect. East North Central, West North Central, South Atlantic, East South Central, and Mountain all predominately used 1/2 in. polyisocyanurate foam in 2004 and 2009 (with the exception of the South Atlantic that shifted to over $80 \% 1$ in. polyisocyanurate foam in 2009.) The West South Central foam percentages shifted from over $70 \% 1 / 2$ in. foam to $11 / 2$ in. polyisocyanurate foam between 1999 through 2009. In the Pacific Division, the trend changed from $1 / 2$ in. foam to $3 / 4$ in. foam in 2004 , and then split between 3/4 in. and $1 \mathrm{in}$. foam in 2009. The Middle Atlantic Division shifted from predominately 1/2 in. polyisocyanurate foam in 1999, to splitting $1 / 2$ in. and 1 in. in 2004, and ending with $100 \% 1$ in. polyisocyanurate foam in 2009. Data was not reported in 1996.

\subsubsection{Possible Code Influences}

The changes in single-layer wall sheathing polyisocyanurate foam thicknesses were not likely related to energy code changes.

\subsection{NAHB Survey Data Analysis - Homes with Two Layers of Wall Sheathing}

The NAHB survey results for two layers of wall sheathing are presented in Figure 5.4. Builders were asked what percentage of their homes had a layer of foam sheathing placed over a layer of structural sheathing material. 


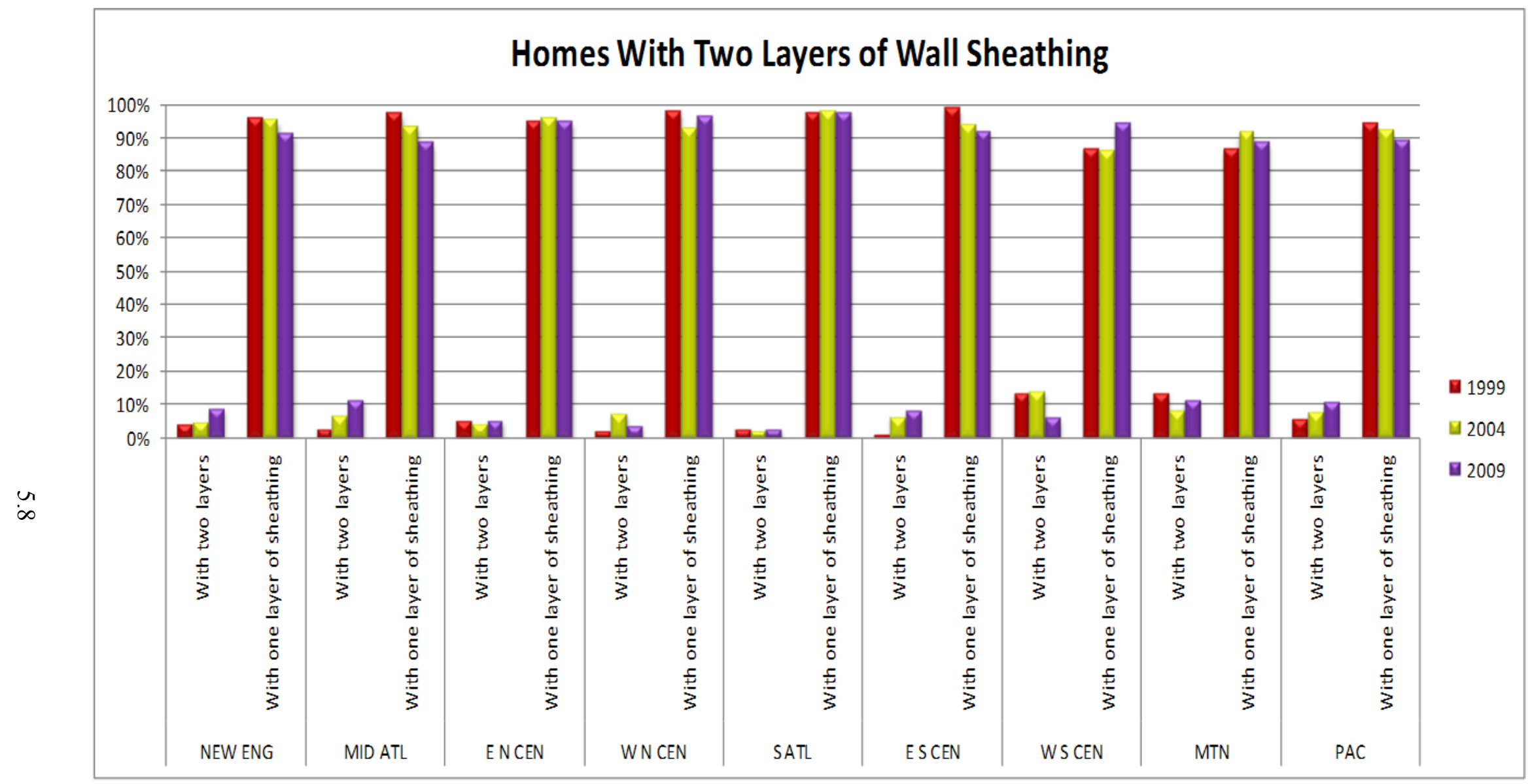

Figure 5.4. Homes with Two Layers of Wall Sheathing 


\subsubsection{Trends Identified}

From a nationwide perspective, all of the division trends (with exception of West South Central) showed that there were an increasing number of homes with two layers of wall sheathing. West South Central decreased the amount of two layer sheathing from 14\% to 6\% in 2009. New England, Middle Atlantic, East South Central, and the Pacific Divisions have all doubled the amounts of homes that have two layer wall sheathing since 1999. Data was not reported in 1996.

\subsubsection{Possible Code Influences}

The changes in two layers of wall sheathing were not likely related to energy code changes.

\subsection{NAHB Survey Data Analysis - Double-Layer Wall Sheathing Extruded Foam Thickness}

The NAHB survey results for double-layer wall sheathing extruded foam thickness are presented in Figure 5.5. Builders were asked about the typical thickness of the extruded foam they used, and given the following choices:

- $1 / 2$ in.

- $5 / 8$ in. or $3 / 4$ in.

- 1 in.

- $11 / 2$ in.

- 2 in. or greater. 


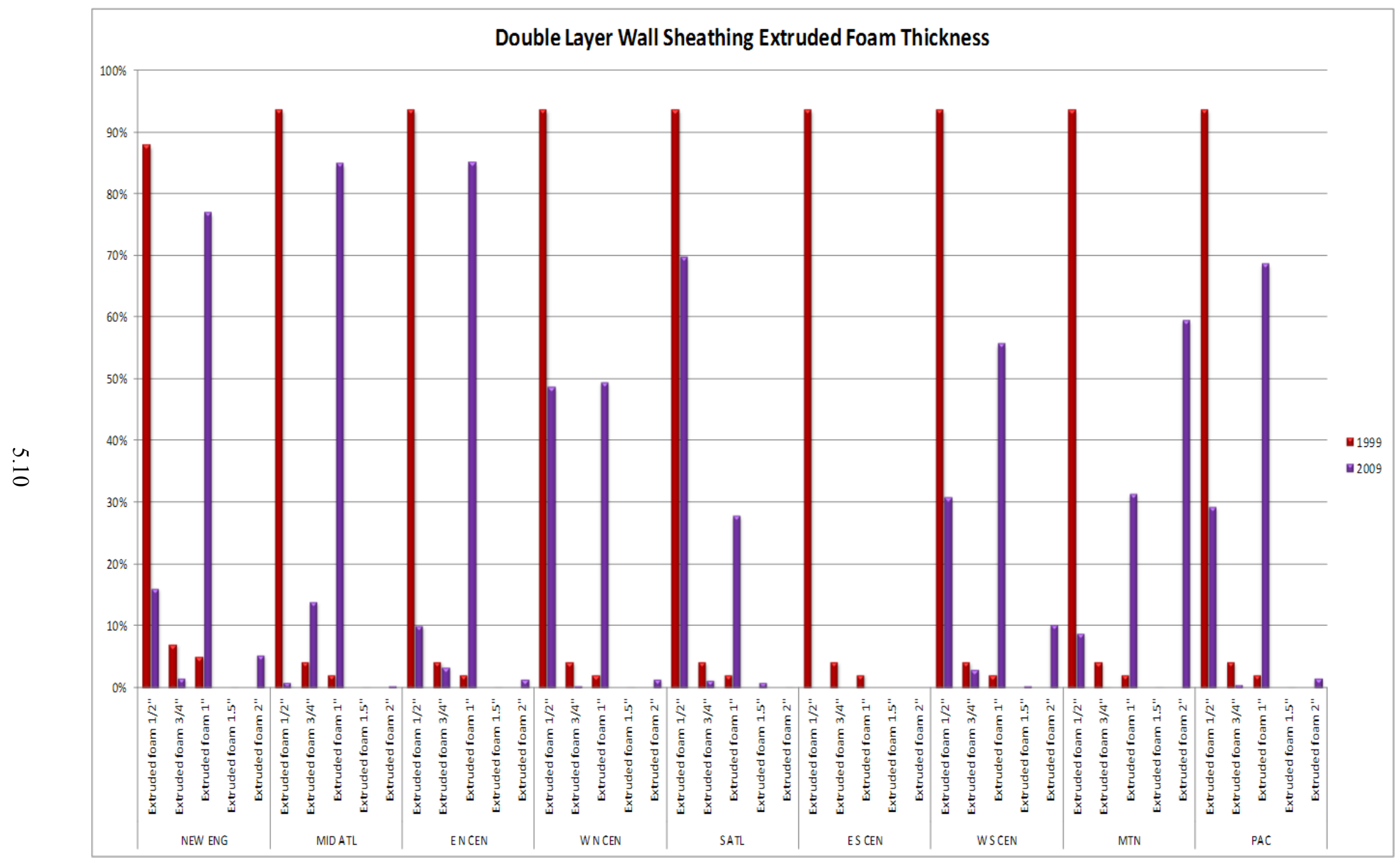

Figure 5.5. Double-Layer Wall Sheathing Extruded Foam Thickness 


\subsubsection{Trends Identified}

Nationally, in 1999, each of the census divisions had over $80 \%$ of their home inventories using $1 / 2$ in. extruded foam in homes with two layers of wall sheathing; however, by 2009, the New England, Middle Atlantic, East North Central, West South Central, and the Pacific regions averaged $60 \%$ use of 1 in.

extruded foam. Data was not reported in 1996 and 2004. East South Central did not report data for 2009.

\subsubsection{Possible Code Influences}

The change from $1 / 2$ in. to 1 in. was not likely energy code related.

\subsection{NAHB Survey Data Analysis - Double-Layer Wall Sheathing Expanded Foam Thickness}

The NAHB survey results for double-layer wall sheathing expanded foam thickness are presented in Figure 5.6. Builders were asked about the typical thickness of the expanded foam they used, and given the following choices:

- $1 / 2$ in.

- $5 / 8$ in. or $3 / 4$ in.

- 1 in.

- $11 / 2$ in.

- 2 in. or greater. 


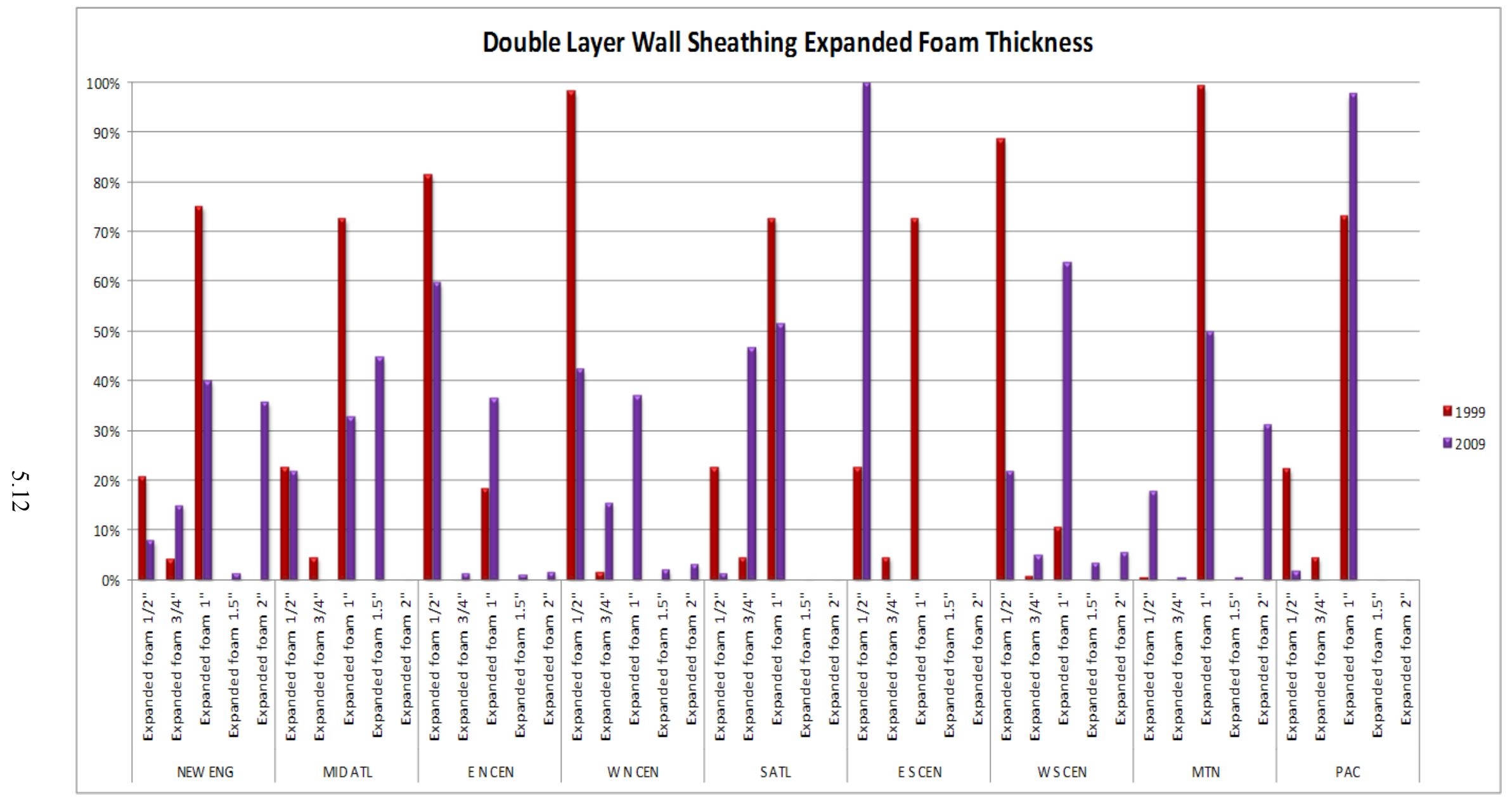

Figure 5.6. Double-Layer Wall Sheathing Expanded Foam Thickness 


\subsubsection{Trends Identified}

Nationally, from 1999 to 2009, every census region increased the thickness of two-layered expanded foam used except East South Central, although each region experienced differing levels of change. For example, in the Middle Atlantic region, builders dramatically decreased their preference for $1 \mathrm{in}$. foam for $11 / 2$ in. foam, while in the Mountain region, there was noticeable movement from $1 \mathrm{in}$. foam to $2 \mathrm{in}$. foam. It was unclear why the East South Central showed significant changes from 1 in. foam to $1 / 2$ in. foam, but survey samples from future years may expose this as a temporary anomaly. Although the particular changes in each region were somewhat unique, the national trend indicated an overall movement toward thicker foam layers in general. Data was not reported in 1996 and 2004.

\subsubsection{Possible Code Influences}

The changes in double-layer wall sheathing were not likely related to energy code changes.

\subsection{NAHB Survey Data Analysis - Double-Layer Wall Sheathing Polyisocyanurate Foam Thickness}

The NAHB survey results for double-layer wall sheathing polyisocyanurate foam thickness are presented in Figure 5.7. Builders were asked about the typical thickness of the polyisocyanurate foam they used, and given the following choices:

- $1 / 2$ in.

- $5 / 8$ in. or $3 / 4$ in.

- 1 in.

- $11 / 2$ in.

- 2 in. or greater. 


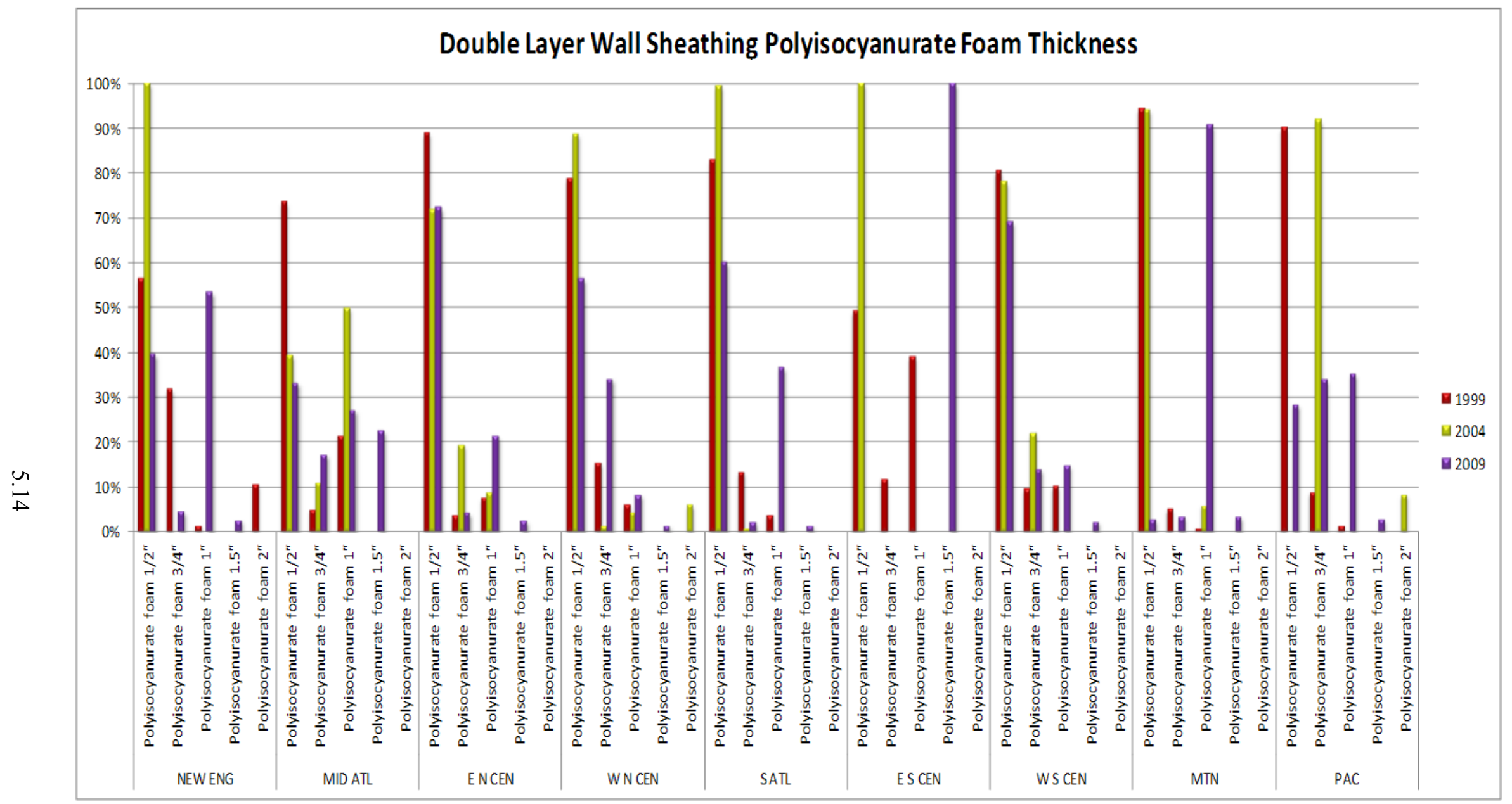

Figure 5.7. Double-Layer Wall Sheathing Polyisocyanurate Foam Thickness 


\subsubsection{Trends Identified}

There were no distinct national trends identified. In 1996, East South Central and New England Divisions both had more $1 / 2$ in. polyisocyanurate foam in the homes with two layer wall sheathing than the other sizes, but had a small presence in the other sizes as well. This differed from the rest of the country since it was dominant in the $1 / 2$ in. foam without many deviations. Three divisions, New England, South Atlantic, and East South Central, all had 1/2 in. polyisocyanurate foam in $100 \%$ of the homes that had two-layer wall sheathing in 2004. None of those three divisions kept all $100 \%$ of their inventory at 1/2 in. foam. East South Central reported 100\% in 1 1/2 in. foam, and New England and South Atlantic had a mix between $3 / 4 \mathrm{in}$. and $1 \mathrm{in}$. foam. The remaining divisions predominantly had $1 / 2$ in. foam, but spread over $1 / 2$ in., $3 / 4$ in., 1 in., and $11 / 2$ in. None of the census divisions trended to 2 in. polyisocyanurate foam.

\subsubsection{Possible Code Influences}

The changes in double-layer wall sheathing polyisocyanurate foam were not likely related to energy code changes. 



\subsection{Insulation}

The Environmental Protection Agency estimated that homeowners typically saved up to $20 \%$ of heating and cooling costs (or up to $10 \%$ of total energy costs) by air sealing their homes and adding insulation in attics, floors over crawl spaces, and accessible basement rim joists ${ }^{1}$. Batts, blankets, loose fill, and low-density foams, as well as special foam, such as polyisocyanurate and polyurethane, created a number of options for builders to customize insulation needs for any home. In comparison to windows, insulation normally accounted for more than $80 \%$ of exterior wall space alone, and together with the ceiling and floor, created the most important barrier between conditioned spaces and the outside environment.

The insulation data set included:

- slab-on-grade homes without insulation

- slab floor insulation R-value

- slab perimeter insulation R-value

- crawl space ground floor insulation R-value

- crawl space ground floor insulation type

- crawl space wall insulation R-value

- crawl space wall insulation type

- basement ground floor insulation type

- basement ground floor insulation R-value

- basement wall insulation R-value

- basement wall insulation type, exterior wall insulation type

- exterior wall cavity R-value, flat ceiling insulation type

- cathedral ceiling insulation type

- ceiling insulation R-value.

\subsection{NAHB Survey Data Analysis - Slab-on-Grade Homes Without Insulation}

The NAHB survey results for slab-on-grade homes without insulation are presented in Figure 6.1. Builders were asked what type of insulation they typically used for slab-on-grade foundations, or if no insulation was used for the slab.

\footnotetext{
${ }^{1} \mathrm{http}: / /$ www.energystar.gov/index.cfm?c=home_sealing.hm_improvement_methodology
} 


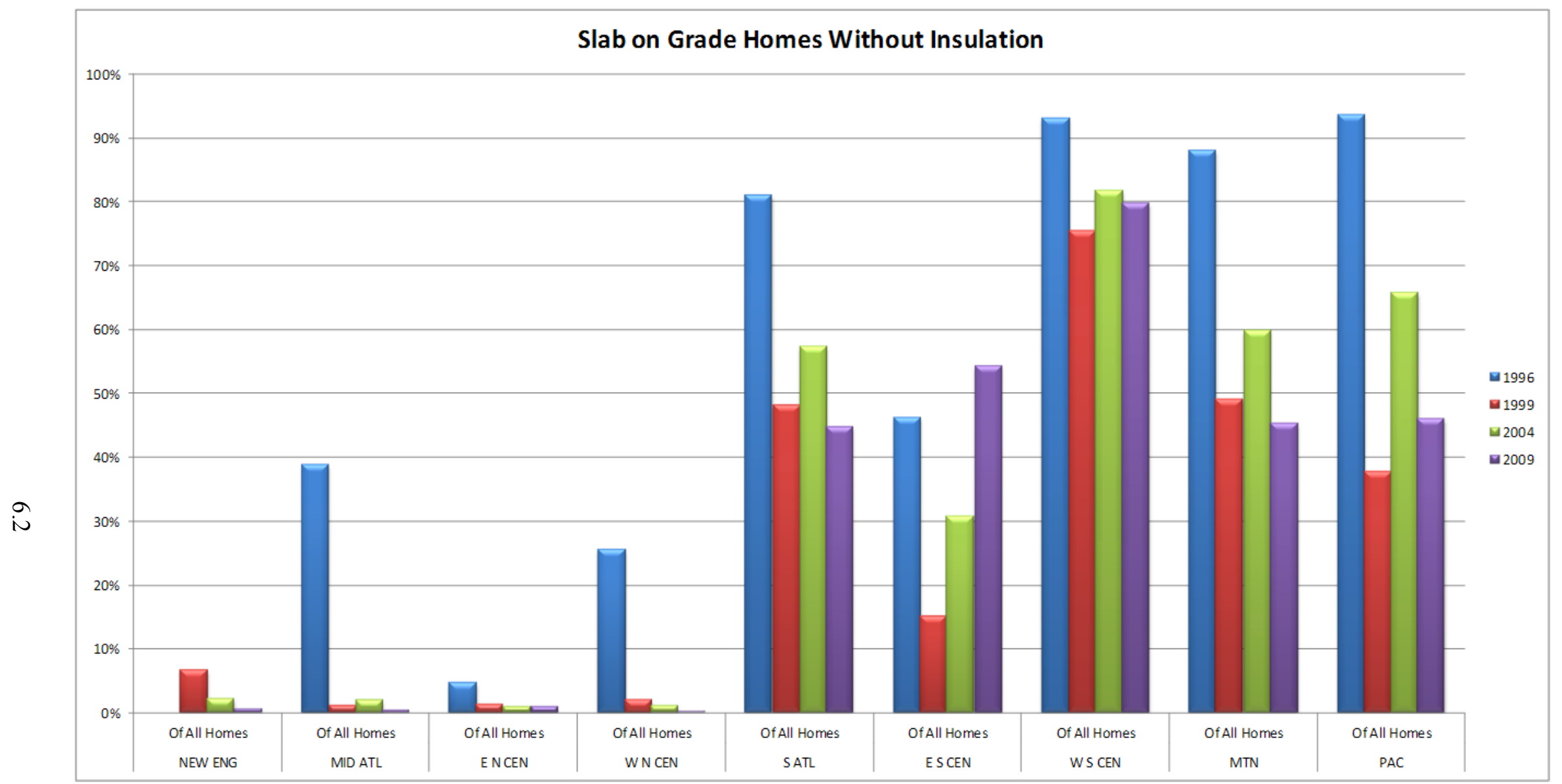

Figure 6.1. Slab-on-Grade Homes Without Insulation 


\subsubsection{Trends Identified}

Slab-on-grade foundations were found much more frequently in warm climates than in cooler ones, and therefore, created difficulties in accurately assessing national trends. Nonetheless, there were pronounced decreases in the presence of uninsulated slab-on-grade homes in almost all regions after 1996, followed by inconsistent changes in the years thereafter.

Middle Atlantic and West North Central Divisions both had over 20\% slab-on-grade homes without insulation in 1996. In following years, the percent of slab-on-grade homes without insulation dropped below 5\%. The only division in the country that had a raise in homes without insulation was East South Central. There was an initial drop from 1999 to 2004, but raised again to over 50\% in 2009. South Atlantic, West South Central, Mountain, and Pacific Divisions were each above $80 \%$ of homes without insulation in 1996; this figure dropped below $50 \%$ by 2009. West South Central Division had the highest percentage in 1999, but also continued to have the highest percentage of homes without insulation in 2009 (80\%). East North Central Division had the lowest percentage in 1999 of 5\%, and dropped down to below $3 \%$ by 2009 .

\subsubsection{Possible Code Influences}

The 1995 MEC required slab edge insulation in several climate zones, and probably played a role in the aforementioned decrease in uninsulated homes after 1996.

\subsection{NAHB Survey Data Analysis - Slab Floor Insulation R-Value}

The NAHB survey results for slab floor insulation R-value are presented in Figure 6.2. Builders were asked to select their typical slab floor insulation R-values from among the following choices:

- less than 3.75

- R-3.75 to R-5.0

- R-7.5

- $\mathrm{R}-10$ or greater. 


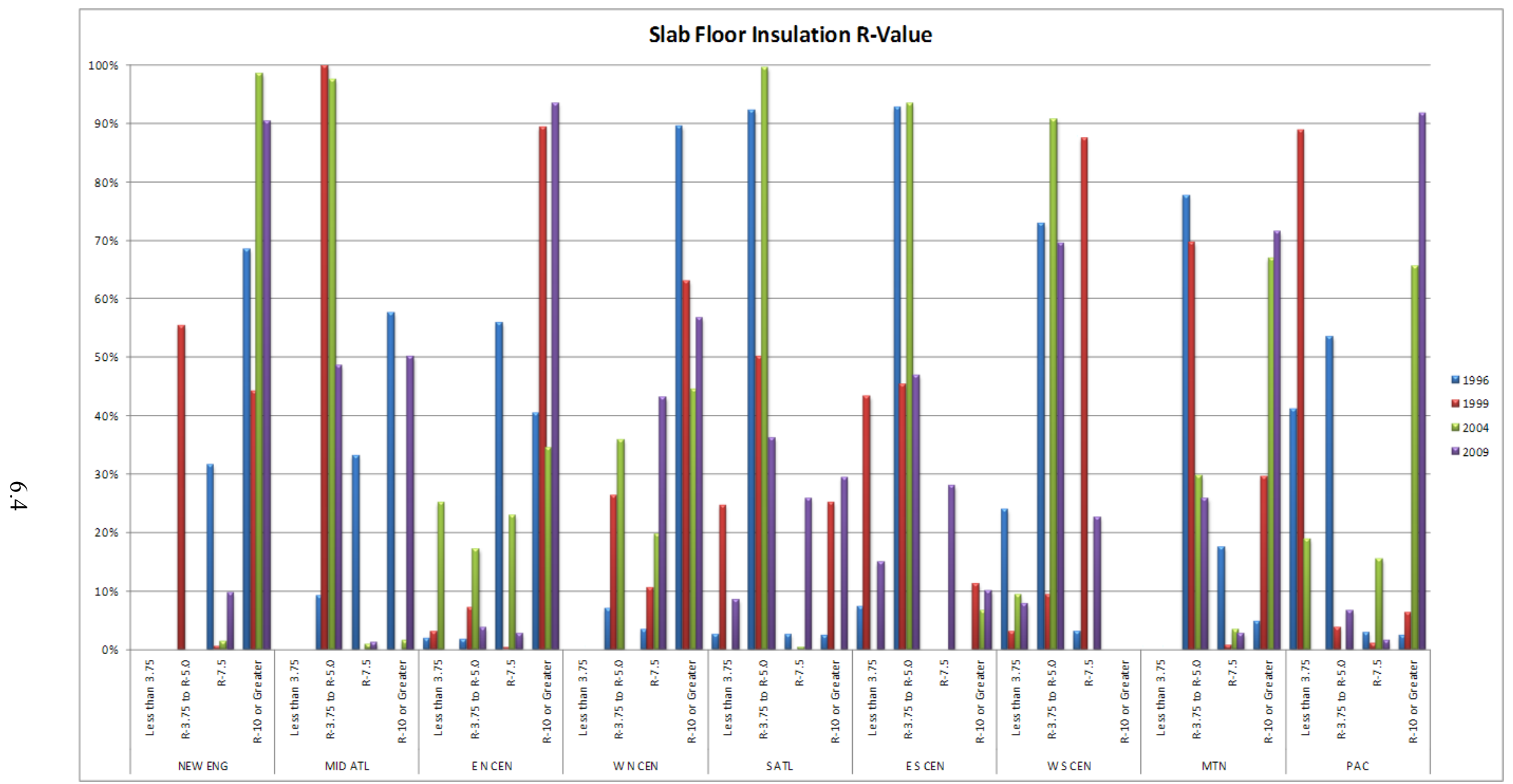

Figure 6.2. Slab Floor Insulation R-value 


\subsubsection{Trends Identified}

There were no distinct national trends identified. West North Central had $88 \%$ of homes with slab floor insulation R-values greater than or equal to R-10, but the trend headed downward leaving the percentage in 2009 under 60\%. Pacific Division made a turn between 1996 and 2009. In 1996, the homes insulation R-value was predominately split between R-value less than 3.75 and R-3.75 to R-5.0. Then, in $1999,88 \%$ of the R-values were less than 3.75, and from 2004 to 2009 , the R-values shifted to R-10 or greater. Mountain Division R-values trended between R-3.75-5.0, with the highest percentages in 1996, and then decreased through 2009, and R-10 or greater, had the lowest percentages in 1996, and rose through 2009, ending at 72\%. The East North Central Division trended between R-7.5 and the R-10 or greater between the four year data span. The rest of the divisions, including the Middle Atlantic, South Atlantic, East South Central, and West South Central Divisions, all primarily used slab floor insulation Rvalues of R-3.75 to R-5.0, with smaller percentages of 30\% or less in R-7.5 and R-10 or greater.

\subsubsection{Possible Code Influences}

The 2003 IECC required R-9 and above slab edge insulation in several code climates for residential buildings with 15\% window-to-wall ratio, and required R-5 and above in climate zones 4 and higher. Most builders used 2-in. insulation to achieve R-9.

\subsection{NAHB Survey Data Analysis - Slab Perimeter Insulation R-Value}

The NAHB survey results for slab perimeter insulation R-value are presented in Figure 6.3. Builders were asked to select their typical slab perimeter insulation R-values from among the following choices:

- less than 3.75

- R-3.75 to R-5.0

- R-7.5

- R-10 or greater. 


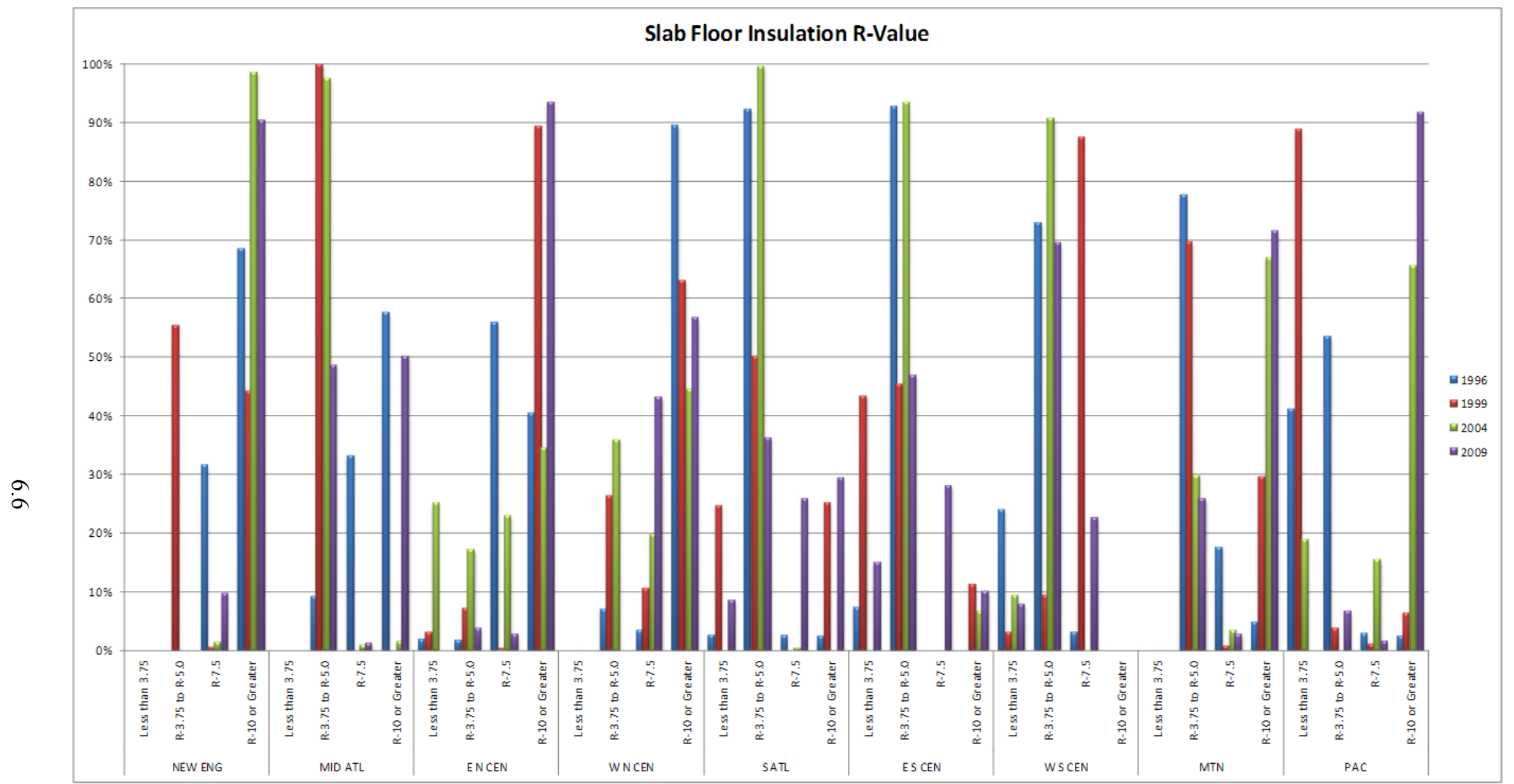

Figure 6.3. Slab Perimeter Insulation R-value 


\subsubsection{Trends Identified}

Nationally, there were no distinct trends identified. New England and Middle Atlantic both trended to R-10 or greater slab perimeter insulation R-values. West North Central, East South Central, West South Central, and Mountain Divisions all reported dominance in 1996 with R-values between R-3.75 to R-5.0. The trend progressed to a dominance of R-10 or greater, with the exception of West South Central, which continued to build houses with R -3.75 to R-5.0. The Pacific Division had the greatest change with supremacy in 1996 when R-values less than 3.75 changed to over $90 \%$ of the slab perimeter insulation Rvalues of R-10 or more. The East North Central showed R-values in R-7.5 to be the greatest percentages of over $65 \%$, and in 2009 , almost $90 \%$ of the homes built had slab perimeter insulation R-values of R-10 or greater.

\subsubsection{Possible Code Influences}

The changes in slab perimeter insulation R-value were not likely related to energy code changes.

\subsection{NAHB Survey Data Analysis - Crawl Space Insulation R-Value}

The NAHB survey results for crawl space insulation R-value are presented in Figure 6.4. Builders were asked to specify the R-value of insulation used in crawl spaces from among the following choices:

- R-7 or less

- R-11

- R-13

- R-19

- R-22 or greater. 


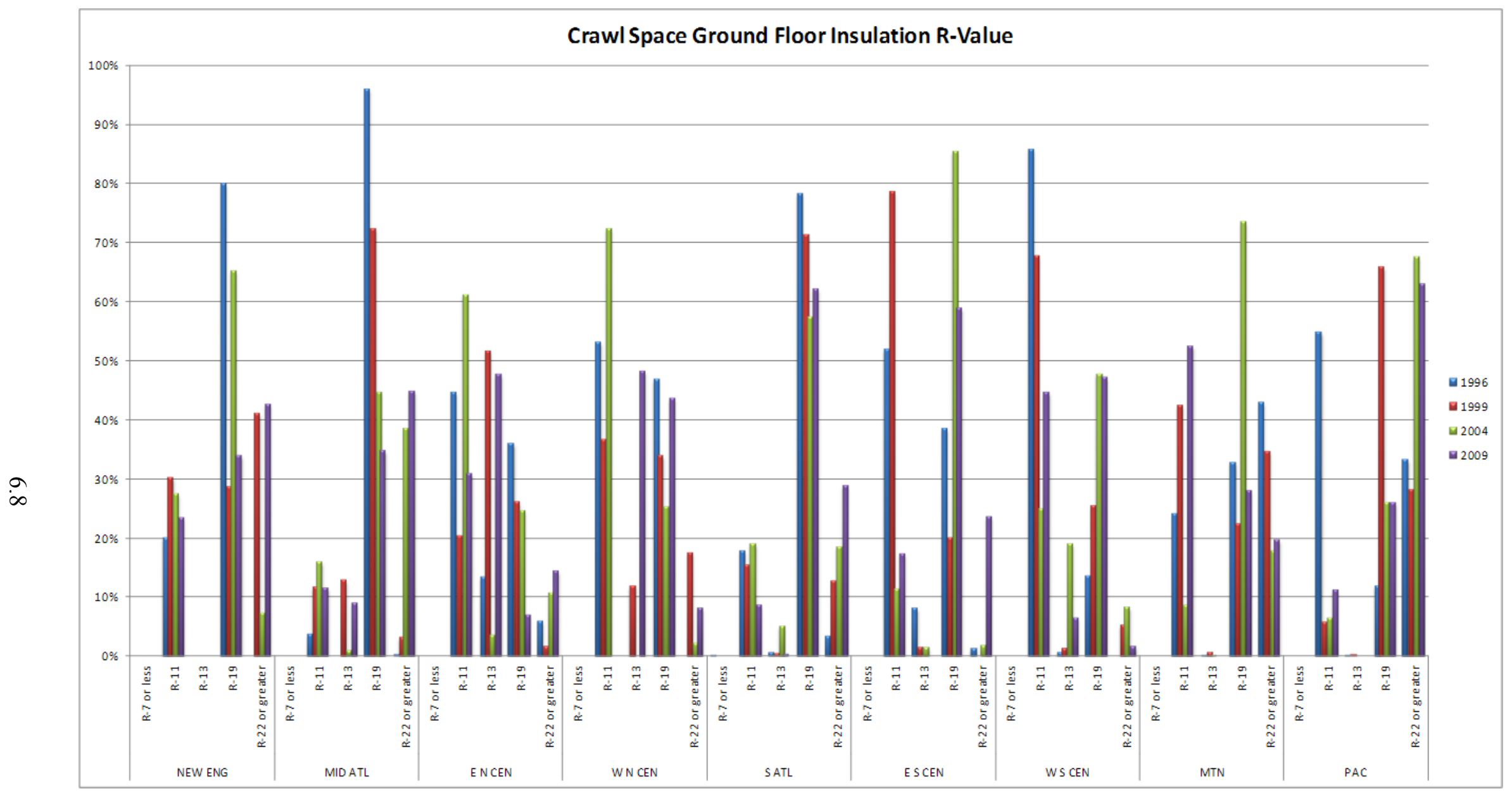

Figure 6.4. Crawl Space Insulation R-value 


\subsubsection{Trends Identified}

Consistent movement throughout the country was seen toward higher R-values particularly at R-19. New England had crawl space ground floor insulation R-values of R-19 (80\%) in 1996, while trends showed R-22 or greater over $40 \%$ in 2009 (with R-19 over 30\% and R-11 over 20\%). The Middle Atlantic Division had over 90\% of crawl space ground floor insulation R-value of R-19 in 1996.

Similarly, New England and the Middle Atlantic split R-19 and R-22 or greater with over 30\% and 40\%, respectively. In East North Central, East South Central, and West North Central, trends were between R-11 and R-19, unlike in South Atlantic and Pacific Divisions where the dominance was in R-19. Unlike the rest of the country, West South Central and Mountain division split between R-11 and R-19.

\subsubsection{Possible Code Influences}

The 2000 IECC required a minimum R-19 floor insulation in several climate zones.

\subsection{NAHB Survey Data Analysis - Crawl Space Insulation Type}

The NAHB survey results for crawl space insulation type are presented in Figure 6.5. Builders were asked to specify the type of insulation used in crawl spaces from among the following types:

- fiberglass batt

- fiberglass blown

- rockwool batt

- cellulose blown

- foam plastic

- spray foam, 


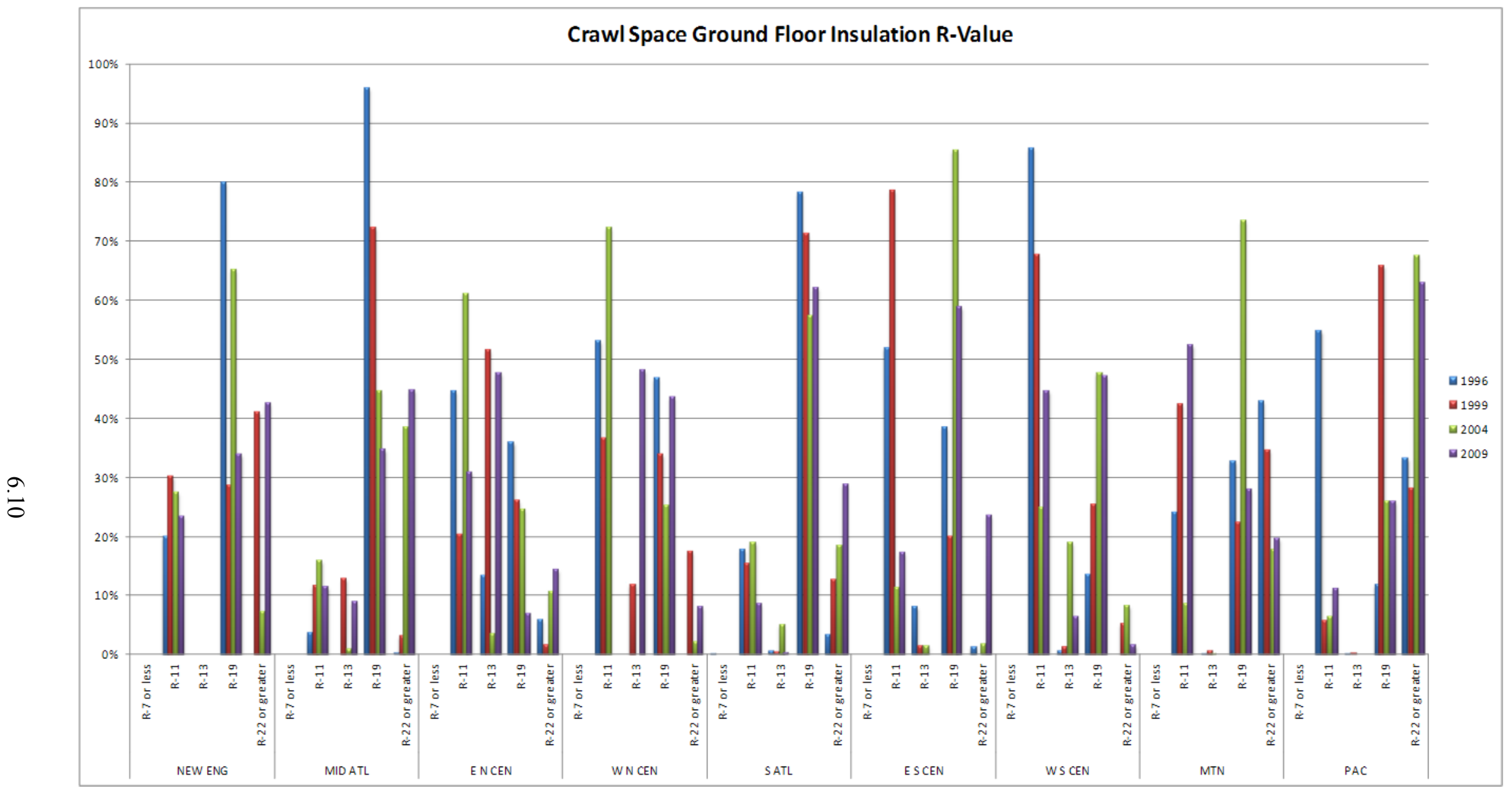

Figure 6.5. Crawl Space Insulation Type 


\subsubsection{Trends Identified}

All of the census divisions predominately used fiberglass batting for the insulation type in the crawl space ground floor. West South Central Middle Atlantic, East South Central, and the South Atlantic Divisions started to use spray foam in 2009.

\subsubsection{Possible Code Influences}

The 2000 IECC required R-19 floor insulation for several climate zones.

\subsection{NAHB Survey Data Analysis - Crawl Space Wall Insulation R-Value}

The NAHB survey results for crawl space wall insulation R-value are presented in Figure 6.6. Builders were asked to specify R-values from among the following choices:

- less than R-5

- R-5 to R-6.9

- R-7 to R-8.9

- R-9 to R-10.9

- R-11 to R-12.9

- R-13

- greater than R-13.

Data from 1996 and 2004 was not reported for New England. Data was not reported in 1996, 1999, and 2009 for West South Central. 


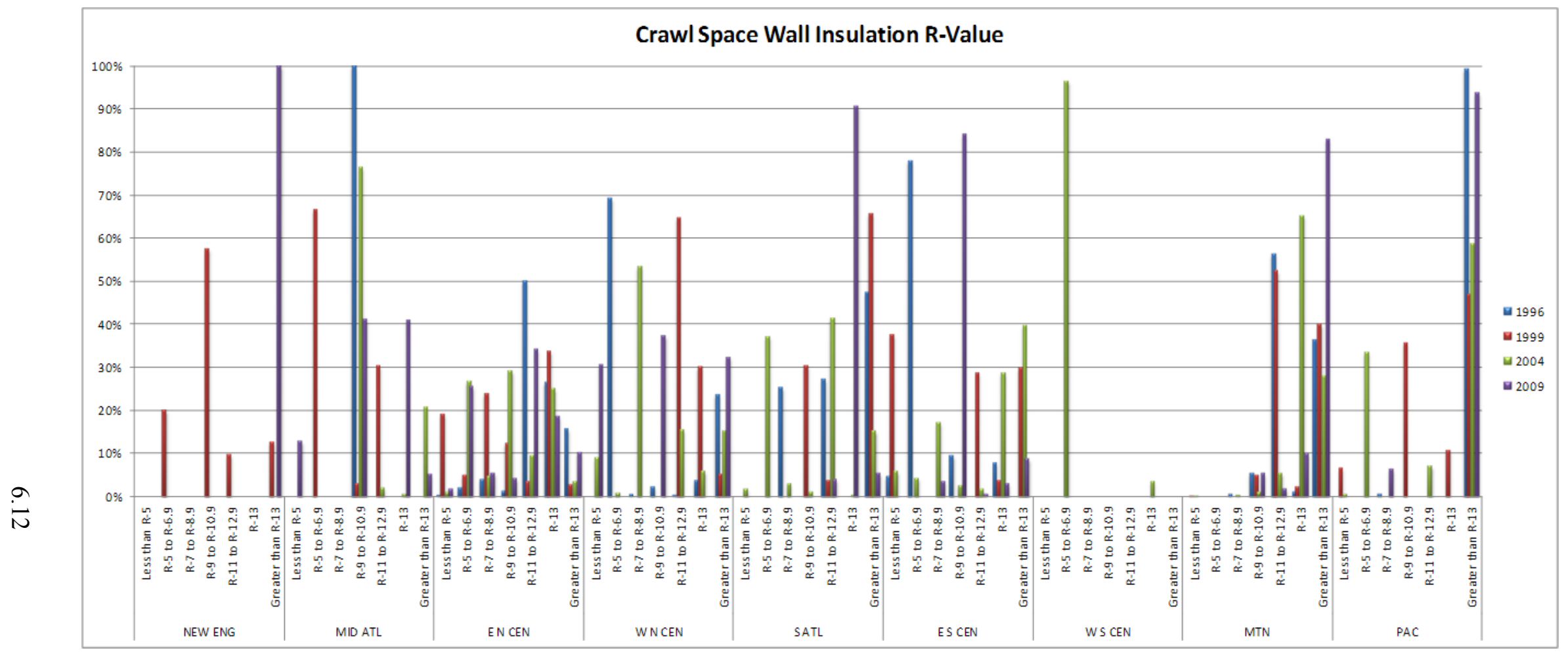

Figure 6.6. Crawl Space Wall Insulation R-value 


\subsubsection{Trends Identified}

There were no distinct national trends identified. In New England, the crawl space wall insulation Rvalue centered around R-9 to R-10.9 in 1999, but went to $100 \%$ R-13 and higher by 2009. West South Central reported crawl space wall insulation R-values of R-5 to R-6.9 in 2004. The Pacific Division reported close to $100 \%$ greater than R-13 values in 1999, and continued in 2009 to have over $90 \%$ of crawl space wall insulation R-values greater than R-13. Middle Atlantic, West North Central, and East South Central all trended from lower R-values to settle between R-9 and R-10.9 for the majority of the homes built. The Mountain Division trended from crawl space wall insulation R-values of R-11 to R12.9 (over 50\% in 1999) to over 80\% greater than R-13 in 2009. The East North Central Division and the South Atlantic Division both started with insulation R-values across the board. In 2009, both of the divisions settled closer to R-13, with the South Atlantic having $90 \%$.

\subsubsection{Possible Code Influences}

The 2003 IECC made provisions for R-values in several climate zones.

\subsection{NAHB Survey Data Analysis - Crawl Space Wall Insulation Type}

The NAHB survey results for crawl space wall insulation type are presented in Figure 6.7. Builders were asked to specify the type of insulation used from among the following types:

- fiberglass batt or blanket

- fiberglass board

- rockwool batt

- extruded polystyrene

- spray foam

- expanded polystyrene

- polyisocyanurate

- other.

Data was not reported in 1996 and 2004 for New England. Data was not reported for 1996 and 2009 for West South Central. 


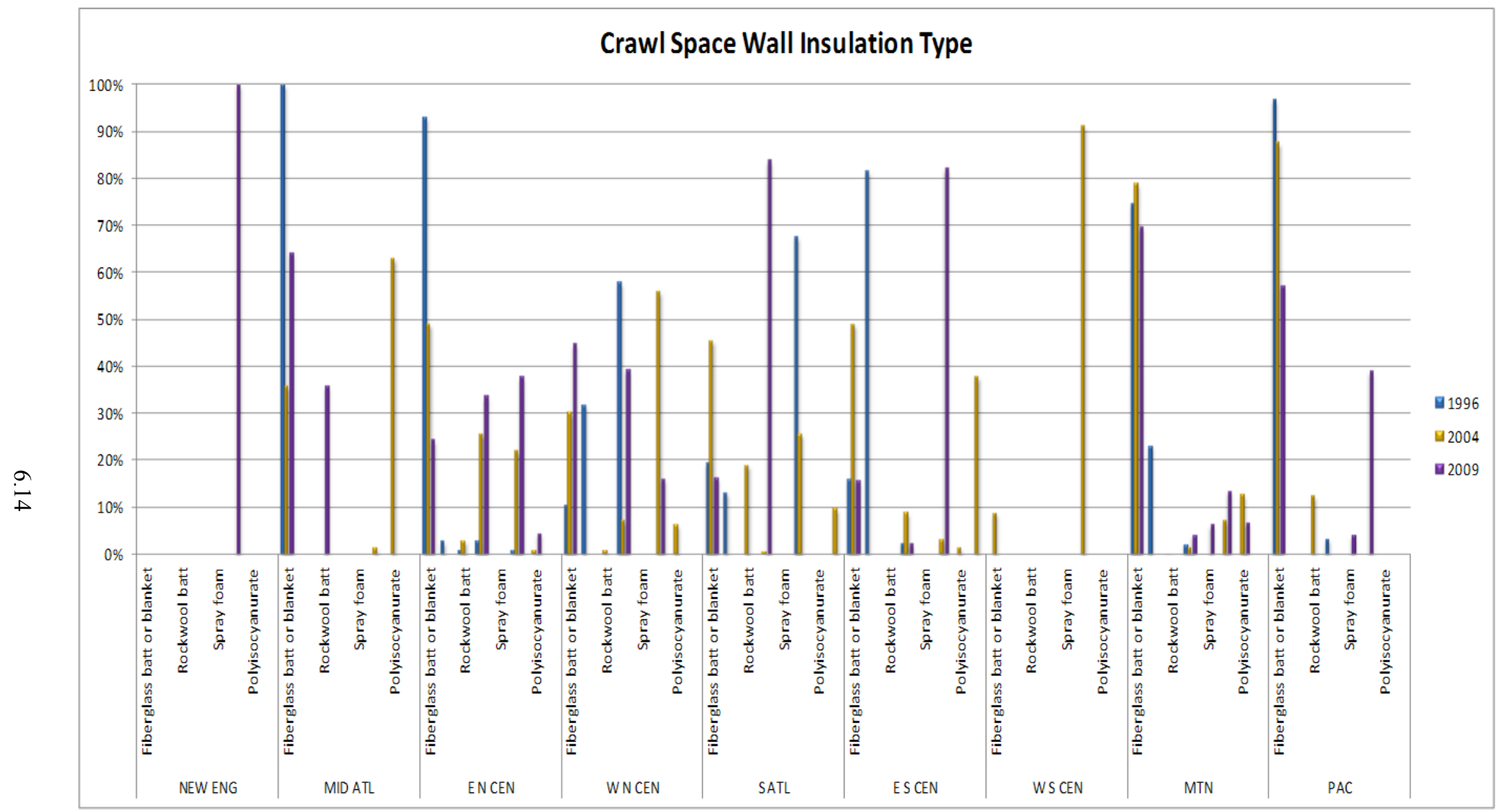

Figure 6.7. Crawl Space Wall Insulation Type 


\subsubsection{Trends Identified}

No distinct national trends were identified. New England Census Division had 100\% expanded polystyrene crawl space wall insulation type in 2009 . West South Central had over $90 \%$ dominance in expanded polystyrene crawl space wall insulation type. The Mountain, Pacific, Middle Atlantic, and East North Central Divisions all predominately used fiberglass batting or blankets for the crawl space wall insulation type in 1999. The Mountain Division continued to predominantly use fiberglass batt/blanket through 2009. The trend through 2004 and 2009 split between expanded polystyrene, extruded polystyrene, and rockwool batting. In 1999, West North Central predominantly used extruded polystyrene, but shifted toward expanded polystyrene crawl space wall insulation type in 2004. In 1999, the South Atlantic Division used expanded polystyrene predominantly, but shifted to extruded polystyrene in 2009. The East South Central Division reported over $80 \%$ of their crawl space wall insulations used fiberglass board. This changed almost exactly to expanded polystyrene in 2009 (over $80 \%)$.

\subsubsection{Possible Code Influences}

The trends are likely due to builder preferences, rather than energy code influenced.

\subsection{NAHB Survey Data Analysis - Basement Floor Insulation Type}

The NAHB survey results for basement floor insulation type are presented in Figure 6.8. Builders were asked to specify basement floor insulation type from among the following choices:

- fiberglass batt

- fiberglass blown

- rockwool batt

- cellulose blown

- spray foam

- foam board

- none - insulated wall instead

- none - neither walls nor floors insulated.

All of the census divisions predominately used fiberglass batting for the insulation type in the basement ground floor. 


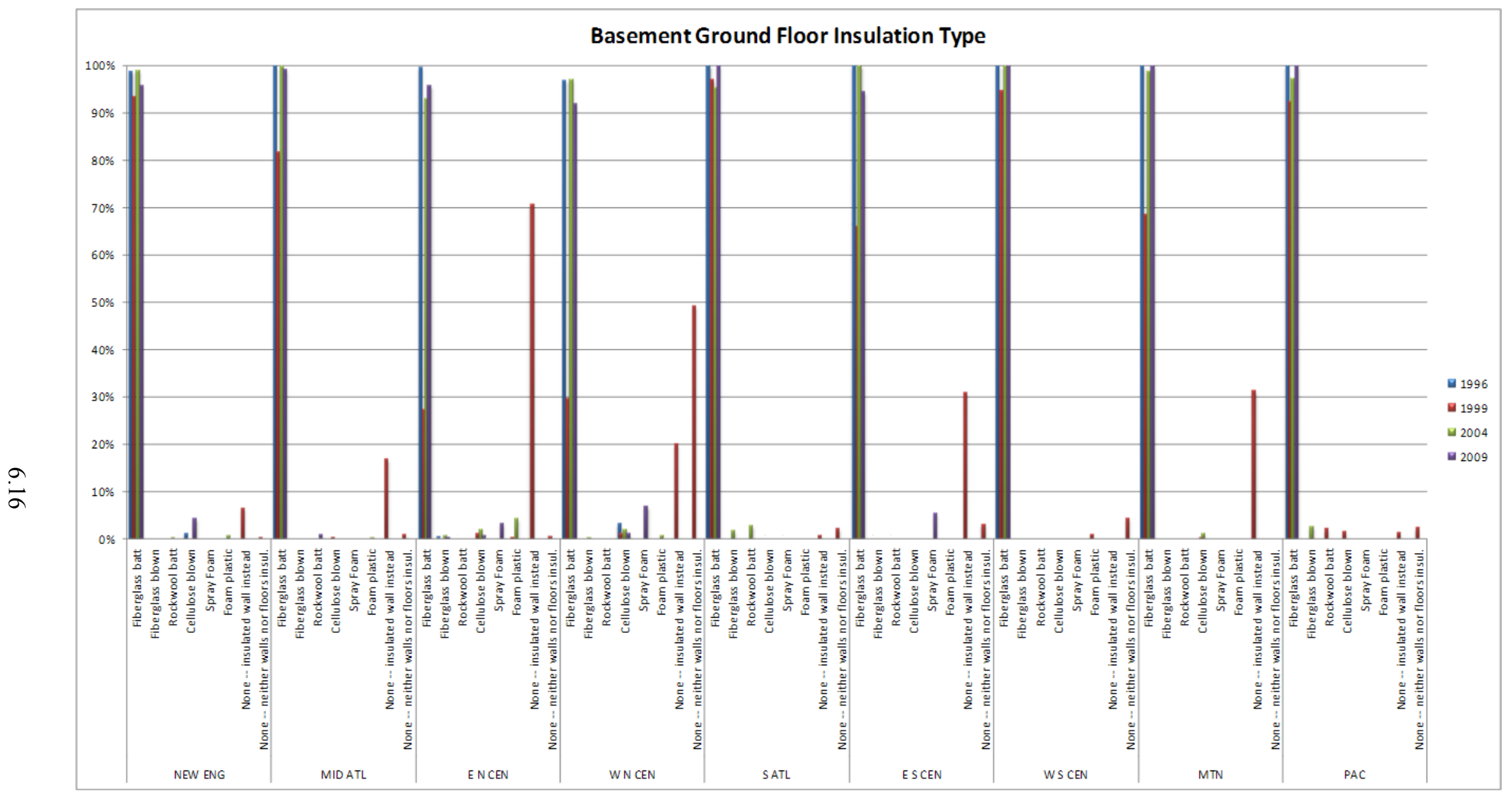

Figure 6.8. Basement Floor Insulation Type 


\subsubsection{Trends Identified}

In 1999, East North Central, West North Central, East South Central, and the Mountain Divisions all reported that no insulation was used in the basement floors. Also in the West North Central Division, almost $50 \%$ of the homes reported having neither insulated walls nor floors.

\subsubsection{Possible Code Influences}

The changes in basement floor insulation were not likely related to energy code changes.

\subsection{NAHB Survey Data Analysis - Basement Floor Insulation R-Value}

The NAHB survey results for basement floor insulation R-value are presented in Figure 6.9. Builders were asked to specify the basement floor insulation R-value from among the following choices:

- R-7 or less

- R-11

- R-13

- R-19

- R-22 or greater. 


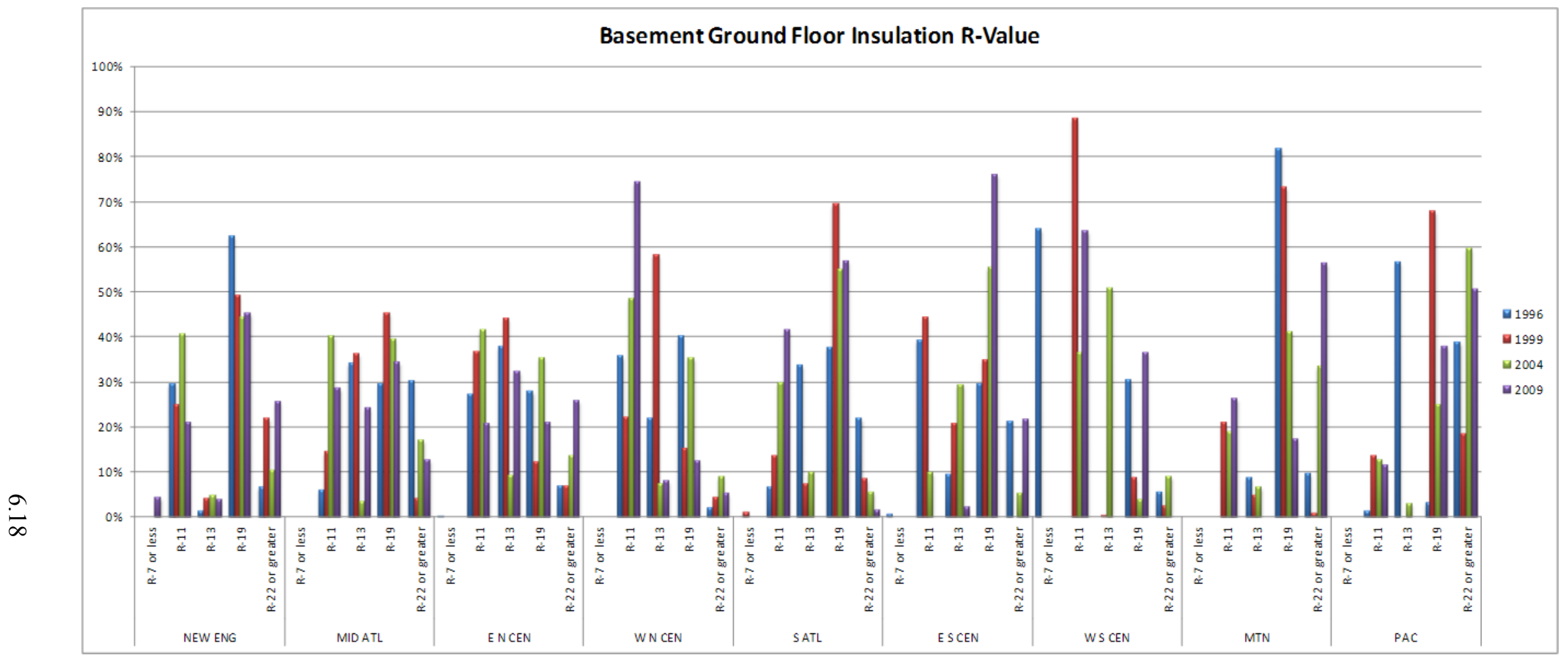

Figure 6.9. Basement Floor Insulation R-value 


\subsubsection{Trends Identified}

Nationally, no distinct trends were identified. New England, Middle Atlantic, South Atlantic, East South Central, and Mountain Divisions all began their basement ground floor insulation R-value trends dominant in R-19. With the exception of the Mountain Division, which increased to R-22, the trend stayed with R-19 for the basement ground floor insulation type. In both the Middle Atlantic and East North Central Divisions, the R-values were almost equal across the chart, and across the years. General trends actually increased to the R-22 or greater R-value category. The West South Central Division reported a dominance of over $60 \%$ R-7 or less in 1996, and 30\% in R-19. The trend changed to over $60 \%$ in R-11 insulation types, and also over 35\% in R-19 values.

\subsubsection{Possible Code Influences}

The changes in basement floor insulation R-values were not likely related to energy code changes.

\subsection{NAHB Survey Data Analysis - Basement Wall Insulation R-Value}

The NAHB survey results for basement wall insulation R-value are presented in Figure 6.10. Builders were asked to specify the R-value of basement wall insulation from among the following choices:

- less than R-5

- $\mathrm{R}-7.5$

- R-10

- R-11

- R-13

- greater than R-13. 


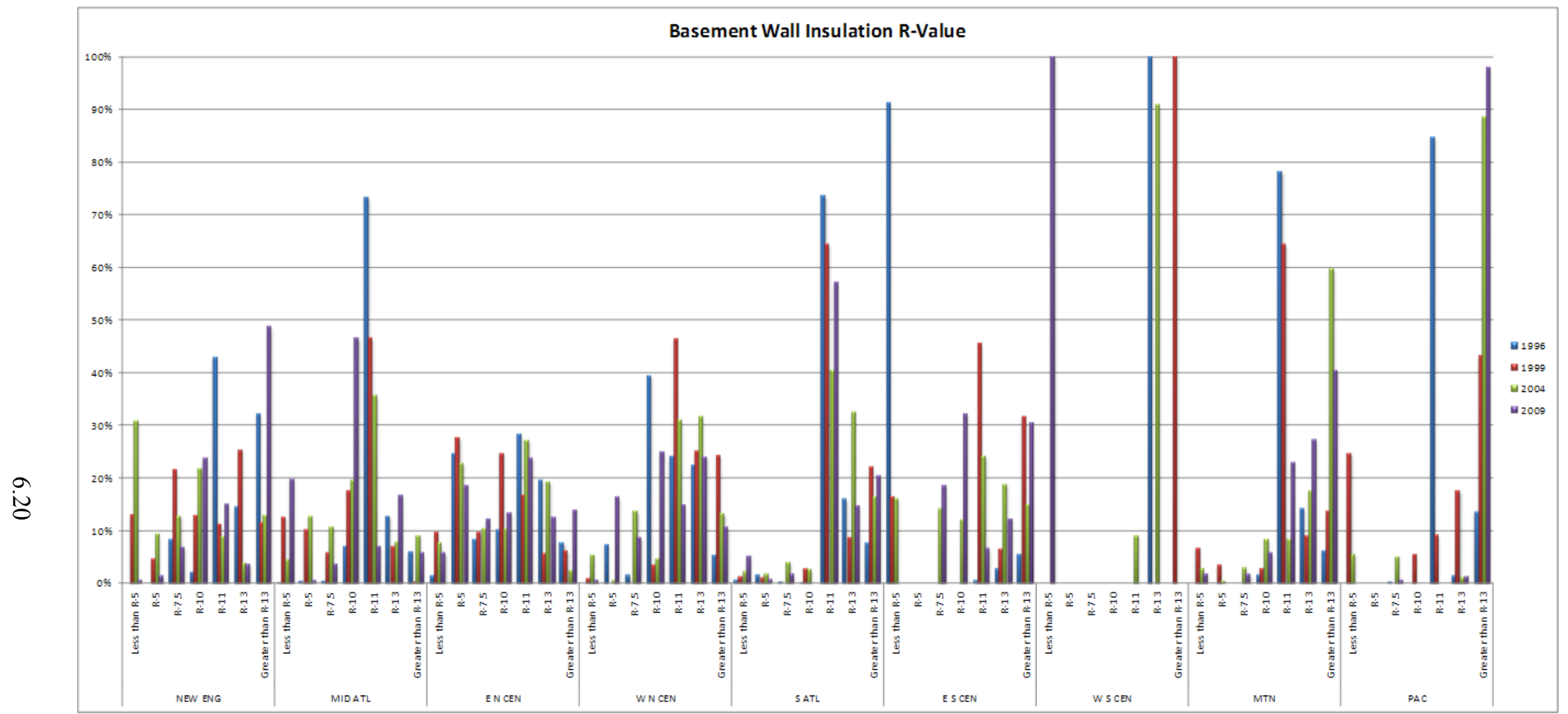

Figure 6.10. Basement Wall Insulation R-value 


\subsubsection{Trends Identified}

There were no distinct nationwide trends identified. In the West South Central Division, $100 \%$ of the basement wall insulation R-values were reported for R-13 in 1996, trending to 100\% greater than R-13 in 1996, and then to $100 \%$ less than R-5 in 2009. The Pacific Division trended from over $80 \%$ R-11 (1996) basement wall insulation R-values to over 95\% R-values greater than R-13 in 2009. East South Central also reported over 90\% insulation R-values less than R-5 in 1996, but then averaged below 35\% R-10, R-11, R-13, and greater than R-13 in 2009. The Mountain, New England, South Atlantic and Middle Atlantic predominately had insulation R-values of R-11 in 1996, but all trended to a higher than $40 \%$ greater than R-13 values by 2009, with the exception of Middle Atlantic that had an R-value of R-10 predominantly in 2009, and South Atlantic which kept over 50\% of the basement wall insulation R-values at R-11. East North Central and West North Central Divisions did not have a single dominant R-value reported in their data. Instead, there was an increase of the higher R-values, and decreases in the lower Rvalues.

\subsubsection{Possible Code Influences}

The 1995 MEC and 1998 IECC adopted increased levels of basement wall insulation R-values.

\subsection{NAHB Survey Data Analysis - Basement Wall Insulation Type}

The NAHB survey results for basement wall insulation type are presented in Figure 6.11. Builders were asked to specify the type of basement wall insulation used, from the following choices:

- fiberglass batt

- rockwool batt

- fiberglass board

- extruded polystyrene

- polyisocyanurate

- other.

- Data was not reported in 2009 in West South Central. 


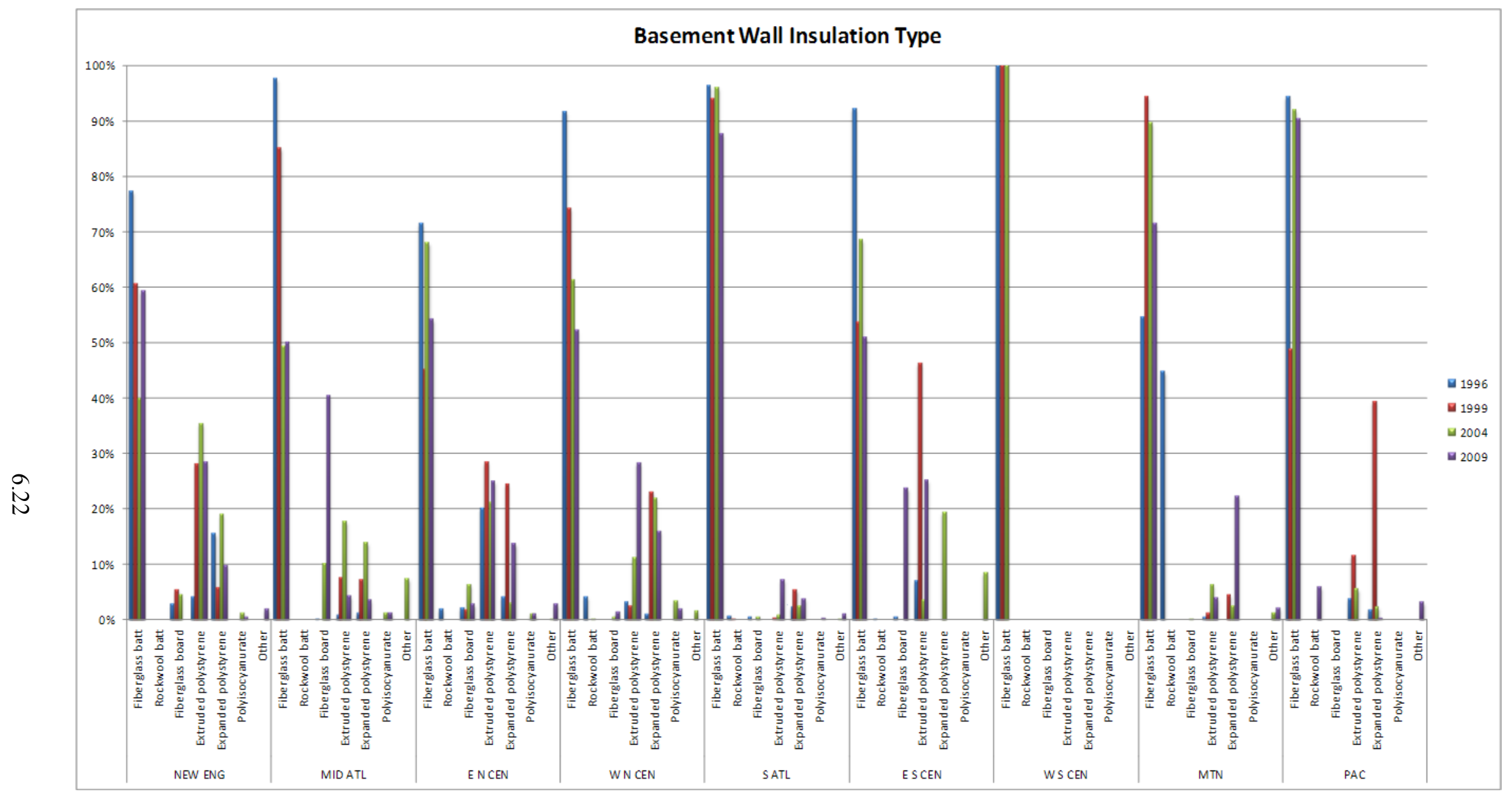

Figure 6.11. Basement Wall Insulation Type 


\subsubsection{Trends Identified}

There were no distinct national trends identified. West South Central had 100\% fiberglass batt basement wall insulation types for 1996, 1999, and 2004. The Pacific and South Atlantic Division had over $90 \%$ of their basement wall insulation types in fiberglass batting, with exception in the Pacific in 1999 when expanded polystyrene was used almost 40\%. New England, East North Central, East South Central, and the West North Central all used fiberglass batting predominantly in 1996, though, from 1999 through 2009, the percentages dropped as extruded polystyrene was used more often (which was, on average, a $20 \%$ decline). The Mountain Division reported using a split between fiberglass batting and rockwool batting in 1999. No other report showed the use of rockwool batting in the Mountain Division; in 2009, the preferred choice in basement wall insulation type was fiberglass batting. In 1999, the Middle Atlantic had over $95 \%$ of its basement wall insulation types in fiberglass batting. The use of fiberglass batting declined down to $50 \%$ in 2009 , with $40 \%$ of the insulation types being fiberglass board instead of batting.

\subsubsection{Possible Code Influences}

The changes in basement wall insulation were not likely related to energy code changes.

\subsection{NAHB Survey Data Analysis - Exterior Wall Insulation Type}

The NAHB survey results for exterior wall insulation type are presented in Figure 6.12. Builders were asked what material they typically used to insulate exterior walls, and were provided with the following materials to choose from:

- fiberglass batt

- fiberglass blown behind mesh

- fiberglass blown-on, no mesh

- rockwool batt

- spray foam

- cellulose blown behind mesh

- cellulose blown-on, no mesh

- foam board

- other. 


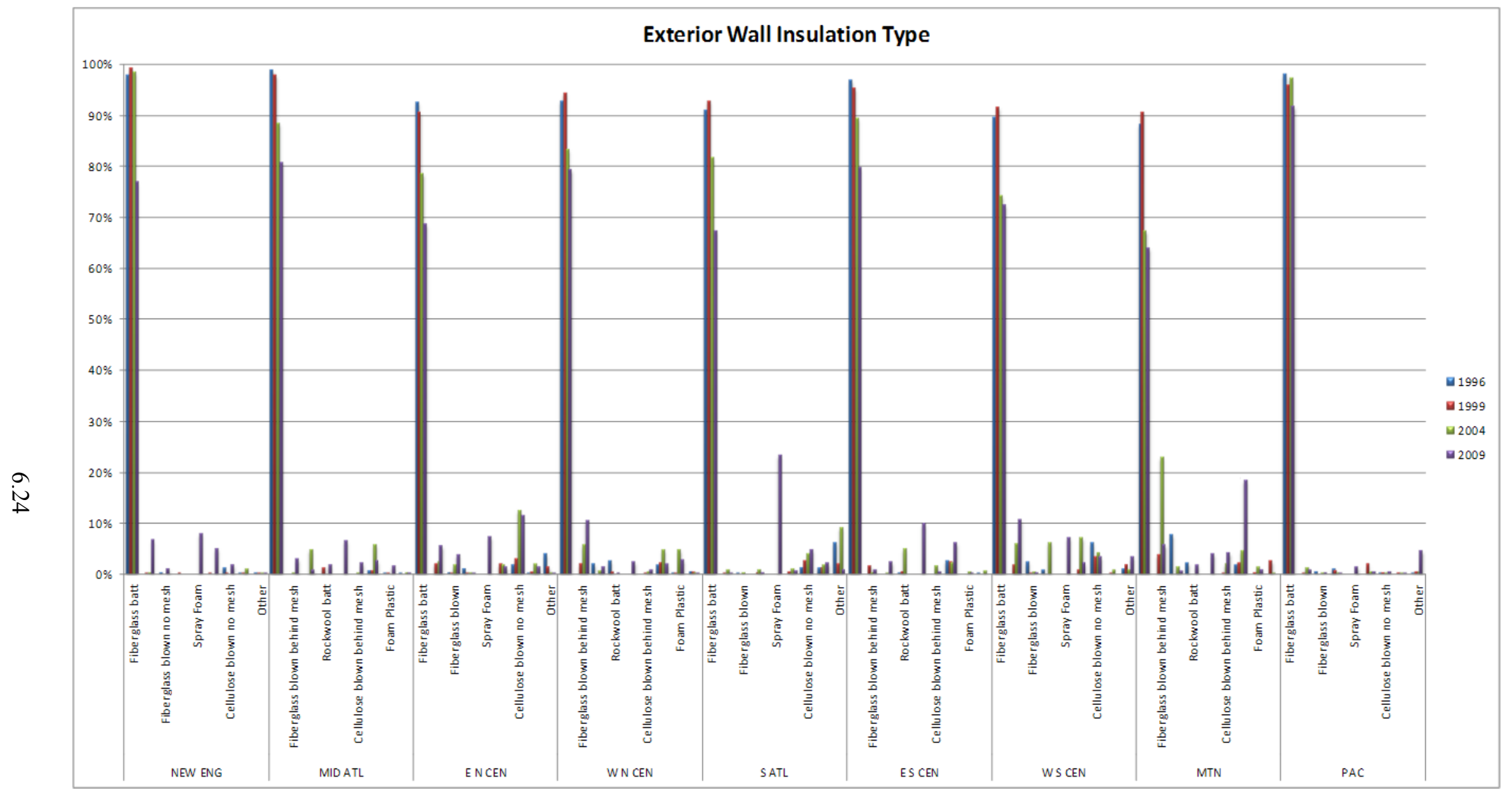

Figure 6.12. Exterior Wall Insulation Type 


\subsubsection{Trends Identified}

All of the census divisions predominately used fiberglass batting for the insulation type in the exterior wall. Each year, the percentages of fiberglass batting that was used in the exterior walls decreased, which reduced the percentages to fiberglass blown behind mesh and cellulose blown.

\subsubsection{Possible Code Influences}

The changes in exterior wall insulation were not likely related to energy code changes.

\subsection{NAHB Survey Data Analysis - Exterior Wall Cavity R-value}

The NAHB survey results for exterior wall cavity R-value are presented in Figure 6.13. Builders were asked to specify the R-value of the wall cavity insulation material they used from among the following choices:

- R-7 or less

- R-9 and R-11

- $\mathrm{R}-13$

- R-14 and R-15

- R-19

- $\mathrm{R}-20$ or greater. 


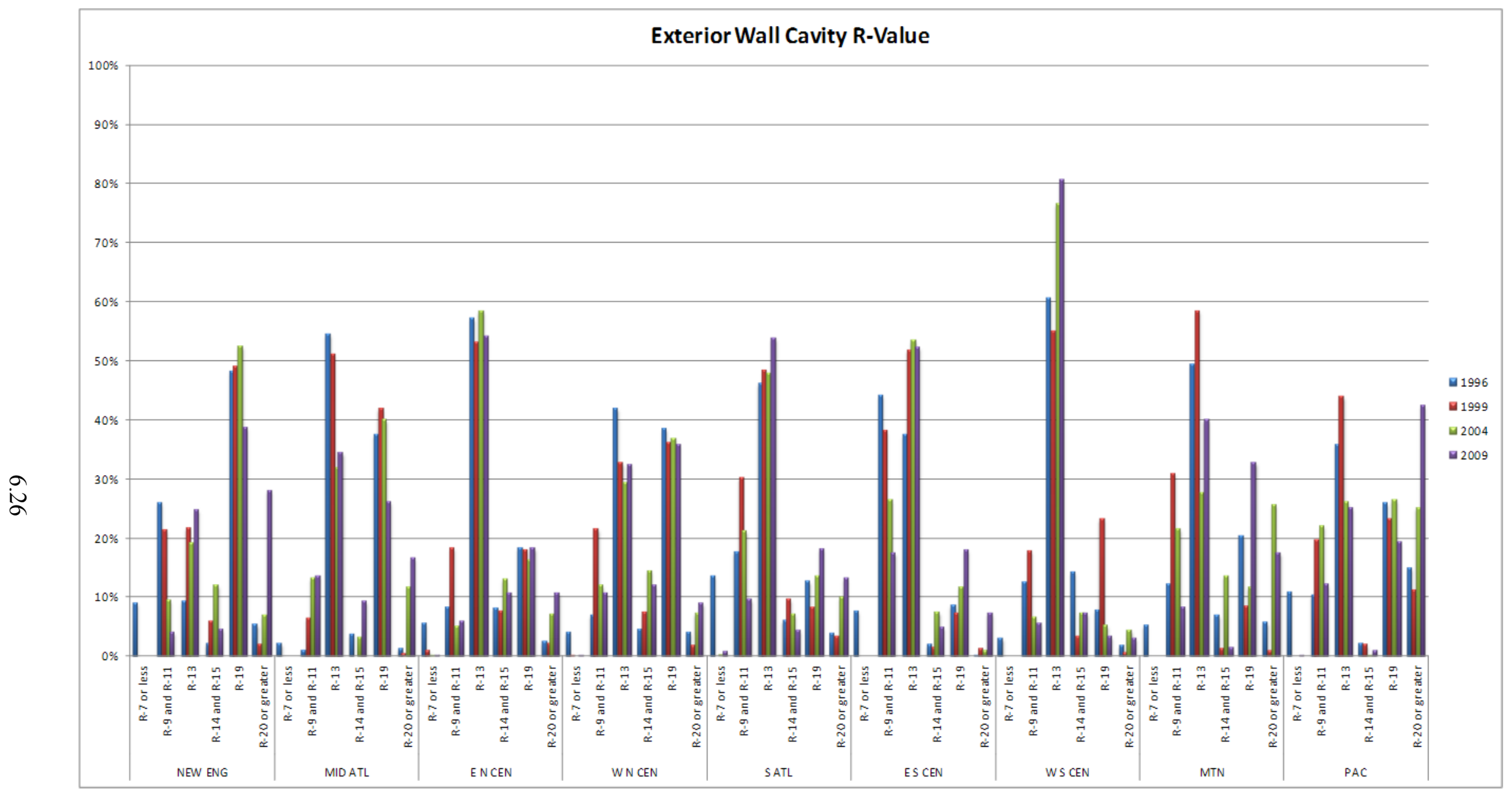

Figure 6.13. Exterior Wall Cavity R-value 


\subsubsection{Trends Identified}

No distinct national trends were identified. The Middle Atlantic, East North Central, South Atlantic, West South Central, Pacific and the Mountain Divisions all predominately used R-13 for the exterior wall cavity R-value. In each of these divisions, the trend stayed R-13, with exceptions in the Pacific, Mountain, and Middle Atlantic, where the trends lead to R-19 and R-20 or greater. New England reported dominance in exterior wall cavity R-values of R-19 in 1999, and continued to have over 30\% in R-19, but increased its R-20 or greater percentages to over 25\%. In 1999, the East South Central Division reported a split in exterior wall cavity R-values between R-9 to R-11 and R-13. By 2009, the R-9 to R-11 had decreased by about $20 \%$, and the R-13 and R-19 values increased.

\subsubsection{Possible Code Influences}

The 2003 IECC required exterior wall cavity R-values of 19 in colder climate zones.

\subsection{NAHB Survey Data Analysis - Flat Ceiling Insulation Type}

The NAHB survey results for flat ceiling insulation type are presented in Figure 6.14. Builders were asked to identify the percentage of flat ceilings they insulated with the following materials:

- fiberglass batt and blown

- fiberglass batt

- fiberglass blown

- rockwool batt

- rockwool blown

- cellulose blown

- spray foam

- foam board

- other

- none. 


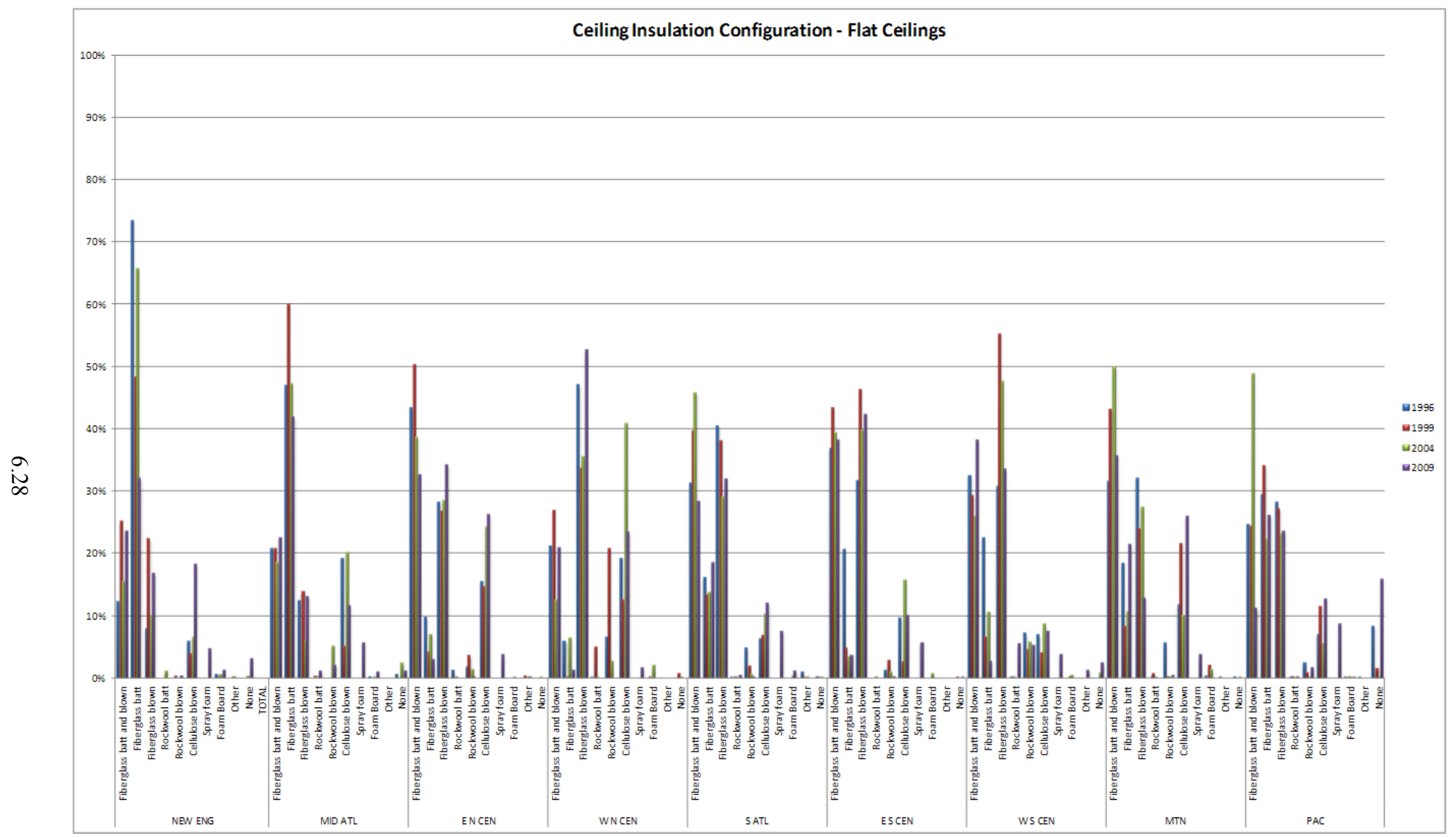

Figure 6.14. Flat Ceiling Insulation Type 


\subsubsection{Trends Identified}

Nationwide, no distinct national trends were identified. The East North Central, South Atlantic, East South Central, West South Central, Mountain, and Pacific Divisions shared a dominance in fiberglass batt and blown. Trends in these divisions also showed a combination of fiberglass batt and blown ceiling insulation configurations for flat ceilings. New England and Middle Atlantic predominately used fiberglass batting for the flat ceiling insulation, and it trended dominantly with about $20 \%$ shifting to fiberglass batt and blown. In 1996, the West North Central Division used blown fiberglass for their flat ceiling insulation configuration, and the predominant use remained the same in 2009.

\subsubsection{Possible Code Influences}

The changes in flat ceiling insulation were not likely related to energy code changes. 


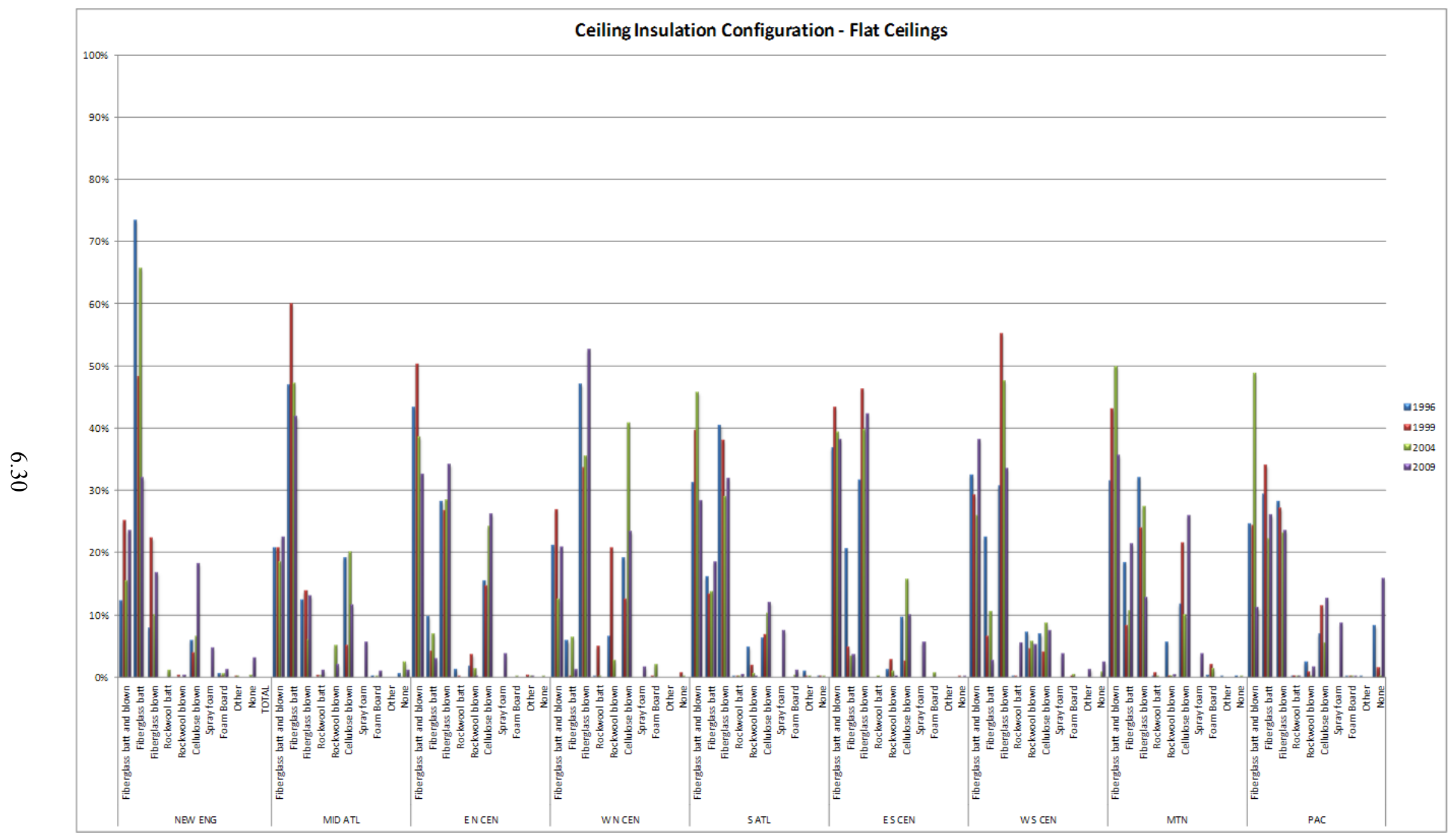

Figure 6.15. Flat Ceiling Insulation Type 


\subsection{Cathedral Ceiling Insulation Type}

The NAHB survey results for cathedral ceiling insulation type are presented in Figure 6.15. Builders were asked what percentage of their cathedral ceilings were insulated with the following materials:

- fiberglass batt

- rockwool batt

- spray foam

- foam board

- other

- none. 


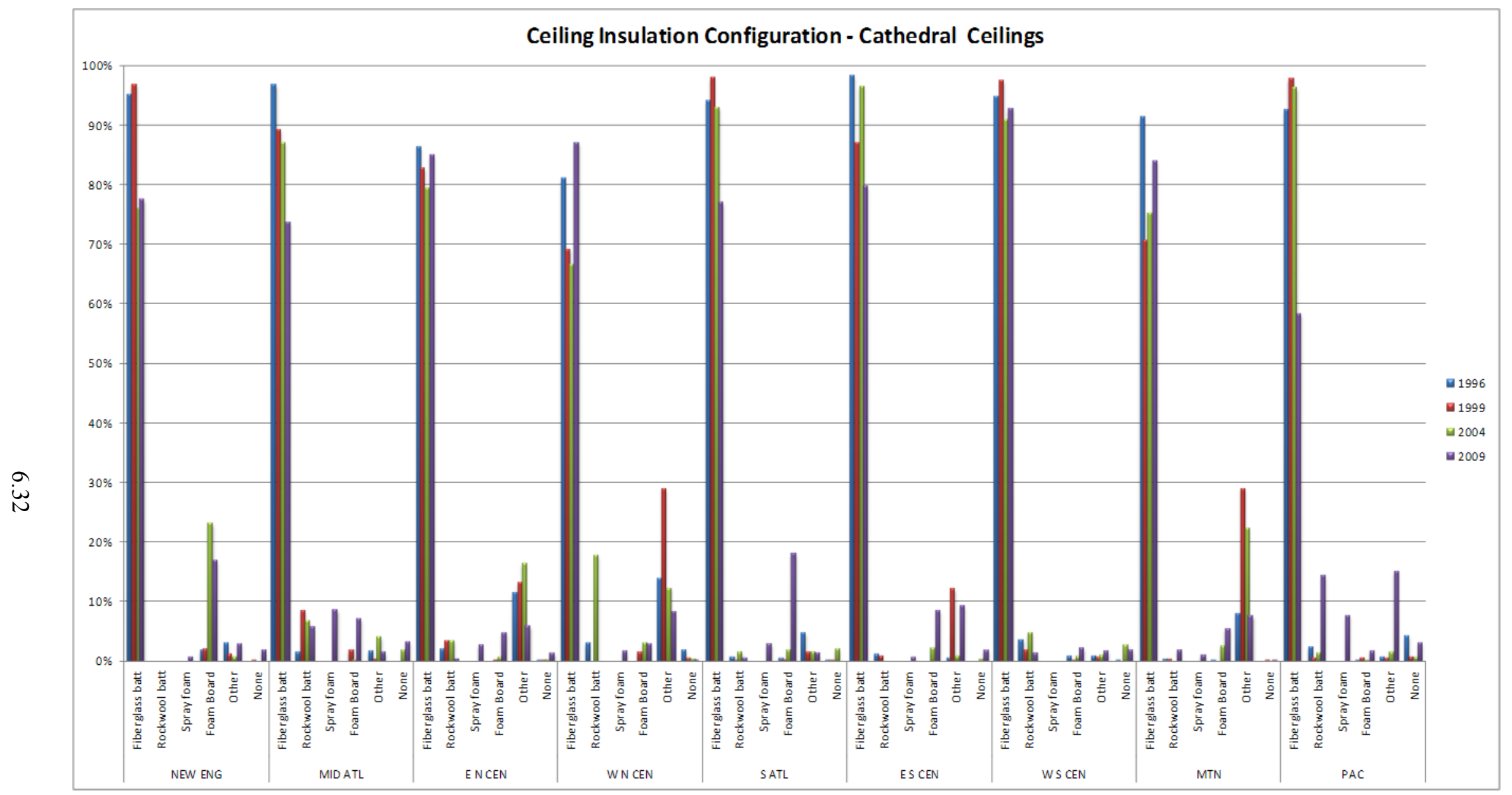

Figure 6.16. Cathedral Ceiling Insulation Type 


\subsubsection{Trends Identified}

In all nine national divisions, fiberglass batting was dominantly used in the ceiling insulation configuration for cathedral ceilings. In New England, there was a small showing (less than 20\%) of foam board in 2009. In the Pacific Division, the fiberglass batting dropped significantly, and shifted over 10\% to rockwool batting and other.

\subsubsection{Possible Code Influences}

The changes in cathedral ceiling insulation were not likely related to energy code changes.

\subsection{NAHB Survey Data Analysis - Ceiling Insulation R-Value}

The NAHB survey results for ceiling insulation R-value are presented in Figure 6.16. Builders were asked to specify the R-value of their ceiling insulation from among the following choices:

- R-7 or less

- R-9 and R-11

- R-13

- $\mathrm{R}-14$ and R-15

- R-19

- R-21

- $\mathrm{R}-22$

- R-24 and R-26

- $\mathrm{R}-30$

- R-31 through R-38

- R-40 or greater. 


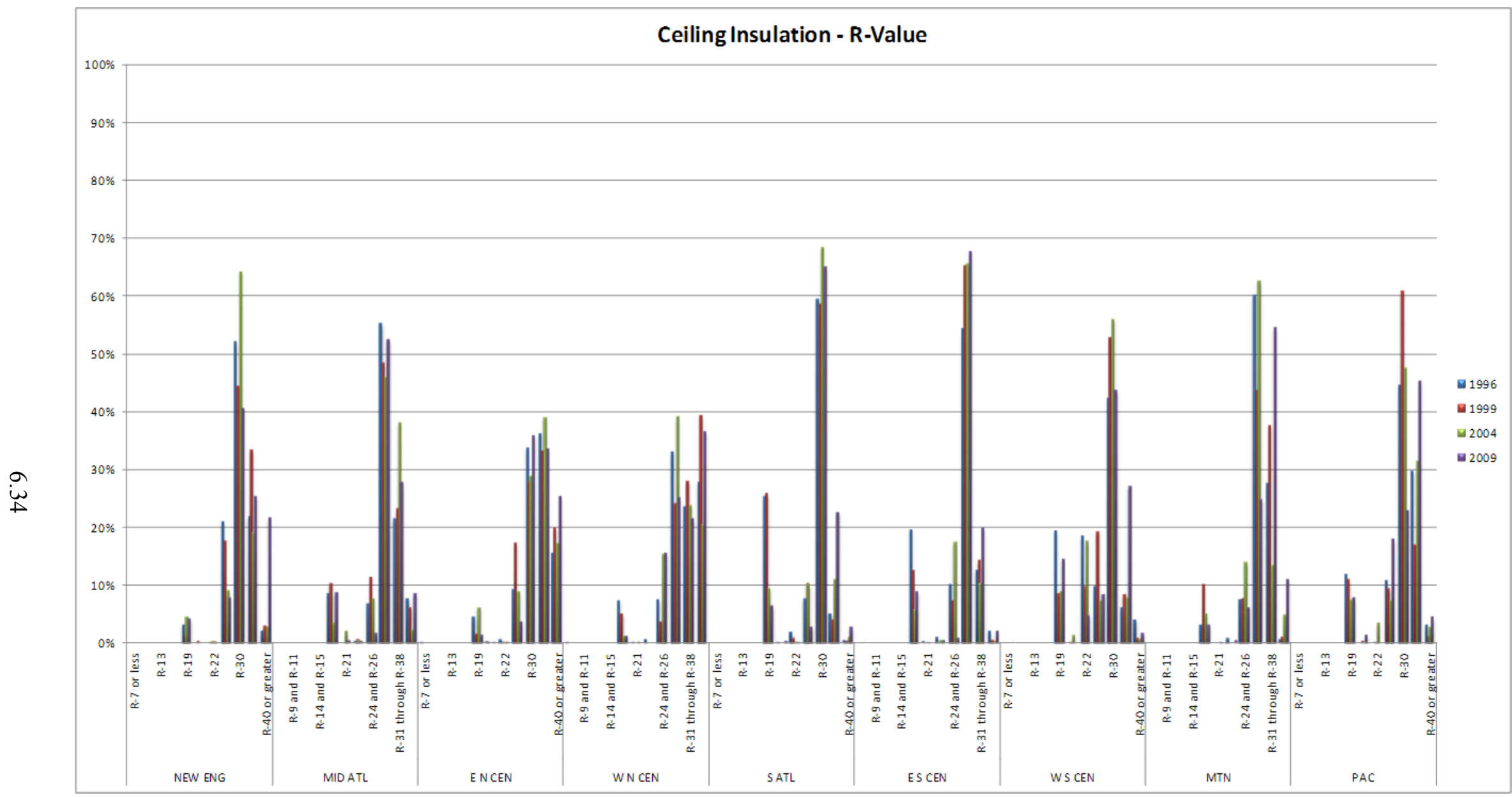

Figure 6.17. Ceiling Insulation R-value 


\subsubsection{Trends Identified}

Nationally, no distinct trends were identified. New England, Middle Atlantic, South Atlantic, East South Central, Mountain, and the Pacific Divisions showed dominance in R-30 ceiling insulation Rvalues. The trend remained constant in all six divisions. East Central and West South Central tended to have between R-30 and R-40 or greater ranging between 20-35\% in each. The trend stayed the same. West South Central was dominant in R-30 ceiling insulation R-values in 1996, but in 2009, over 25\% of the R-values for ceiling insulation were in R-31 through R-38.

\subsubsection{Possible Code Influences}

The 1998 IECC, and other codes, required R-30 or higher for all except homes in hot climate zones. 



\subsection{Heating, Ventilation, and Air Conditioning}

Specific analyses are presented for type of heating equipment units, type of heating and cooling systems, special types of HVAC units, efficiency rating of gas and oil furnace units, cooling equipment unit types, and air conditioner efficiency rating.

\subsection{NAHB Survey Data Analysis - Type of Heating Equipment Units}

The NAHB survey results for type of heating equipment units are presented in Figure 7.1. Builders were asked to specify the type of heating equipment they typically installed from among the following choices:

- gas (excluding combo systems)

- electric (including stand-alone heat pumps)

- oil (excluding combo systems)

- wood. 


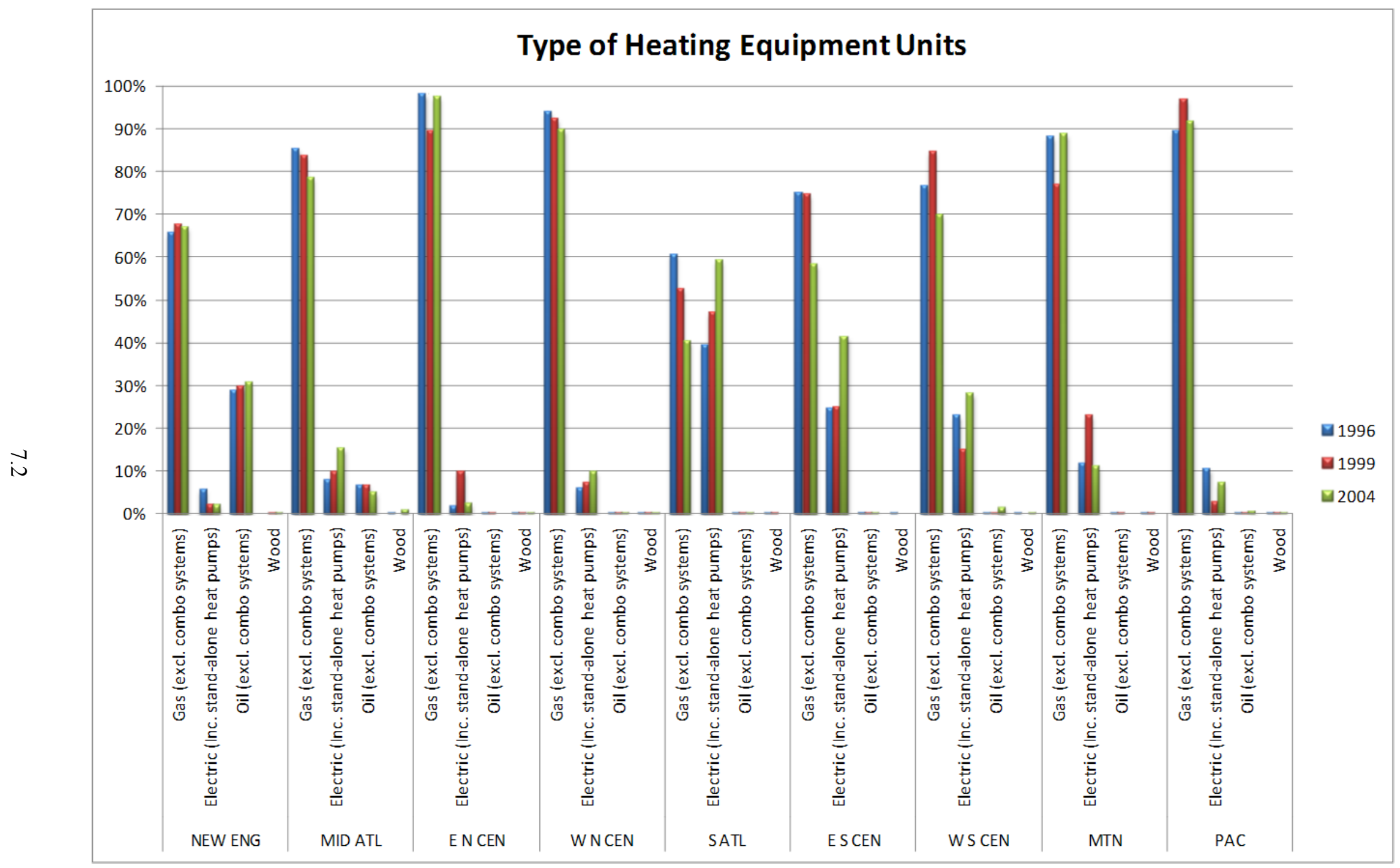

Figure 7.1. Type of Heating Equipment Units 


\subsubsection{Trends Identified}

Although no national trends were identified, gas heating units were the dominate type of heating in the New England, Middle Atlantic, East North Central, West North Central, Pacific, and Mountain Divisions through the 1996-2004 data years. South Atlantic and East South Central split between gas and electric heating units, both with trends increasing towards electric units from 1996-2004. In New England, from 1996-2004, there was also 27-30\% usage of oil-type heating units. Middle Atlantic, West South Central, and Pacific also reported minimal use of oil-type units only in 2004.

\subsubsection{Possible Code Influences}

The changes in the types of heating units used were not likely related to energy code changes.

\subsection{NAHB Survey Data Analysis - Type of Heating and Cooling Systems}

The NAHB survey results for type of heating and cooling systems are presented in Figure 7.2. Builders were asked to specify what types of heating and cooling systems they typically installed from among the following categories:

- furnace

- heat pump

- no primary heating system

- geothermal heat pump. 


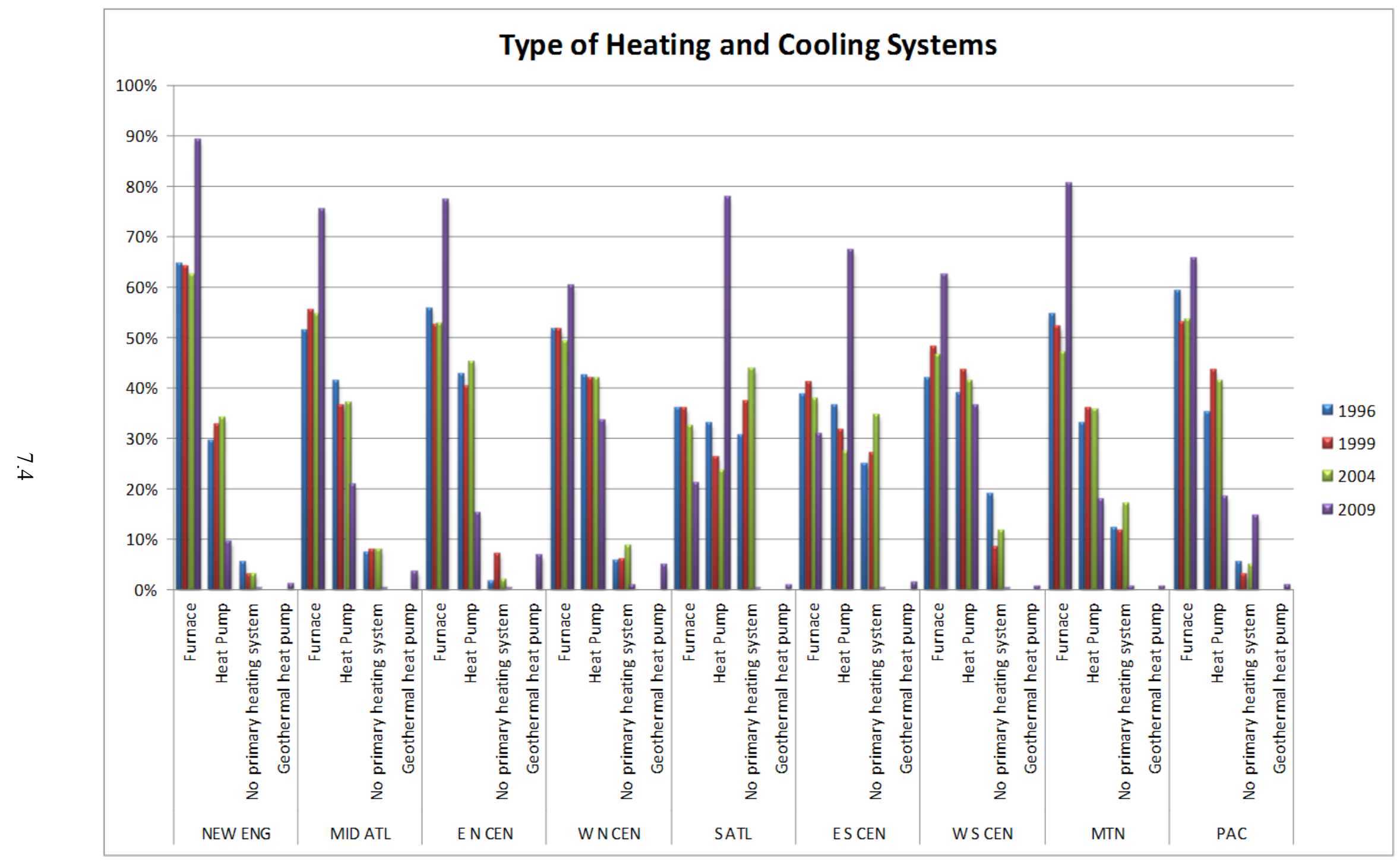

Figure 7.2. Type of Heating and Cooling Systems 


\subsubsection{Trends Identified}

In seven of the nine census divisions (New England, Middle Atlantic, East North Central, West North Central, West South Central, Mountain, and Pacific) furnace heating and cooling systems dominated in all years (1996-2009). These seven census divisions also saw a clear upward trend between 2004 and 2009, increasing from $10 \%$ to almost $30 \%$ in some divisions. Heat pumps held about $40 \%$ of the unit inventory in East South Central and the South Atlantic before 2009, when heat pump usage jumped between 30$50 \%$. In the South Atlantic and East South Central, there was an increase in homes having no primary heating system until 2009, when almost all of the divisions dropped below $1 \%$.

\subsubsection{Possible Code Influences}

The changes in the types of heating and cooling systems used were not likely related to energy code changes.

\subsection{NAHB Survey Data Analysis - Special Types of HVAC Units}

The NAHB survey results for special types of HVAC units are presented in Figure 7.3. Builders were asked to specify what special types of HVAC systems they installed from among the following choices:

- a combination

- electric, convection, and radiant

- mini splits. 


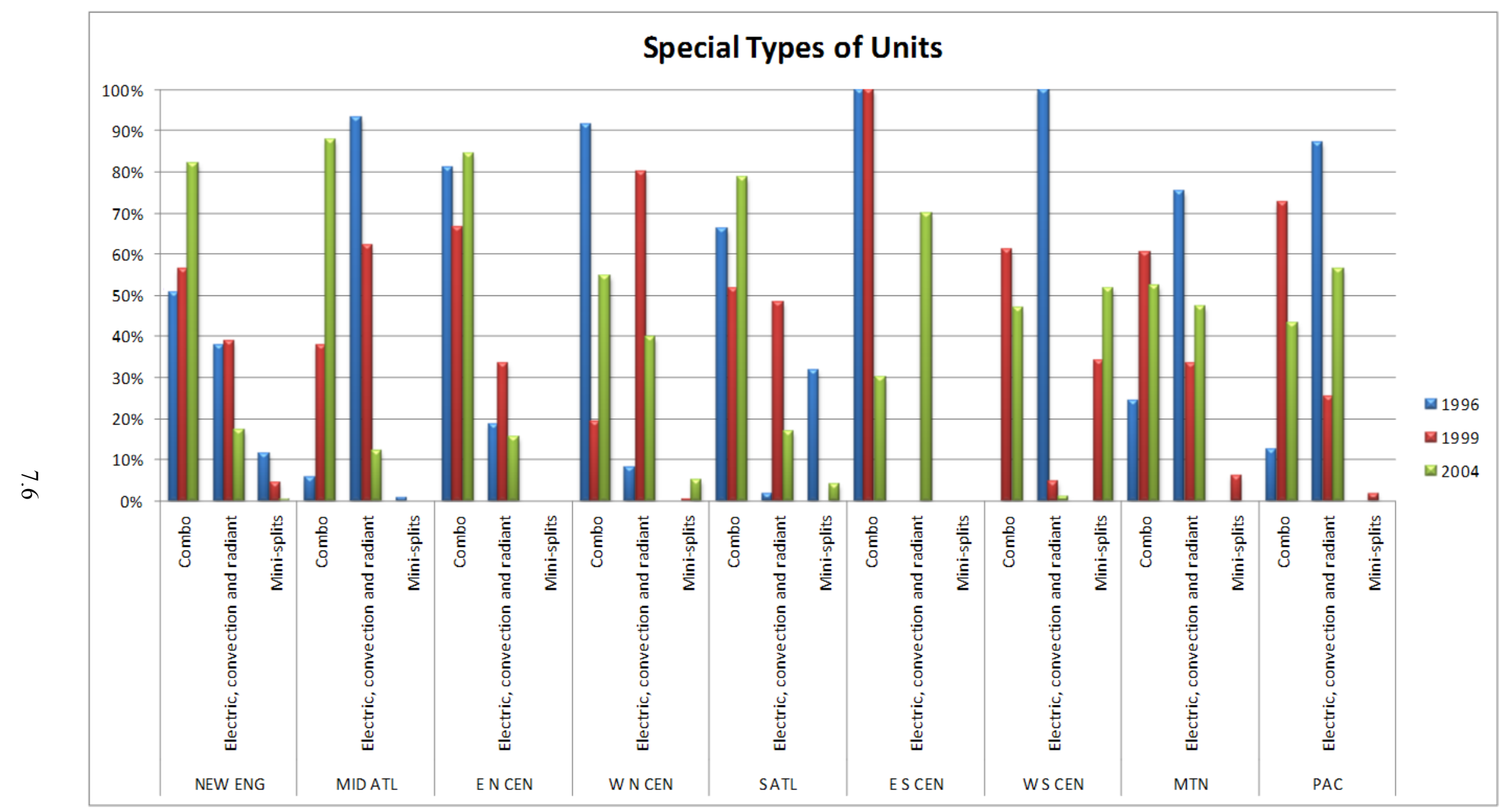

Figure 7.3. Special Types of HVAC Units 


\subsubsection{Trends Identified}

No distinct national trends were identified. The Middle Atlantic, Pacific, West South Central, and Mountain Census Divisions had 0-25\% combo units while New England, East North Central, West North Central, South Atlantic, and East South Central Census Divisions had over 50\% combo units. East South Central reported 100\% inventory in combo units for 1996 and 1999, but dropped to 30\% in 2004 when electric units increased to $70 \%$ from previously unused. The Middle Atlantic Census Division had over $90 \%$ electric units in 1996, and decreased to just over $60 \%$ in 1999 , and down below $15 \%$ in 2004 . Then, combo units increased from 5\% in 1996 to 38\% in 1999 and to 88\% in 2004. West North Central's inventory was dominated by combo units in 1996, but shifted dramatically from $92 \%$ to $20 \%$ in 1999 , and reflected the increase of electric units to $80 \%$ before becoming constant at $55 \%$ for combo and $40 \%$ for electric units in 2004. The Mountain and Pacific Divisions also shifted erratically between combo and electric units, both having less combo units in 1996, large increases in 1999, and settling back close to $50 \%$ in inventories for combo and electric units. Mini splits did not compare to the combo and electric units in inventory numbers, and made small appearances in New England, Mountain, and Pacific Divisions. In the West Central Division, however, mini splits reported 34\% in 1999, and increased to $52 \%$ in 2004 .

\subsubsection{Possible Code Influences}

The changes in special types of HVAC units used were not likely related to energy code changes.

\subsection{NAHB Survey Data Analysis - Efficiency Rating of Gas and Oil Furnace Units}

The NAHB survey results for efficiency rating of gas and oil furnaces are presented in Figure 7.4. Builders were asked to provide the efficiency ratings of gas and oil furnaces that they installed from among the following choices:

- less than $78 \%$

- $78 \%$ to $79.9 \%$

- $80 \%$ to $89.9 \%$

- $90 \%$ to $95 \%$

- $95.1 \%$ or greater

- don't know. 


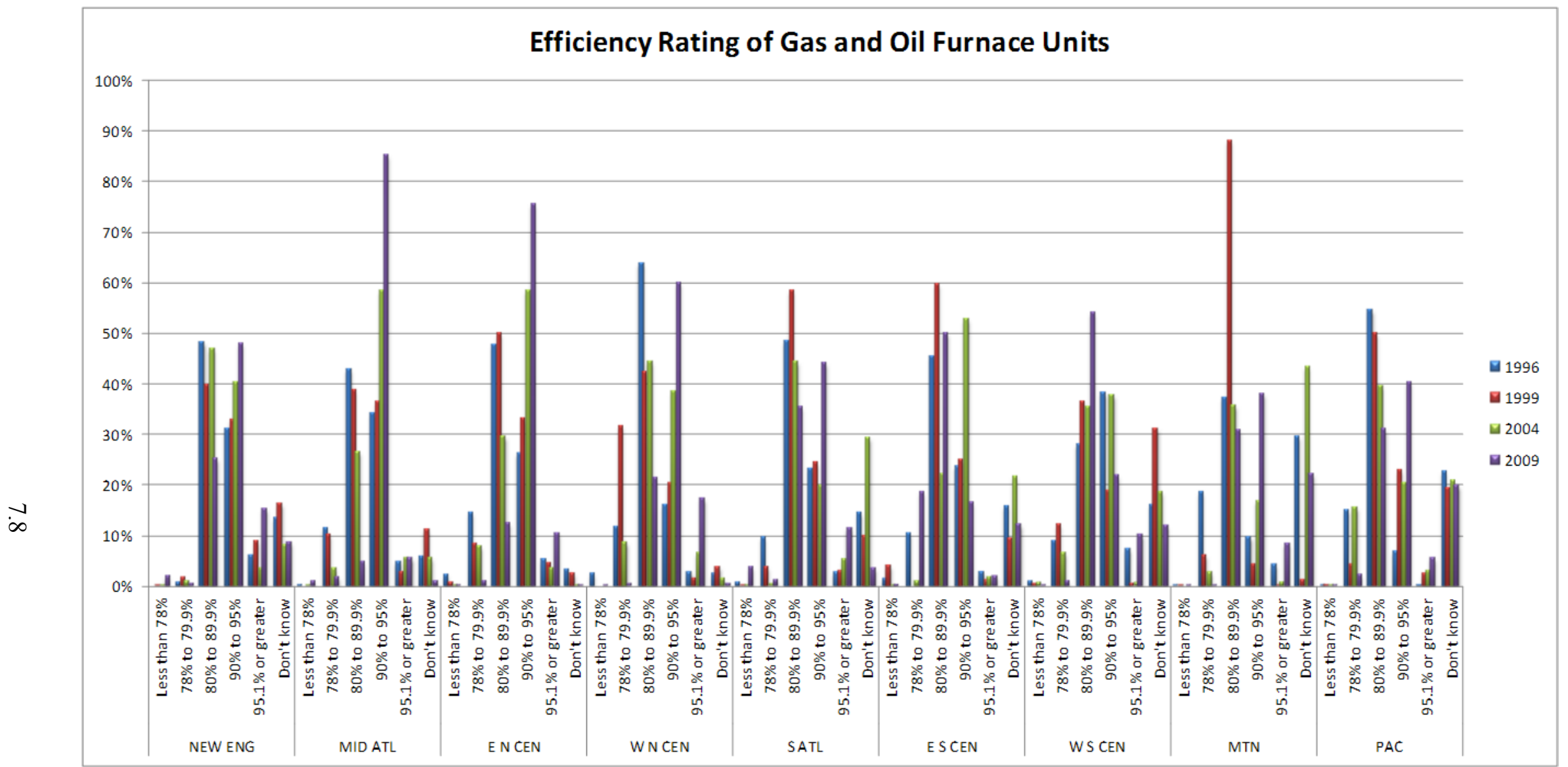

Figure 7.4. Efficiency Rating of Gas and Oil Furnace Units 


\subsubsection{Trends Identified}

Nationally, all of the census divisions' inventories centered between units with 78\%-95\% efficiency. Trends from 1996 through 2009 showed an increase in units with higher efficiencies. In 1999, South Atlantic, East South Central, and Pacific Divisions increased to units with $80 \%$ to $89.9 \%$ efficiencies. And Middle Atlantic had 85\% of units with 90\%-95\% efficiency in 2009.

\subsubsection{Possible Code Influences}

National Appliance Energy Conservation Act required furnaces to be at least $78 \%$ electric. Increased furnace efficiencies with $90 \%$ or above may have been the result of tradeoffs used to reduce wall Rvalues to R-13 in cold climates starting with IECC 2000.

\subsection{NAHB Survey Data Analysis - Air Conditioner Efficiency Rating}

The NAHB survey results for air conditioner efficiency rating are presented in Figure 7.5. Builders were asked to specify the efficiency rating of air conditioners that they installed from among the following choices:

- less than 13 seasonal energy efficiency ratio (SEER)

- 13.0 to 14.9 SEER

- 15.0 to 16.9 SEER

- 17.0 to 18.9 SEER

- 19.0 to 20.9 SEER

- 21 SEER or higher

- don't know. 


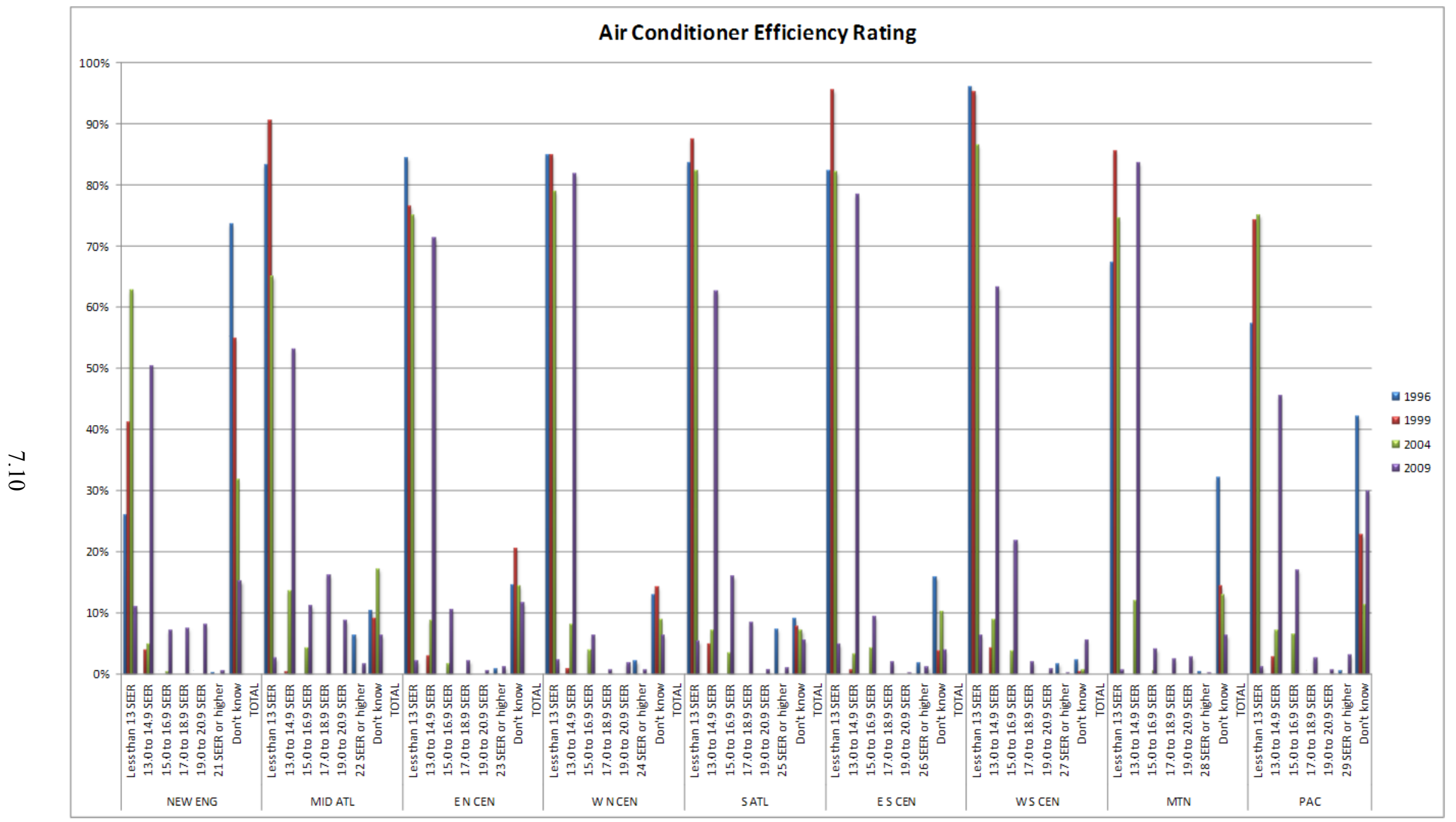

Figure 7.5. Air Conditioner Efficiency Rating 


\subsubsection{Trends Identified}

Nationally, no distinct trends were identified. In the New England Division, over $70 \%$ of the homes did not know the air conditioner efficiency rating in 1996. This reduced to fewer than $20 \%$ by 2009 . Unknown air condition efficiency ratings were common throughout the country with every division reporting an incidence of less than 45\%. Before 2009, the air conditioner efficiency rating was predominately below 13 SEER across the country. In 2004, efficiency ratings of 13.0 -14.0 SEER and 15.0-16.9 SEER were recorded, but it was less than $20 \%$ of the homes. All of the census divisions showed dominance in air conditioner efficiency ratings in the 13.0 to 14.9 SEER rating.

\subsubsection{Possible Code Influences}

National Appliance Energy Conservation Act requirements raised the efficiency of air condition units from SEER 10 to SEER 13 in 2006. 






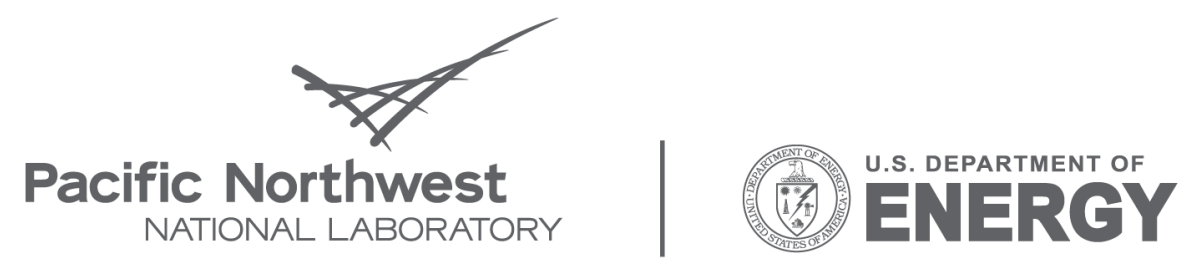

Proudly Operated by Battelle Since 1965

902 Battelle Boulevard

P.O. Box 999

Richland, WA 99352

1-888-375-PNNL (7665)

www.pnl.gov 